
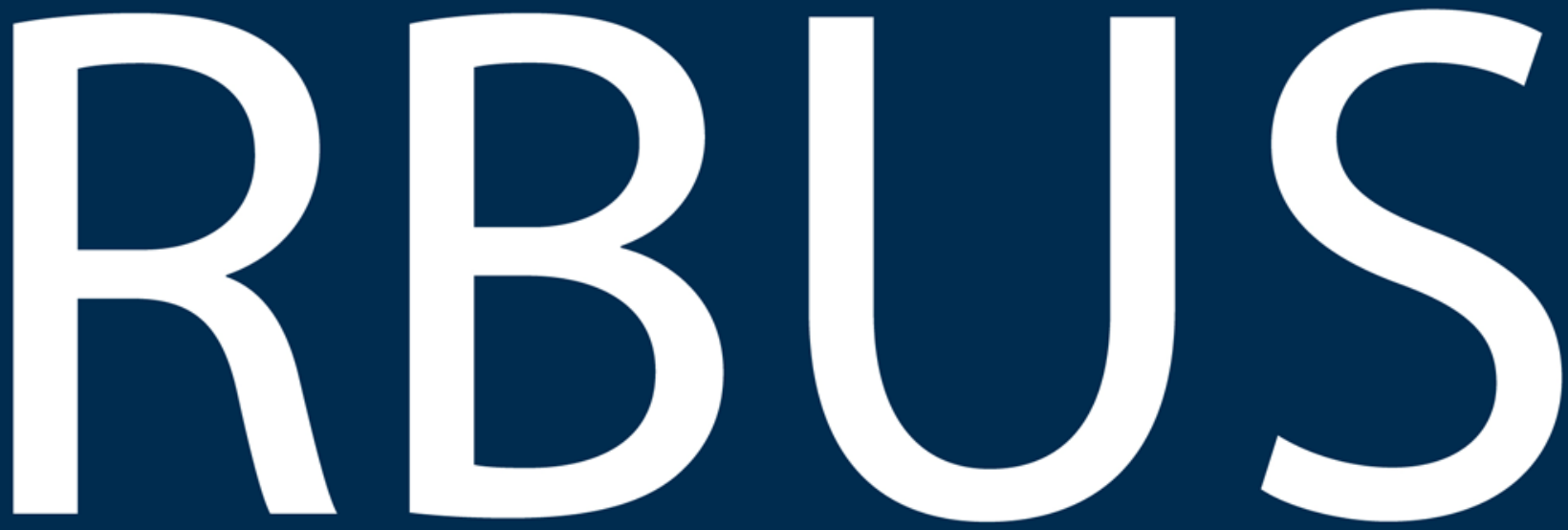

SOCIEDAD BRASILEÑA DE ULTRASONOGRAFÍA

ISSN - 2675-4800 
》〉

ABRACE

CADA MOMENTO DA

VIDA COM LIBERDADE

E SEGURANÇA.

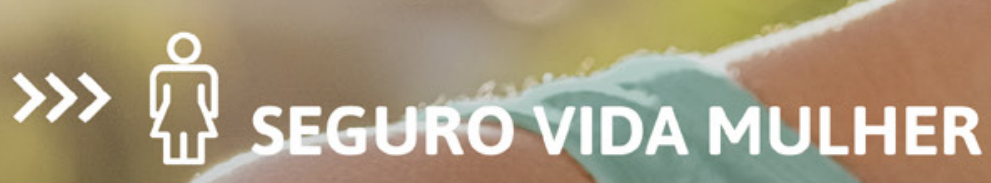

O Seguro Vida Mulher do Sicoob foi criado especialmente para proteger você e quem você ama. Além de oferecer as coberturas tradicionais por morte e invalidez, que resguardam o conforto de sua familia, o Seguro Vida Mulher do Sicoob oferece proteção financeira para você em vida, em casos de doenças graves. Confira alguns benefícios:

- Indenização em caso de invalidez permanente.

- Indenização em caso de morte natural ou acidental.

- Indenização em caso de doenças graves.

- Assistência funeral.

Central de Relacionamento:

Centro-Oeste e Norte: (62) 3221-2000

Sudeste: 08007771136

[3] 잉 sicoobunicentrobrasileira

Somos feitos de valores.

sicoob.com.br

\section{$\checkmark$ SICOOB}


Copyright (C) 2020 by: RBUS - Sociedad Brasileña De Ultrasonografía

Editora : D\&D Comunicação Ltda

CIP - Brasil - Catalogação na Fonte

Dartony Diocen T. Santos CRB-1 (1 Região)3294
R454 RBUS - Sociedad Brasileña de Ultrasonografía
V.28, n. 28. Marzo 2020 -
Goiânia:. DED Comunicação Ltda.
52p. : il. ( Publicación semestral)
1. Revista. 2. Ultrasonido. 3. Citología. 4. Ginecología.
I.Título.

CDU: $616.62(52)=134.3$

Impresso no Brasil

Índice para catalogo sistemático:

Printed in Brazil - 2020

CDU: $616.62(52)=134.3$

\section{JUNTA DIRECTIVA DE LA SBUS | 2018-2021}

\section{PRESIDENTE}

Rui Gilberto Ferreira

VICE PRESIDENTE

Adilson Cunha Ferreira

SECRETARIO GENERAL

Maurício Saito

1er SECRETARIO

Pedro Pires Ferreira Neto

TESORERO GENERAL

Waldemar Naves do Amaral

ler TESORERO

Fernando Marum Mauad DIRECTOR CIENTÍFICO Y CULTURAL

Sang Choon Cha

DIRECTOR DE DEFENSA PROFESIONAL

Carlos Stéfano Holffmann Britto

DIRECTOR SOCIAL Y DE

COMUNICACIÓN

Jorge Alberto Bianchi Telles

\section{CONSEJO FISCAL}

Dra. Rejane Maria Ferlin

Dr. Washington Luiz Ferreira Rios

Dra. Maithe Vendas Galhardo

\section{SUPLENTES}

Dr. Monres José Gomes

Dr. Manoel Chaves Filho

CONSULTIVO

Dra. Lucy Kerr

Dr. Sang Choon Cha

Dr. Waldemar Naves do Amaral

EDITORES EN JEFE

Antonio Gadelha da Costa

Heverton Pettersen (MG)

Waldemar Naves do Amaral
EDITORES ADJUNTOS

Sang Choon Cha (SP)

Roberto A. D. Cardoso (SP)

EDITORIAL

Ademar Yamanaka

Adilson Cunha Ferreira

Antonio Gadelha da Costa

Carlos Stéfano Hoffmann Britto

Francisco Mauad Filho

Jorge Fonte de Rezende Filho

Jose Carlos Gaspar Junior

Lucy Kerr

Luiz Augusto Antonio Batista

Luiz Eduardo Machado

Marcos Faria

Marcello Viggiano

Milton Bricola Filho

Monres Jose Gomes
Patricia Spara Gadelha

Rosemeire Fernandes Garcia

Rui Gilberto Ferreira

Sebastiao Marques Zanforlin Filho

Sergio Luiz Simoes

Viviane Almeida De Alcantara Lopes

Walter Pereira Borges

CONSELHO EDITORIAL INTERNACIONAL Kypros Nicolaides - INGLATERRA Rodrigo Ruano - ESTADOS UNIDOS Jader CrUz - PORTUGAL

Afonso Cohen - PORTUGAL

Nicola Volpe - ITALIA

Baskaran Thilaganathan - INGLATERRA

Waldo Sepulveda-CHILE

Fernando Bonilla - ESPANHA

Anna Bianchi - URUGUAY

Pran Pandya - INGLATERRA
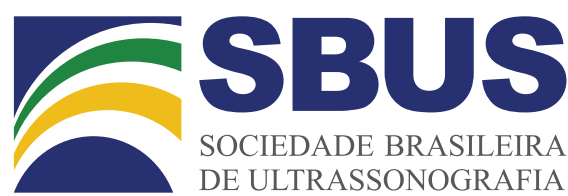

SOCIEDADE BRASILEIRA

DE ULTRASSONOGRAFIA

\section{SOCIEDADE BRASILEIRA DE ULTRASSONOGRAFIA}

Rua Teodoro Sampaio, 352 - Conj. 53/54

Pinheiros CEP: 05406-000 - São Paulo - SP

Teléfonos: (11) 3081-6049|(11) 3081-6736

Sitio web:www.sbus.org.br-E-mail:sbus@sbus.org.br

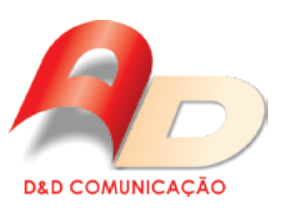

D\&D COMUNICAÇÃO

RUA 27-A No 142 - SETOR AEROPORTO

TELÉFONO: (62) 3941-7676

TRADUCCIÓN: SOLEDAD MONTALBETTI

PERIODISTA RESPONSABLE: DÁRIOÁLVARES

DIAGRAMACIÓN: LETHICIA SERRANO 
La revista aceptará material original para su publicación en el campo relacionado a la ecografía. La revista publicará:

1. Artículos originales completos, ya sean prospectivos, experimentales o retrospectivos.

2. Informes de casos de gran interés siempre que estén bien documentados clínicamente y en laboratorio.

3. Ediciones especiales con anales, colecciones de trabajos presentados en congresos brasileños patrocinados por la SBUS y suplementos con trabajos volcados sobre un tema de gran interés.

4. Artículos de revisión, incluidos metanálisis y comentarios editoriales, mediante invitación, cuando sean solicitados a miembros del consejo editorial.

\section{PROCESAMIENTO}

Todo el material enviado será analizado por el Comité Editorial de la revista compuesto por: editores de la revista y el periódico, consejo editorial, editores asociado, colaboradores y adjuntos; quedando prohibida la identificación a los revisores de los autores o el servicio donde se desarrollaron los trabajos, así como los revisores no serán identificados por los autores, excepto cuando ellos lo soliciten. Una vez recibidos, los artículos serán fechados y codificados y sus autores serán notificados de la entrega. Los artículos que no cumplan con los estándares editoriales serán rechazados en esta etapa. Aquellos que estén de acuerdo serán enviados a dos revisores designados por el Editor. Los autores serán informados de la aceptación y de cualquier modificación eventualmente sugerida por el Comité Editorial. Cuando se soliciten modificaciones, los autores deberán devolver el trabajo corregido dentro de los 15 días, debiendo justificar si alguna sugerencia no fuere aceptada.

\section{DERECHOS DE AUTOR (COPYRIGHT)}

Es una condición de publicación en la que los autores transfieren los derechos de autor de sus artículos a la Sociedade Brasileira de Ultrassonografia (Sociedad Brasileña de Ultrasonografía - SBUS). La transferencia de derechos de autor a la revista no afecta los derechos de patente o los acuerdos relacionados a los autores. Se pueden reproducir figuras, fotos o tablas de otras publicaciones, siempre que estén autorizados por el propietario. El material publicado se convierte en propiedad de SBUS, pudiendo reproducirse con su consentimiento.

\section{ASPECTOS ÉTICOS}

El Comité Editorial sigue los principios de la Declaración de Helsinki y recomendamos que los autores de los artículos enviados obedezcan a la comisión ética y cumplan los requisitos legales y reglamentarios para experimentos en seres humanos con drogas, incluido el consentimiento informado, de acuerdo con los procedimientos necesarios en su institución o país. Toda la información del paciente debe ser anónima, en particular, se debe verificar que el número de identificación y el nombre del paciente fueron retirados de las fotos del ultrasonido. Para más detalles, acceda al sitio web de la comisión de ética e investigación (http://www.datasus. gov.br/conselho/comissões/ética/conep.htm).

\section{AUTORIDAD Y RESPONSABILIDAD}

El contenido intelectual de los trabajos es responsabilidad exclusiva de los autores. El Comité Editorial no asumirá ninguna responsabilidad por las opiniones o declaraciones de los autores. El Comité Editorial hará todo lo posible para evitar datos incorrectos o inexactos. El número de autores debe limitarse a seis.

\section{ENVÍO DE ARTÍCULOS}

Los autores enviarán copias junto con conjuntos de figuras, fotos o tablas y guardarán una copia para referencia. El texto debe identificar a un autor como el corresponsal al que se le enviarán las notificaciones de la revista. Deberá contener la dirección completa, el número de teléfono y la dirección de correo electrónico de esta persona. Los trabajos deben enviarse a sbus@sbus.org.br o clinicaorigen@gmail.com

\section{PRESENTACIÓN}

Los artículos deben escribirse en doble espacio y deben contener los siguientes temas: Título (portugués e inglés), resumen (portugués e inglés), introducción, métodos, resultados, discusión, agradecimientos y referencias. Cada tema debe comenzar en una nueva página. Los relatos de casos deben estructurarse en: introducción, informe de casos, discusión y referencias. La primera página debe incluir: título, nombre y apellido de los autores y su filiación, títulos (no más de 20 letras), palabras clave (5-8) y la dirección de correo electrónico. La segunda página debe contener el título del manuscrito en el encabezado y se debe tener cuidado en el resto del texto para que el servicio o los autores no puedan ser identificados (eliminarlos).

\section{RESUMEN}

El resumen de los artículos originales debe dividirse en secciones que contengan información que permita al lector tener una idea general del artículo, dividiéndose en los siguientes temas: objetivos, métodos, resultados y conclusiones. No debe exceder las 250 palabras. El resumen de los casos clínicos debe estar en un solo párrafo. Una versión en inglés del resumen y las palabras clave debe ser proporcionado.

\section{ESTILO}

Las abreviaturas deben estar en mayúsculas y no utilizar un punto después de las letras, por ejemplo: US Y no U.S.. Los análisis estadísticos deben ser pormenorizados en el tema referente a los métodos. No se permitirán pies de página, excepto en las tablas. El Comité Editorial se reserva el derecho de modificar los manuscritos cuando sea necesario para adaptarlos al estilo bibliográfico de la revista.

\section{LITERATURA CITADA}

Las referencias deben numerarse consecutivamente a medida que aparecen en el texto y luego en figuras y tablas si es necesario, citadas en números sobrescritos, por ejemplo: "El trabajo reciente sobre el efecto del ultrasonido 22 muestra que.... Todas las referencias deben citarse al final del artículo siguiendo la siguiente información:

1. et al. no es utilizado. Todos los autores del artículo deben ser citados.

2. Las abreviaturas de revistas médicas deben seguir el formato Index Meddicus.

3. Las obras no publicadas, los artículos en preparación o las comunicaciones personales no deben usarse como referencias. Cuando absolutamente necesarias, solo deben ser citadas en el texto.

4. No utilizar artículos que sean difíciles o restringidos para los lectores, seleccionando los más relevantes o recientes. En los artículos originales, el número de referencia debe limitarse a 25 y los casos clínicos y cartas a 10.

5. La exactitud de los datos de referencia es responsabilidad de los autores.

Las referencias deben seguir el estilo de Vancouver como en los ejemplos a continuación:

Artículos de periódicos: Cook CM, Ellwood DA. A longitudinal study of the cervix in pregnancy using transvaginal ultrasound. Br J Obstet Gynaecol $1966 ; 103: 16-8$

In press: Wyon DP. Thermal comfort during surgical operations. J Hyg Camb 20-;in press (colocar el año actual).

Artículo en libro editado: Speroff L, Glass RH, Kase NG. In Mitchell C, ed. Clinical Gynecologic

Endocrinology and Infertility. Baltimore, USA: Williams \& Wilkins, 1994:1-967.

\section{AGRADECIMIENTOS}

Dirigidos a las contribuciones científicas o materiales de otros que no justifican coautoría.

\section{ILUSTRACIONES}

Todas las ilustraciones deben ser identificadas con el nombre del autor principal y el número de la figura. Todas las ilustraciones deben ser citadas en el texto y numeradas según su aparición, por ejemplo, la figura 3. 
ULTRASONOGRAFÍA PARA MEDIR LA TRANSLUCENCIA NUCAL Y EL RASTREAMIENTO PRENATAL GENÉTICO ..13 LORHAYNE AFONSO SIQUEIRA, TÁRIK KASSEM SAIDAH, PATRÍCIA GONÇALVES EVANGELISTA, WALDEMAR NAVES DO AMARAL

PREVALENCIA DE LESIONES NEUROLÓGICAS DIAGNOSTICADAS POR ULTRASONOGRAFÍA TRANSFONTANELAR EN RECIÉN NACIDO A TÉRMINO

LORENA CABRAL DE CASTRO LOURENZO, MIDIÃ FONSECA LIMA, SIMONE CARRIJO SANTOS, PATRÍCIA GONÇALVES EVANGELISTA

ULTRASONOGRAFÍA EN EL DIAGNÓSTICO DE LA OBSTRUCCIÓN INTESTINAL FETAL: UN CASO CLÍNICO ........21

VALDIVINA ETERNA FALONE, WALDEMAR NAVES DO AMARAL FILHO, TARIK KASSEM SAIDAH, PATRÍCIA MENDONÇA LEITE, THAYNARA DE MORAES PACHECO, LORENA TASSARA QUIRINO VIEIRA, ANTÔNIO DE MORAIS JÚNIOR, WALDEMAR NAVES DO AMARAL

ASPECTO ULTRASONOGRÁFICO DEL DISPOSITIVO ANTICONCEPCIONAL FEMENINO PERMANENTE ESSURE ${ }^{\circledR}$ RELATO DE CASO

LEONARDO DE SOUZA PIBER, CAIO VINÍCIUS DA FONSECA SILVA, GEORGIA DE SÁ CAVALCANTE TEIXEIRA, GABRIELA RAMOS REZENDE DEL CASTILHO, MATHEUS FLORENTINO DOS SANTOS, REBECA GUIMARÃES RIBEIRO DE ALMEIDA, MARIA TERESA NATEL DE ALMEIDA, MARIA ELENA GUIMARÃES RIBEIRO DE ALMEIDA

LINFOMA EN EMBARAZO CON FETO VIVO: UN CASO CLÍNICO 28

VALDIVINA ETERNA FALONE, WALDEMAR NAVES DO AMARAL FILHO, TARIK KASSEM SAIDAH, ADRIELLY JOICE MENDES SANTANA BRANDÃO, THAYNARA DE MORAES PACHECO, LORENA TASSARA QUIRINO VIEIRA, MATHEUS FERREIRA GONÇALVES, WALDEMAR NAVES DO AMARAL

FASCITIS NODULAR: UN CASO SIMULANDO PATOLOGÍA SOSPECHOSA A ULTRASONOGRAFÍA

ANA CAROLINA SILVA, LUIZA CAIXETA, GABRIEL TOFANI, LAIO RASPANTE, ELIZABETH DE AYUB, LETICIA AZEREDO, LEONARDO PEREIRA, CARLOS HENRIQUE SILVA

DIAGNÓSTICO PRENATAL DE ESQUIZENCEFALIA CON EVOLUCIÓN PROGRESIVA UNILATERAL A BILATERAL UN CASO CLÍNICO

RENATO MURTA, MARCOS FARIA, LUCCA PENNA FARIA, BRUNO PENNA FARIA, HEVERTON PETTERSEN

SINOVITIS VELLONODULAR PIGMENTADA: UN CASO CLÍNICO

JORGE GARCIA, ANA CLAUDIA PEREIRA LIMA, PROCÓPIO DE FREITAS, AUGUSTO CESAR SAAB BENEDETI, FERNANDO MARUM MAUAD,

FRANCISCO MAUAD FILHO

ULTRASONOGRAFÍA DOPPLER EN LA EVALUACIÓN DEL REFLUJO GASTROESOFÁGICO

THALITA BARBOSA DUTRA DE MIRANDA, ARIELA MAULLER VIEIRA PARENTE, LARISSA BARBOSA DUTRA DE MIRANDA, MÔNICA SILVA CARNEIRO, AVELINO PEIXOTO NETO, HAYTHAM LOAIY IBRAHIM KARAJAH, WALDEMAR NAVES DO AMARAL 


\section{INCERTIDUMBRES Y SENTIDO COMÚN}

Vivimos, sin lugar a dudas, un momento de incertidumbre, inseguridad y ansiedad con la pandemia Covid-19, declarada por la Organización Mundial de la Salud (OMS) el 11 de marzo de 2020. Una vez más la ciencia ocupa un lugar central en los debates y atención mundiales en la búsqueda de la tan ansiada cura de este mal que no elige raza, nacionalidad, sexo o clase social. El momento es de alerta, sentido común y observancia de todas las normas preventivas recomendadas por la OMS. Fomentar la investigación y la producción científica es uno de los principales pilares de la SBUS, una entidad acreditada que desempeña un papel importante en el universo médico nacional. En este escenario, la Revista Brasileira de Ultrasonografía - RBUS (Revista Brasileña de Ultrasonografía), tradicionalmente conocida como Revista Azul, desempeña un papel fundamental, convirtiéndose en una herramienta extraordinaria para la difusión de la investigación científica en la USG, compartiendo experiencias y conocimiento a través de artículos relevantes e inéditos. Para ampliar el alcance de nuestra publicación científica, a partir de esta edición también pondremos a disposición versiones digitales en inglés y español. Otra gran noticia: cada artículo ahora tiene un código QR, lo que hace que las descargas sean aún más ágiles y sin complicaciones. Participe usted también en estas páginas que ayudan a valorar aún más la ultrasonografía brasileña.

\section{ANTONIO GADELHA DA COSTA HEVERTON PETTERSEN WALDEMAR NAVES DO AMARAL}

\section{RUI GILBERTO FERREIRA}

PRESIDENTE DE LA SBUS

EDITORES EN JEFE 


\title{
EVALUACIÓN ULTRASONOGRÁFICA Y CITOLÓGICA DE 499 NÓDULOS TIROIDEOS
}

\author{
LEONARDO PIBER ${ }^{1,2}$, CARLA FREITAS ${ }^{2}$, THIAGO TEIXEIRA² ${ }^{2}$, ARTHUR BEZERRA ${ }^{2}$, MAYRA FERNANDES $^{2}$, \\ REGINA YOSHIASSU ${ }^{2}$
}

\section{RESUMEN OBJETIVOS}

Verificar los hallazgos ultrasonográficos y citológicos en punciones de aspiración con aguja fina de tiroides (PAAF). MÉTODOS: Estudio transversal retrospectivo en el que fueron evaluados 499 nódulos tiroideos mediante ultrasonografía y examen citológico en el período de octubre de 2018 a agosto de 2019 en pacientes de ambos sexos, en un Centro de Diagnóstico privado en la ciudad de São Paulo.

RESULTADOS: De los 499 nódulos puncionados en 334 pacientes, 44 (8.8\%) pertenecían al sexo masculino y 455 (91.2\%) al sexo femenino. Del número total de pacientes, 31 (9.3\%) eran hombres y 303 (90.7\%) eran mujeres, con edades entre 13 y 88 años. Fueron obtenidas tres muestras hemorrágicas (0.6\%), cuyos nódulos fueron puncionados nuevamente. La prevalencia de malignidad fue de $4.8 \%$ y la frecuencia de nódulos benignos fue de $92.4 \%$.

CONCLUSIÓN: Los análisis evidencian que el perfil ultrasonográfico y citológico de los nódulos tiroideos está de acuerdo con la literatura actual, lo que puede auxiliar en la auditoría de los resultados en los centros de diagnóstico por imágenes.

\section{PALABRAS CLAVE: ENFERMEDADES DE LA GLÁNDULA TIROIDES, GLÁNDULA TIROIDES, NEOPLASIAS, NÓDULO, BIOPSIA GUIADA POR IMAGEN, ULTRASONOGRAFÍA, ULTRASONOGRAFÍA DE INTERVENCIÓN.}

\section{INTRODUCCIÓN}

La tiroides es una glándula de pequeño porte que se encuentra en la región cervical infrahioidea. ${ }^{1}$ La glándula tiroides está controlada por la hormona estimulante de la tiroides (TSH), que promueve la señalización y, a través de ella, son producidos reguladores de gran importancia para el crecimiento y el desarrollo del metabolismo².

Entre las enfermedades que afectan la tiroides, los nódulos tiroideos son frecuentes, con una prevalencia del 4 al $7 \%$ en la población adulta, si el diagnóstico se realiza mediante un examen físico; y del 17 al 67\% en casos de investigación con ultrasonido (US). ${ }^{3,4}$ La alta sensibilidad del US, lo torna una excelente forma de detección.

Las características ultrasonográficas predicen una mayor o menor probabilidad de nódulos benignos o malignos. ${ }^{3} \mathrm{El}$ Thyroid Imaging Reporting and Data System publicado por el American College of Radiology (ACR TI-RADS) es un sistema para clasificar los hallazgos de ultrasonografía (USG) de nódulos tiroideos ${ }^{5}$, que correlaciona estos hallazgos con la posible clasificación citológica, caracterizando el potencial maligno del nódulo de acuerdo con las características encontradas. El US debe realizarse en modo B, para reducir variaciones entre los observadores. Los nódulos son, de esta forma, clasificados en cinco categorías, siendo la última la de mayor riesgo de malignidad, o sea, posee un patrón de gravedad creciente ${ }^{6}$ - (ver figuras 1-10).

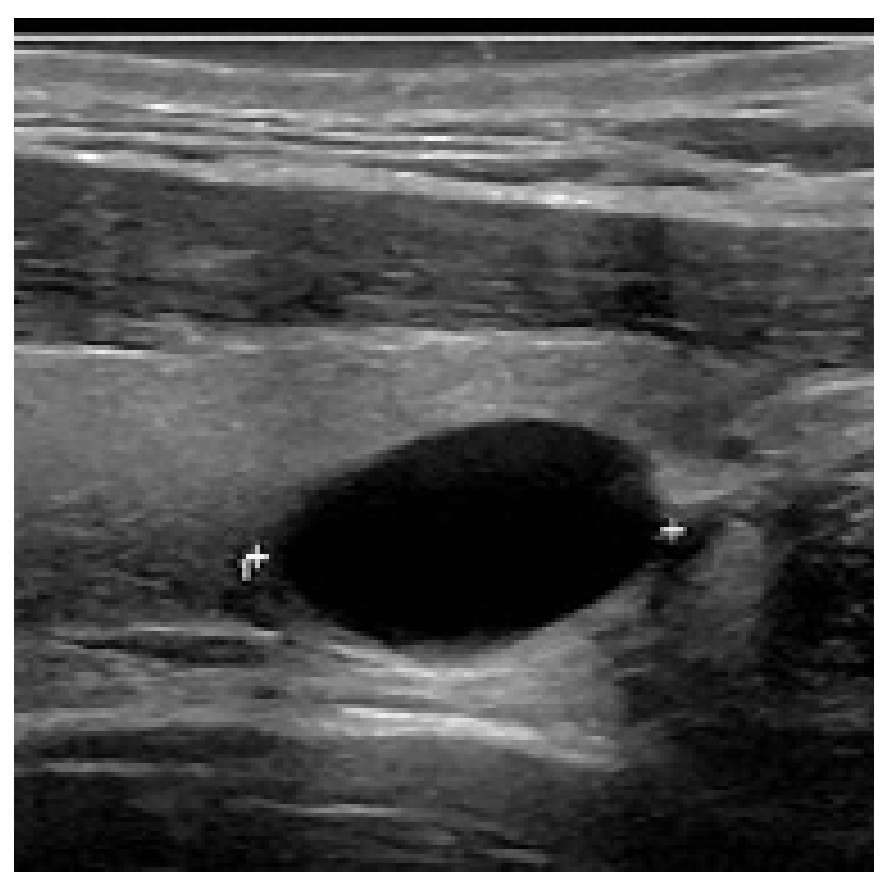

Figura 1 - Descripción: nódulo anecoico, quístico, bien definido, sin microcalcificaciones, que mide $1,5 \mathrm{~cm}$. ACR TI-RADS ' ${ }^{1}$. Citología: quiste coloide. Bethesda I.
1. Universidade Santo Amaro

2. CDB Inteligência Diagnóstica
Dirección para correspondencia:

Leonardo Piber

Rua Marechal Deodoro, 135 apt. 62B - Santo Amaro

São Paulo - CEP 04738-000

Email: lpiber@prof.unisa.br 


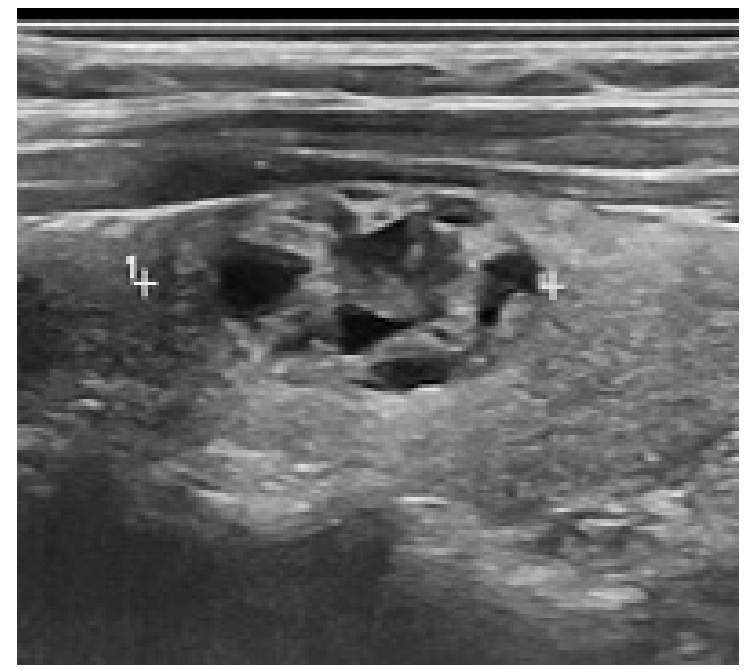

Figura 2 - Descripción: nódulo isoecogénico, mixto, bien definido, paralelo a la piel, sin microcalcificaciones, midiendo $2,2 \mathrm{~cm}$. ACR TI-RADS 2. Citología: nódulo coloide, Bethesda II.

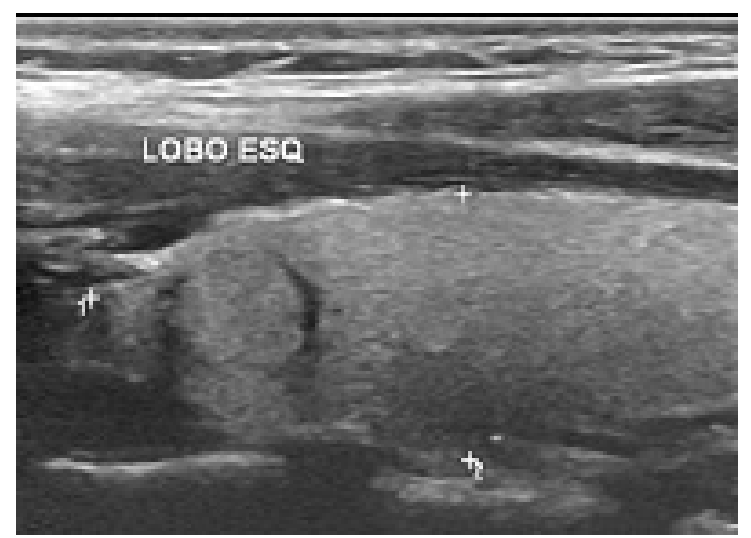

Figura 3 - Descripción: nódulo isoecogénico sólido, bien definido, paralelo a la piel, sin microcalcificaciones, midiendo $0,8 \mathrm{~cm}$. ACR TI-RADS 3. Citología: Lesión folicular de significado incierto, Bethesda III.

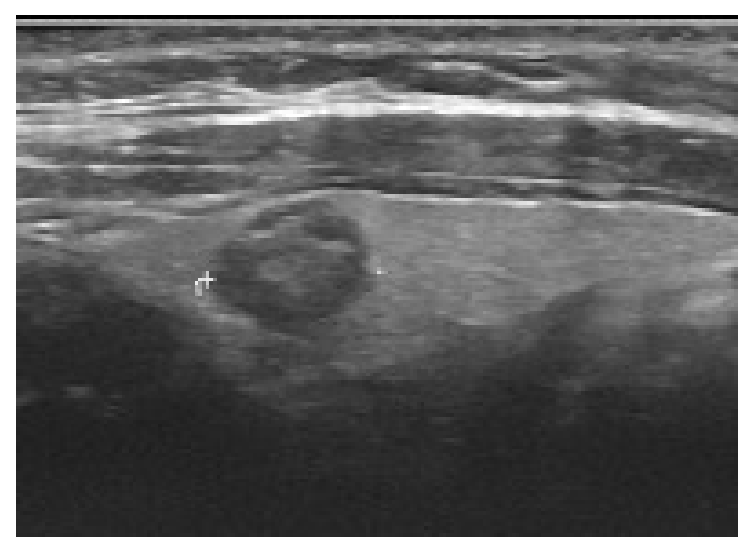

Figura 4 - Descripción: nódulo hipoecogénico, predominantemente sólido, bien definido, regular, paralelo a la piel, sin microcalcificaciones, que midiendo $0,8 \mathrm{~cm}$. ACR TI-RADS 3 . Citología: nódulo coloide, Bethesda II.

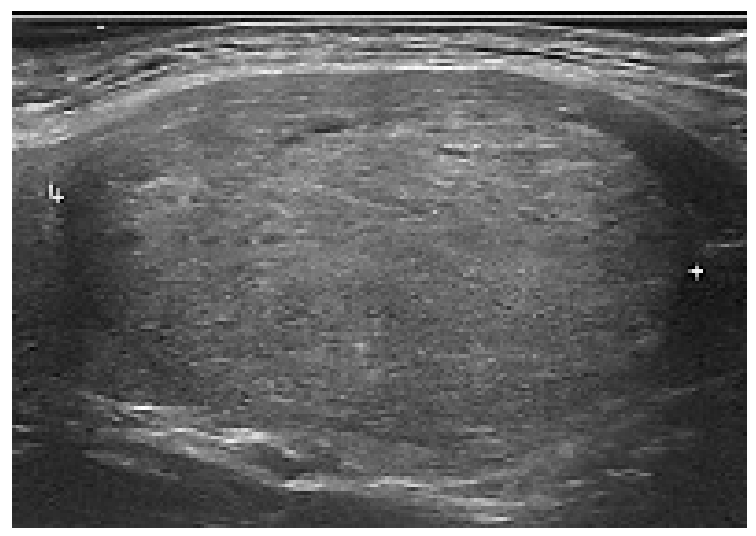

Figura 5 - Descripción: nódulo hipoecogénico, casi totalmente sólido, bien definido, regular, paralelo a la piel, sin microcalcificaciones, midiendo $4.1 \mathrm{~cm}$. ACR TI-RADS 4. Citología: nódulo coloide, Bethesda II.

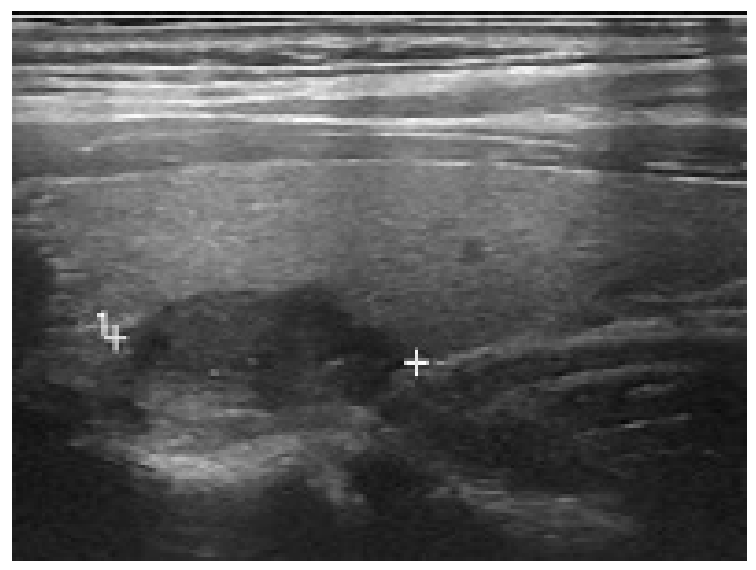

Figura 6 - Descripción: nódulo hipoecogénico, sólido, bien definido, irregular, paralelo a la piel, sin microcalcificaciones, midiendo 1,6 cm. ACR TI-RADS 4. Citología: nódulo coloide, Bethesda II.

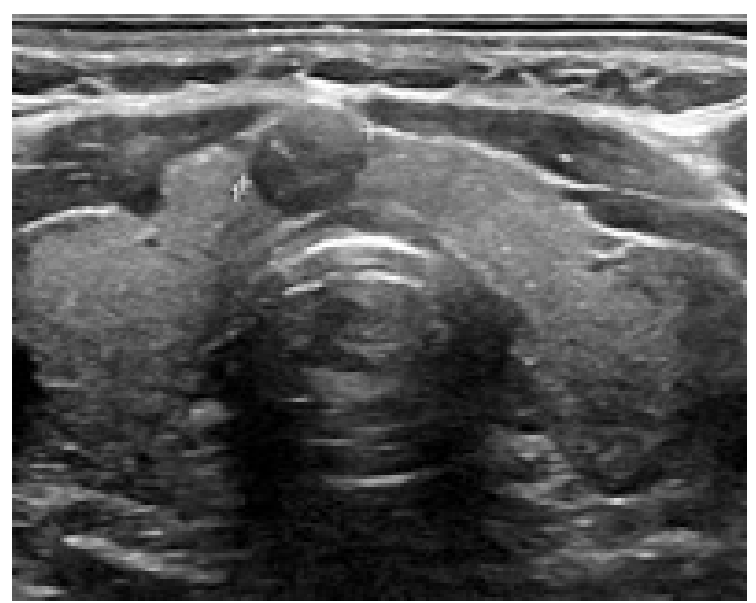

Figura 7 - Descripción: nódulo hipoecogénico, sólido, bien definido, irregular, paralelo a la piel, sin microcalcificaciones, midiendo $0,7 \mathrm{~cm}$ en la región del istmo. ACR TI-RADS 4. Citología: carcinoma papilar, Bethesda V. 


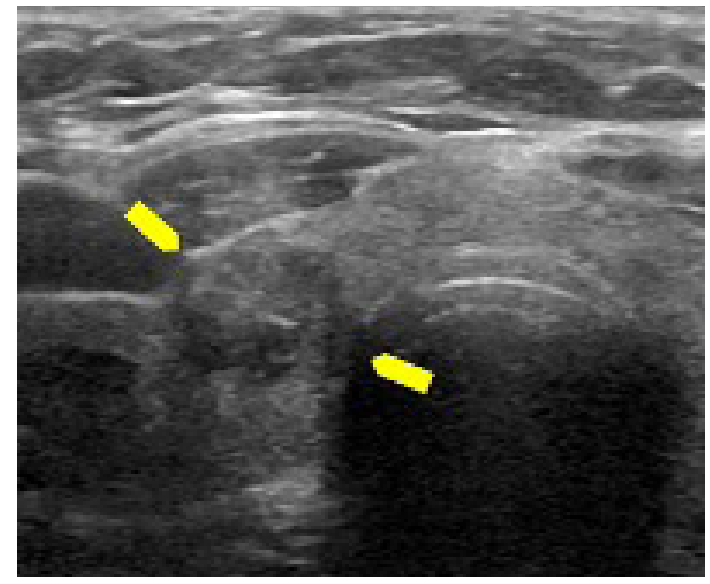

Figura 8 - Descripción: nódulo hipoecogénico, sólido, bien definido, irregular, paralelo a la piel, sin microcalcificaciones, midiendo 1,2 cm (flechas amarillas). ACR TI-RADS 4. Citología: carcinoma papilar, Bethesda V.

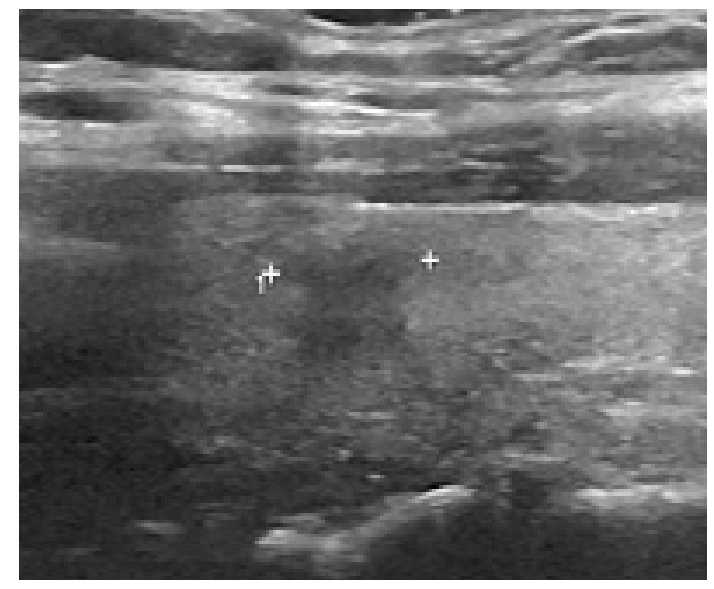

Figure 9 - Description: solid, hypoechogenic nodule, with imprecise limits, irregular, parallel to the skin, without microcalcifications, measuring $0.7 \mathrm{~cm}$. ACR TI-RADS 4. Cytology: Lymphocytic thyroiditis, Bethesda II.

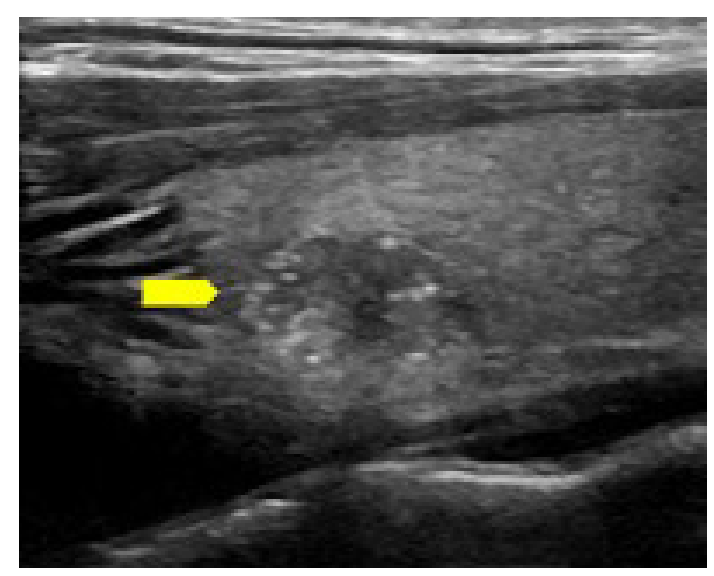

Figura 10 - Descripción: nódulo hipoecogénico, sólido, bien definido, con microcalcificaciones, midiendo $1,2 \mathrm{~cm}$ (flecha amarilla). ACR TI-RADS 5. Citología: carcinoma papilar, Bethesda V.
La clasificación de ACR TI-RADS varía de 1 (benigno) a 5 (alta sospecha de malignidad), a partir de TI-RADS 3, dependiendo del tamaño presentado por el nódulo, se indica aspiración con aguja fina (PAAF) o seguimiento clínico. Por ejemplo, PAAF es indicada para nódulos mayores o iguales a un centímetro y TI-RADS 5, si el nódulo es TIRADS 3 (bajo riesgo de malignidad), la biopsia es indicada si el nódulo mide $2.5 \mathrm{~cm}$ o más. Esto se propuso para evitar procedimientos invasivos, como la biopsia, de forma indiscriminada. ${ }^{7}$

Las características sugestivas de malignidad observadas en la ultrasonografía, modo B, son composición nodular sólida superior al 50\%, forma irregular, más alto que ancho, microcalcificaciones, porción excéntrica sólida, alteración en la ecogenicidad como hipoecogenicidad marcada, nódulos sólidos. $6,8,9$

La punción es realizada con una aguja transdérmica insertada en región específica y, si asociada a la USG, es posible visualizar en tiempo real el posicionamiento de la aguja y recoger material de los nódulos caracterizados como potencialmente malignos. ${ }^{10}$

El material recogido se somete a un análisis citopatológico y es así clasificado de acuerdo con el sistema Bethesda, que está dividido en seis categorías: muestra no diagnóstica (I), benigna (II), lesión atípica/folicular de significado incierto (III), sospechoso de neoplasia folicular o neoplasia folicular (IV), sospechoso de malignidad (V) y maligna (VI) ${ }^{3}$. Esto ayuda en la comunicación entre citopatólogos, reduce procedimientos innecesarios y facilita el intercambio de datos entre laboratorios e instituciones. ${ }^{11}$

El interés principal de la biopsia por aspiración se centra en su potencial para distinguir nódulos de naturaleza benigna de aquellos que requieren intervención quirúrgica. La precisión de la PAAF en la identificación de nódulos benignos lleva a una reducción en el número de intervenciones quirúrgicas innecesarias.

\section{MÉTODOS}

Se trata de un estudio transversal, de selección completa, con muestreo por conveniencia. La población objetivo fueron todos los pacientes que programaron la punción por aspiración con aguja fina de tiroides guiada por ultrasonido (PAAF) para la investigación de la patología de tiroides en un centro de diagnóstico por imágenes privado en la ciudad de São Paulo, de ambos sexos, según lo solicitado por su médico asistente entre octubre de 2018 y agosto de 2019.

Fueron excluidos del estudio aquellos que no aceptaron participar o ser examinados y aquellos que no firmaron el formulario de consentimiento informado. Los datos fueron extraídos del formulario de solicitud de análisis citopatológico estándar del servicio. Las variables analizadas fueron: edad, género, características del nódulo, como composición, ecogenicidad, forma, margen, presencia de calcificación, tamaño, ubicación, clasificación ACR TI-RADS, resultado de la citopatología y clasificación de Bethesda.

Los exámenes ultrasonográficos fueron realizados en 
decúbito dorsal horizontal, con hiperextensión cervical para facilitar el acceso a la glándula, con exploración longitudinal y transversal, utilizando un modelo Logiq ${ }^{7}$ de la marca General Electric Company (GE).

El procedimiento incluyó tres etapas: recolección, preparación del material y análisis microscópico e interpretación del frotis, por el servicio de citología.

Esta investigación fue aprobada por el Comité de Ética e Investigación de la Universidad Santo Amaro, cuyo número de aprobación es CAAE 97937018.1.0000.0081.

\section{RESULTADOS}

De los 499 nódulos puncionados en 334 pacientes (índice de 1,5 nódulos por paciente), 44 (8,8\%) fueron nódulos en hombres y $455(91,2 \%)$ en mujeres. Del número total de pacientes, 31 (9.3\%) eran hombres y 303 (90.7\%) eran mujeres, con edades entre 13 y 88 años. Se obtuvieron tres muestras hemorrágicas $(0.6 \%)$, cuyos nódulos fueron puncionados nuevamente. La tabla 1 muestra la cantidad de nódulos puncionados por pacientes. La mayoría de los pacientes $(67.0 \%)$ tuvo un nódulo puncionado.

\begin{tabular}{lll}
\hline número de nódulos & $\begin{array}{l}\text { cantidad de nódulos } \\
\text { perforado por paciente }\end{array}$ & cantidad de nódulos total \\
\hline 1 & 224 & 224 \\
2 & 76 & 152 \\
3 & 24 & 72 \\
4 & 4 & 16 \\
5 & 3 & 15 \\
6 & 2 & 12 \\
7 & 0 & 0 \\
\hline Total & 1 & 499 \\
\hline
\end{tabular}

Tabla 1 - Distribución de la cantidad de nódulos tiroideos, por paciente, puncionados entre octubre de 2018 y agosto de 2019. São Paulo, 2020.

La Tabla 2 muestra los diversos resultados del análisis citopatológico de los nódulos tiroideos. De estos, $4.8 \%$ fueron carcinoma papilar.

\begin{tabular}{lcc}
\hline Citopatología de nódulos tiroideos & N & $\%$ \\
\hline Nódulo coloide & 395 & 79,2 \\
Tiroiditis linfocítica & 59 & 11,8 \\
Carcinoma papilar & 24 & 4,8 \\
Atipias de sentido indeterminado & 12 & 2,4 \\
Quiste coloide & 6 & 1,2 \\
Neoplasia folicular de células de Hurthle & 2 & 0,4 \\
Nódulo adenomatoso & 2 & 0,2 \\
\hline Total & 1 & \\
\hline
\end{tabular}

Tabla 2 - Distribución, según el diagnóstico citopatológico, de los nódulos tiroideos puncionados entre octubre de 2018 y agosto de 2019. São Paulo, 2020.

Para la compasión de las variables, se optó por seguir con dos grupos, nódulos cuyo diagnóstico fue carcinoma papilar y nódulo coloide. Los otros diagnósticos no presentaron un número absoluto suficiente para esta comparación bioestadística descriptiva.

La Tabla 3 presenta las variables estudiadas, destacando las características de los nódulos basados en ACR TI-RADS. La clasificación de Bethesda está directamente relacionada al diagnóstico citopatológico.

\begin{tabular}{|c|c|c|c|c|}
\hline \multirow[t]{2}{*}{ Variáveis analizadas } & $\begin{array}{l}\text { carcinoma } \\
(\mathrm{N}=24)\end{array}$ & papilar & $\begin{array}{l}\text { nódulo } \\
(\mathrm{N}=395)\end{array}$ & coloide \\
\hline & $\mathrm{N}$ & $\%$ & $\mathrm{~N}$ & $\%$ \\
\hline \multicolumn{5}{|l|}{ género } \\
\hline femenino & 20 & 83,3 & 358 & 90,6 \\
\hline masculino & 4 & 16,7 & 37 & 9,4 \\
\hline
\end{tabular}

Años de edad)

mediana

$42,5 \quad 48$

intervalo

18 a 59

17 a 88 
composición

\begin{tabular}{lcccc} 
Sólido o casi completamente sólido & 18 & 75,0 & 163 & 41,3 \\
mezclado & 6 & 25,0 & 205 & 51,9 \\
Quistico o casi completamente quístico & 0 & 0,0 & 27 & 6,8 \\
& & & & \\
& & & & \\
ecogenicidad & 23 & 95,8 & 252 & 63,8 \\
hipoecoico & & & & \\
\hline & 1 & 4,2 & 134 & 33,9 \\
\hline isoecoico & 0 & 0,0 & 6 & 1,5 \\
hiperecoico & 0 & 0,0 & 3 & 0,8
\end{tabular}

molde

Más alto que ancho

Más ancho que alto

margen

regular

lobulado

irregular

calcificación

ausencia

macrocalcificación

periférico

microcalcificación

ubicación

\begin{tabular}{lcccc}
\hline & & & & \\
\hline istmo & 2 & 8,3 & 28 & 7,1 \\
lóbulo derecho & 10 & 41,7 & 217 & 54,9 \\
lóbulo izquierdo & 12 & 50,0 & 150 & 38,0
\end{tabular}

talla

$$
\begin{aligned}
& <5 \mathrm{~mm} \\
& >0=5 \mathrm{~mm} \\
& >0=10 \mathrm{~mm} \\
& >0=15 \mathrm{~mm} \\
& >0=20 \mathrm{~mm}
\end{aligned}
$$

ACR-TIRADS

$\begin{array}{lcccc}\text { T1 } & 0 & 0,0 & 2 & 0,5 \\ \text { T2 } & 0 & 0,0 & 79 & 20,0 \\ \text { T3 } & 1 & 4,2 & 167 & 42,3 \\ \text { T4 } & 11 & 45,8 & 135 & 34,2 \\ \text { T5 } & 12 & 50,0 & 12 & 3,0\end{array}$

Clasificación Bethesda

\begin{tabular}{lcccc} 
I & 0 & 0,0 & 0 & 0,0 \\
II & 0 & 0,0 & 395 & 100,0 \\
III & 0 & 0,0 & 0 & 0,0 \\
IV & 1 & 4,2 & 0 & 0,0 \\
V & 13 & 54,2 & 0 & 0,0 \\
VI & 10 & 41,6 & 0 & 0,0 \\
\hline Total & & & & \\
\hline
\end{tabular}

Tabla 3 - Comparación de las características de los nódulos tiroideos puncionados, con diagnóstico de carcinoma papilar y nódulo coloide, entre octubre de 2018 y agosto de 2019. São Paulo, 2020

\section{DISCUSIÓN}

La incidencia del cáncer de tiroides ha aumentado en las últimas décadas, considerando el avance de los métodos de diagnóstico para detectar aspectos sugestivos de malignidad en los nódulos tiroideos no palpables. ${ }^{4,9}$ La caracterización del nódulo según el aspecto de la ultrasonografía se clasifica de acuerdo al ACR TI-RADS, que permite una mejor com- 
prensión y comunicación entre los profesionales de la salud. ${ }^{5}$

Los nódulos tiroideos son encontrados en el 19\% al 67\% de las personas adultas, esto a través del ultrasonido, de los cuales aproximadamente el 10\% son malignos. ${ }^{4,9}$ En este estudio, la tasa de malignidad fue del $4.8 \%$, en concordancia con literatura existente. La frecuencia de nódulos benignos en este estudio, en cambio, fue del 92,4\%, una prevalencia mayor si comparada con la descrita por otros autores, cuyo valor está entre el 69 y $81 \%{ }^{12}$.

Hay determinadas situaciones, como la celularidad insuficiente para el análisis y las muestras hemorrágicas, en las que no es posible realizar el diagnóstico. En el presente estudio, el total de muestras hemorrágicas fue de $0.6 \%$; siendo el porcentaje esperado de muestras hemorrágicas de 1 y $15 \%$. ${ }^{12}$

De todas las neoplasias endocrinas, el 96\% están representadas por el cáncer de tiroides, que es más común en individuos del sexo femenino. ${ }^{4}$ Lo que también fue observado en este estudio fue que 20 de los 24 nódulos $(83,3 \%)$ que se caracterizaron como carcinoma papilar pertenecían a pacientes del sexo femenino, mientras que solo cuatro eran del sexo masculino $(16,7 \%)$.

Este estudio, así como los mencionados anteriormente, posee un mayor número de individuos del sexo femenino con nódulos tiroideos, con una proporción entre hombres y mujeres de aproximadamente $1: 10$. En un estudio similar, la proporción de hombres y mujeres fue de 1: 11.13. Cuando se caracteriza el perfil citológico en el carcinoma papilar de ese estudio, la proporción pasa a ser en 1:5 entre hombres y mujeres.

En el presente estudio, apenas 31 (9.3\%) de los pacientes eran del sexo masculino y $303(90.7 \%)$ eran del sexo femenino. Los valores encontrados son similares a otros estudios como este, realizados en São Paulo, así como en otros estados. Por ejemplo, el trabajo de Ceratti ${ }^{12}$, realizado en São Paulo, trajo un porcentaje del 9,6\% de hombres y $90,4 \%$ de mujeres, de la misma forma, el estudio realizado en Aracajú-SE reveló que apenas 5,2\% de los pacientes eran hombres, mientras que $94.8 \%$ correspondía a pacientes del sexo femenino. ${ }^{14}$

Entre las características ecográficas más prevalentes para el diagnóstico de carcinoma papilar, pueden destacarse la hipoecogenicidad, la consistencia sólida, el margen irregular y la presencia de micro y macrocalcificaciones, como previsto por la Clasificación ACR TI-RADS.

Los análisis evidencian que el perfil ultrasonográfico y citológico de los nódulos tiroideos está de acuerdo con la literatura actual, lo que puede ayudar en la auditoría de los resultados en los centros de diagnóstico por imagen.

\section{AGRADECIMIENTOS}

Agradecimiento a las Dras. Maria Teresa Natel de Almeida, Maria Antonieta Longo Galvão y Danielle Chacon.

\section{REFERENCIAS}

1. Toneto MG, Prill S, Debon LM, Furlan FZ, Steffen N. The history of the parathyroid surgery. Revista do Colégio Brasileiro de Cirurgiões, 2016;
43(3), 214-22.

2. Lof C, Patyra K, Kero A, Kero J. Genetically modified mouse models to investigate thyroid development, function and growth. est Practice $\mathcal{E}$ Research Clinical Endocrinology \& Metabolism. 2018.

3. de Souza Neta AM, de Andrade CIS, Cabral BAF, Cruz JF. Estudos dos nódulos tireoidianos submetidos à punção aspirativa por agulha fina em Aracaju-SE. $18^{\text {a }}$ Semana de Pesquisa da Universidade Tiradentes. "A prática interdisciplinar alimentado a Ciência". 24 a 28 de outubro de 2016.

4. Baldini E, Sorrenti S, Tartaglia F et al. New perspectives in the diagnosis of thyroid follicular lesions. International Journal of Surgery, 2017; 41: S7-S12

5. Migda B, Migda M, Migda MS, Slapa RZ. Use of the Kwak Thyroid Image Reporting and Data System (K-TIRADS) in differential diagnosis of thyroid nodules: systematic review and meta-analysis. European Radiology 2018; 28(6): 2380-8.

6. Rahal Junior A, Falsarella PM, Rocha RD et al. Correlação entre a classificação Thyroid Imaging Reporting and Data System [TI-RADS] e punção aspirativa por agulha fina: experiência com 1.000 nódulos. Einstein 2016; 14: 2 .

7. Tessler FN, Middleton WD, Grant EG et al. ACR Thyroid Imaging, Reporting and Data System (TI-RADS): White Paper of the ACR TI-RADS Committee. Journal of the American College of Radiology, 2017; 14(5).

8. Li W, Zhu Q, Jiang Y, Zhang Q, Meng Z, Sun J, Dai Q. Partially cystic thyroid nodules in ultrasound-guided fine needle aspiration: Prevalence of thyroid carcinoma and ultrasound features. Medicine 2017; 96 (46).

9. Rosário PW, Ward LS, Carvalho GA, Graf H, Maciel RMB, Maciel LMZ, Maia AL, Vaisman M. Thyroid nodule and differentiated thyroid cancer: update on the Brazilian consensus. Arq Bras Endocrinol Metab. 2013; 57(4).

10. Rosini I, Salum NC. Protocolo de cuidados para punção aspirativa por agulha fina de mama e tireoide. Texto \& Contexto Enfermagem 2014; $23(4)$ 


\title{
ULTRASONOGRAFÍA PARA MEDIR LA
}

\section{TRANSLUCENCIA NUCAL Y EL RASTREAMIENTO PRENATAL GENÉTICO}

\author{
LORHAYNE AFONSO SIQUEIRA ${ }^{1}$, TÁRIK KASSEM SAIDAH ${ }^{2}$, PATRÍCIA GONÇALVES EVANGELISTA ${ }^{3}$, \\ WALDEMAR NAVES DO AMARAL ${ }^{3}$
}

\section{RESUMEN}

INTRODUCCIÓN: La ultrasonografía de rutina al comienzo del embarazo permite una mejor evaluación de la edad gestacional, la detección temprana de embarazos múltiples y la malformación fetal clínicamente insospechada. Después de este primer examen se recomienda, en caso de alteraciones, exámenes más precisos para diagnosticar cromosomopatías.

OBJETIVO:Analizar la efectividad del método de ultrasonografía paramedir la translucencia nucal (TN) en la detección de anomalías cromosómicas confirmadas por biopsia de vellosidades coriónicas o amniocentesis, y definir la eficacia de TN como prueba de diagnóstico para anomalías fetales, para establecer la cromosomopatías más frecuente y verificar si la TN puede ser incorporada como elemento rastreador de aneuploidía. MÉTODOS: Este es un estudio analítico observacional, descriptivo y retrospectivo con mujeres embarazadas atendidas de 2007 a 2017 en la Clínica Fértile para el rastreo ultrasonográfico de la translucencia nucal (TN) realizada con edad gestacional entre las semanas $11^{a}$ y $13^{a}$ y seis días de edad gestacional. La medición de TN se consideró aumentada cuando presentó $>2.5 \mathrm{~mm}$. El cariotipo fetal se estableció mediante análisis citogenético del material obtenido mediante biopsia de vellosidades coriónicas o amniocentesis.

RESULTADOS: se estudiaron 219 gestantes, entre ellas 216 con alteraciones en la $T N(>=a 2.5 \mathrm{~mm}$ ), sometidas a confirmación por biopsia de vellosidades coriónicas y 113 con cariotipos normales. Sensibilidad: 100\%, especificidad: 97,3\% Valor predictivo positivo (VPP): 49\%, valor predictivo negativo (VPN): 100\% y precisión:49,8\%. La edad materna más prevalente fue de 18 a 35 años, con exámenes de cariotipo normales y la confirmación por biopsia de vellosidades coriónicas fue el examen de elección y la principal alteración de cariotipo fue 47 XX +21, síndrome de Down.

CONCLUSIÓN: La TN como prueba diagnóstica para aneuploidías fetales mostró sensibilidad del 100\%, VPN 100\%, especificidad 97.3\%, VPP 49\% y precisión 49.7\%. El trastorno cromosómico fetal más frecuente fue la trisomía 21 (síndrome de Down) 47 XX +21 . Teniendo en cuenta que el criterio de la prueba diagnóstica importante para la detección de enfermedades es la sensibilidad, el TN debe incorporarse como tal, ya que la sensibilidad fue plena en este estudio

\section{PALABRAS CLAVE: ULTRASONOGRAFÍA. TRANSLUCENCIA NUCAL, RASTREO. ANOMALÍAS CROMOSÓMICAS.}

\section{INTRODUCCIÓN}

El diagnóstico prenatal (DPN) es un conjunto de técnicas destinadas a investigar la salud fetal durante el período de vida intrauterina, con el objetivo de rastrear anomalías genéticas o congénitas ${ }^{1}$.

La ultrasonografía de rutina al comienzo del embarazo permite una mejor evaluación de la edad gestacional, la detección temprana de embarazos múltiples y la detección temprana de malformación fetal clínicamente insospechada. Es, sin duda, la que más diagnostica, tanto en frecuencia como en número, enfermedades genéticas y no genéticas $\mathrm{y}$, por esta razón, combinada a su bajo costo y a su característica no invasiva, debe ser alentada y priorizada en el diagnóstico prenatal ${ }^{2}$.

La translucencia nucal se configura como una imagen ultrasonográfica hipoecogénica, donde existe la acumulación de líquido en la región posterior del cuello, que ocurre con más exuberancia entre la $10^{\mathrm{a}}$ y $14^{\mathrm{a}}$ semanas de gestación, siendo el principal examen de detección realizado en Brasil. Ante un resultado positivo de una prueba de rastreo, se ofrecerá la posibilidad de una prueba de diagnóstico, que todavía constituye, inevitablemente, un procedimiento invasivo, no obstante de alta precisión ${ }^{3,4}$.

Después de este primer rastreo, en caso de alteraciones, se recomiendan exámenes más precisos para diagnosticar cromosomopatías. Se trata de exámenes que presentaron la posibilidad de realizar el diagnóstico a través de métodos invasivos en la atención prenatal, lo que fue un gran avance, ya que permitió la recolección directa de material fetal para análisis de laboratorio, permitiendo la realización de varias pruebas, como el cariotipo para enfermedades cromosómicas, los ensayos enzimáticos para errores innatos del metabolismo y el análisis molecular en la vida intrauterina ${ }^{5}$.

\footnotetext{
1. Hospital e Maternidade Dona íris.

2. UniEvangélica

3. Universidade Federal de Goiás.
}

Dirección de correo electrónico:

Waldemar Naves do Amaral

Alameda Cel. Joaquim de Bastos, 243 - St. Marista

Goiânia - CEP 74175-150

Email: waldemar@sbus.org.br 
Esto se hace recolectando una muestra del líquido que se encuentra alrededor del bebé (amniocentesis) o un pequeño pedazo de la placenta (biopsia de vellosidades coriónicas, BVC) para buscar anomalías cromosómicas. El examen se realiza insertando una aguja en el vientre de la mujer embarazada, lo que aumenta el riesgo de aborto involuntario. Por lo tanto, estas pruebas no se ofrecen a todas las gestantes ${ }^{6}$.

Actualmente, la "regla de oro" para el diagnóstico prenatal de cromosomopatías es proporcionada por la técnica de cariotipo, que posee una alta precisión, pero depende de procedimientos invasivos para recolectar muestras de material fetal directamente del útero materno, a través de una biopsia de vellosidades coriónicas (BVC) durante el primer trimestre de embarazo o a través de la recolección de líquido amniótico en el segundo trimestre ${ }^{7}$.

El objetivo de este estudio es analizar la efectividad del método de ultrasonografía para medir la translucencia nucal (TN) en la detección de anomalías cromosómicas confirmadas por biopsia de vellosidades coriónicas o amniocentesis.

\section{MÉTODOS}

Se trata de un estudio analítico observacional, descriptivo y retrospectivo con mujeres embarazadas atendidas desde 2007 a 2017 en la Clínica Fértile para la realización de rastreo ultrasonográfico de la translucencia nucal (TN) realizado con edad gestacional entre las semanas $11^{\mathrm{a}}$ y $13^{\mathrm{a}}$ y seis días de embarazo.

La medición de TN se consideró aumentada cuando presentó $>2.5 \mathrm{~mm}$ (ver figuras 1 y 2). El cariotipo fetal fue establecido por medio del análisis citogenético del material obtenido mediante biopsia de vellosidades coriónicas o amniocentesis.

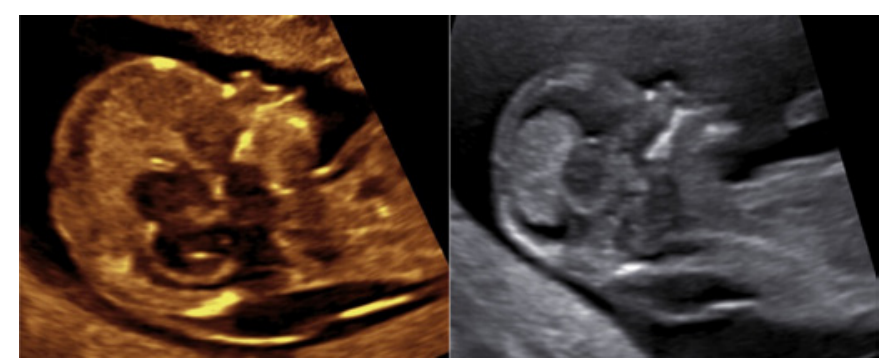

Figuras 1 y 2. Dos casos de translucencia nucal alterada (Cortesía de Faria \& Pettersen $)^{9}$

Los datos se ingresaron y manipularon en Excel, para el tratamiento posterior de los datos utilizando el programa Statistical Package for Social Science (SPSS) de Windows (versión 21.0).

Las variables categóricas se presentaron en forma de tabla, con valores absolutos (f) y valores porcentuales (\%).

La eficiencia fue evaluada mediante la tabla de contingencia, a través de la sensibilidad, especificidad, valor predictivo positivo, valor predictivo negativo y precisión.

En cuanto a los aspectos éticos, se destaca que la investigación se basó en la Resolución n. 466/2012, estando los derechos de los involucrados garantizados, con aprobación del Comité de Ética.

\section{RESULTADOS}

Fueron estudiadas 219 mujeres embarazadas, entre ellas 216 con alteraciones en la TN $(>=$ a $2.5 \mathrm{~mm})$ y tres con TN normal. Todos fueron sometidos a confirmación mediante biopsia de vellosidades coriónicas o amniocentesis.

\begin{tabular}{llll}
\hline \multirow{2}{*}{ TN } & Cariotipo & & Total \\
\cline { 2 - 3 } & Cambiado & Normal & \\
\hline$>2,5$ & 106 & 110 & 216 \\
$\leq 2,5$ & - & 3 & 3 \\
Total & 106 & 113 & 219 \\
\hline
\end{tabular}

Tabla 1 - Distribución de casos de estudios genéticos según pruebas positivas y negativas de cariotipos con TN alterada y TN normal, realizados en la clínica Fértile, Goiânia, Goiás, 2019.

Sensibilidad: 100\%, especificidad: $97,3 \%$, valor predictivo positivo: $49 \%$, valor predictivo negativo: $100 \%$ y precisión: $49,8 \%$. La edad materna más prevalente fue de 18 a 35 años, con exámenes de cariotipo normales y la confirmación por biopsia de vellosidades coriónicas fue la escogida, siendo la principal alteración de cariotipo $47 \mathrm{XX}+21$ (ver figura 3).

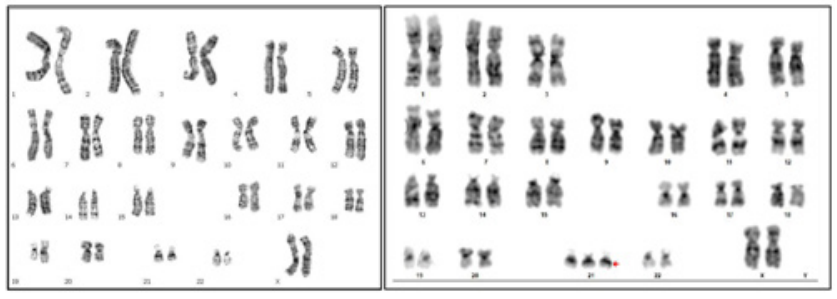

Figura 3. A. Ilustra un estudio citogenético normal $(46, X X)$. B. Ilustra la alteración de cariotipo en el síndrome de Down $(47, \mathrm{XX},+21)$ (Cortesía de Faria \& Pettersen) ${ }^{9}$

\begin{tabular}{|c|c|c|c|}
\hline Variables & $\mathrm{TN}>2,5$ & $\mathrm{TN} \leq \mathbf{2 , 5}$ & TOTAL (\%) \\
\hline \multicolumn{4}{|l|}{ Edad Materna } \\
\hline$<18$ años & 3 & - & $3(1,3 \%)$ \\
\hline 18 a 35 años & 144 & 2 & $146(66,7 \%)$ \\
\hline$>35$ años & 69 & 1 & $70(32,0 \%)$ \\
\hline \multicolumn{4}{|l|}{ Cariotipo } \\
\hline Normal & 110 & 3 & $113(51,6 \%)$ \\
\hline Cambiado & 106 & - & $106(48,4 \%)$ \\
\hline \multicolumn{4}{|l|}{ Examen } \\
\hline Liquido amniótico & 78 & - & $78(35,6 \%)$ \\
\hline Biopsia de vellosidades coriónicas & 138 & 3 & $138(64,4 \%)$ \\
\hline \multicolumn{4}{|l|}{ Cambios de cariotipo } \\
\hline $47 \mathrm{XX}+13$ & 4 & - & $4(3,8 \%)$ \\
\hline $47 \mathrm{XX}+18$ & 13 & - & $13(12,4 \%)$ \\
\hline $47 \mathrm{XX}+21$ & 26 & - & $26(24,8 \%)$ \\
\hline $45 \times 0$ & 9 & - & $9(8,6 \%)$ \\
\hline Otros Cambios & 54 & - & $54(50,5 \%)$ \\
\hline
\end{tabular}

Tabla 2 - Distribución de casos de estudios genéticos según el perfil de las pacientes analizados en la clínica Fértile, Goiânia, Goiás, 2019. 


\section{DISCUSIÓN}

Según Vieira (2016) ${ }^{8}$, la utilización de exámenes prenatales es esencial para hacer una evaluación detallada en el embarazo tanto de la salud del feto como de la madre. La realización de un diagnóstico prenatal precoz puede reducir la mortalidad neonatal y la ultrasonografía es el primer examen realizado para la detección de posibles alteraciones.

Se estudiaron 219 gestantes, entre ellas 216 con alteraciones en la TN $(>=$ a $2.5 \mathrm{~mm})$, sometidas a confirmación por biopsia de vellosidades coriónicas o amniocentesis y 3 con TN normales.

Calculando teniendo en cuenta como valor alterado o no (TN $>=2.5$ o TN $<2.5$ ), tuvimos: Sensibilidad: $100 \%$, especificidad: $97.3 \%$, valor predictivo positivo: $49 \%$, valor predictivo negativo: $100 \%$ y precisión: $49.8 \%$.

El primer estudio en Brasil fue realizado por Faria et al ${ }^{9}$ en 1997 en el que estudiaron 231 fetos y encontraron una sensibilidad del $100 \%$.

En los estudios de Murta y França ${ }^{4}$ se analizaron 1.152 fetos y de estos en 124 casos se realizó un estudio citogenético sobre el material obtenido mediante biopsia de vellosidades coriónicas o amniocentesis y en 1028 el resultado tuvo como base el fenotipo del recién nacido. Se diagnosticaron 23 casos de anomalías cromosómicas en la población estudiada. Entre estos, la medición de TN fue mayor que el percentil 95 en 16 (sensibilidad del 69.5\%). En el grupo de fetos normales (1129 casos), la medición de TN fue mayor que el percentil 95 en 41 evaluaciones (especificidad de $96.3 \%$, valor predictivo positivo y negativo de $28.0 \%$ y $99.3 \%$, respectivamente, tasa de falso positivo de $3.7 \%$ y razón de probabilidad de 19.1).

En los estudios de Saldanha et al. ${ }^{10}$, en $14.2 \%$ de los casos el cariotipo estaba alterado y en el $85.8 \%$ el cariotipo o fenotipo era normal, en fetos con TN aumentada y cariotipo normal, cuanto mayor la medición de TN, mayor la frecuencia de malformaciones estructurales, fueron encontrados especialmente defectos cardíacos, resultados gestacionales adversos y alteraciones en la evaluación postnatal.

Vieira (2013) ${ }^{11}$ analizó 116 casos de translucencia nucal por encima del percentil 95, y en 79 (68\%) fue realizado un cariotipo fetal, dentro de esas alteraciones los fetos con cariotipo normal, hubo un aborto en la $15^{\mathrm{a}}$ semana de gestación con pentalogía de Cantrell, una muerte en la semana $24^{\mathrm{a}}$ con diversas anomalías estructurales, una muerte neonatal sin causa definida y dos casos de comunicación intraventricular (CIV) detectados en el ecocardiograma fetal.

Para Almeida et $\mathrm{al}^{13}$ la oferta de pruebas diagnósticas invasivas debe mantenerse para embarazos con resultados positivos en el rastreo y el asesoramiento debe reforzar la noción de que un resultado negativo no es garantía de un embarazo no afectado, ya que pueden ocurrir falsos negativos.

La edad materna de mayor prevalencia fue de 18 a 35 años, con exámenes de cariotipo normales y la confirmación por biopsia de vellosidades coriónicas fue la escogida y la principal alteración de cariotipo fue $47 \mathrm{XX}+21$.
Emer et al. ${ }^{12}$ evaluaron 840 exámenes de amniocentesis y se diagnosticaron 60 casos, nueve de los cuales fueron trisomía del cromosoma 13, 26 del cromosoma 18 y 25 del cromosoma 21.

Pereira et al. ${ }^{13}$ encontraron 142 casos de cariotipos anormales, siendo la aneuploidía (45.1\%) la más frecuente, seguida de alteraciones estructurales (38.7\%) y mosaicismos (16.2\%). Almeida et al., (2014) encontraron que las trisomías de los cromosomas 21,18 y 13 son prevalentes, lo que representa el $70 \%$ de todas las aneuploidías detectadas en el período prenatal.

Cuando son realizados exámenes prenatales de rastreo, se puede concluir que las aneuploidías que se encuentran entre las anomalías genéticas más comunes según Sbragia et al. ${ }^{14}$ son las trisomías que involucran los cromosomas 13,18 y 21. Entre las trisomías más frecuentes observadas en el nacimiento, podemos observar el síndrome de Down (trisomía 21), precedido por el síndrome de Edwards (trisomía 18).

Con respecto al rastreo prenatal, Henriques ${ }^{15}$ advierte que la detección prenatal de trastornos cromosómicos plantea varias cuestiones éticas con las que se enfrentan las mujeres embarazadas, las parejas y los profesionales de la salud, ya que no ofrece una opción terapéutica para las cromosomopatías. La única medida preventiva posible es la interrupción del embarazo en casos raros. Esto hace que las parejas enfrenten decisiones difíciles, tempranamente en el embarazo, decisiones que deben tomarse rápidamente. Por lo tanto, es necesaria información correcta para estas parejas y esta debe incluir: 1) una breve explicación de las patologías a rastrear; 2) las características de los exámenes ofrecidos y 3 ) las implicaciones de realizar los exámenes: opciones disponibles después de la detección positiva (riesgo aumentado), el riesgo de aborto iatrogénico con la amniocentesis, opciones disponibles después del diagnóstico de una anomalía fetal (interrupción del embarazo , continuación del embarazo y preparación para el nacimiento de un niño con necesidades especiales).

Pereira et $\mathrm{al}^{13}$ destacan la importancia de aclarar que, incluso si el cariotipo tiene un resultado normal, existe la posibilidad de que no sean identificadas algunas alteraciones, requiriendo exámenes más específicos e informes citogenéticos que deben, además de presentar el cariotipo, aclarar a los profesionales de la Salud sobre el hecho de que, en casos de individuos con constitución cromosómica normal que presenten malformaciones, se recomienda la derivación para asesoramiento genético, que orientará el diagnóstico, la conducta terapéutica y el riesgo de recurrencia de problemas genéticos.

La TN como prueba diagnóstica para aneuploidías fetales mostró sensibilidad del 100\%, VPN 100\%, especificidad 97.3\%, VPP 49\% y precisión 49.7\%. \

La cromosomopatía fetal más frecuente fue la trisomía 21 (síndrome de Down) $47 \mathrm{XX}+21$.

Teniendo en cuenta que el criterio de la prueba diagnóstica importante para el rastreo de enfermedades es la sensibilidad, la TN debe incorporarse como tal, puesto que la sensibilidad fue completa en este estudio. 


\section{REFERENCIAS}

1. Bernal L M \& Lopez G. Diagnóstico pré-natal: retrospectiva. Nova 2014; 12(21): 23-36.

2. Pinto Júnior W. Diagnóstico pré-natal. Ciênc. Saúde Coletiva 2002; 7(1): 139-57.

3. Almeida $\mathrm{O}$ et al. A nova era do rastreio pré-natal. Acta Obstet Ginecol Port, 2014; 8(3): 284-90.

4. Murta CGV \& França LC. Medida da Translucência nucal no rastreamento de anomalias cromossômicas. RBGO 2002; 24(3): 167-73.

5. Sanseverino MTV et al. Diagnóstico pré-natal: avanços e perspectivas. Revista HCPA 2001; 3(1): 301-16.

6. Alldred $S$ et al. First trimester serum tests for Down's syndrome screening. Cochrane Database of Systematic Reviews, 2015: 1.

7. Andari VCM. Testes genéticos não invasivos no pré-natal: benefícios e limitações dos exames disponíveis. 2015. Dissertação (mestrado). Faculdade de Ciências Médicas da Santa Casa de São Paulo.

8. Vieira AA. Saúde materno-fetal e técnicas de diagnóstico. Disponível em:< http://www.repositorio.uniceub.br/bitstream/235/9055/1/21437970. pdf $>$. Acesso em: 13 abr. 2016.

9. Faria M, Quintino S, Pettersen H. Rastreamento ultrassonográfico de anomalias cromossômicas através da medida da translucência nucal Análise de 231 fetos. RBGO 1997; 19: 19-30.

10. Saldanha FAT et al. Translucência nucal aumentada e cariótipo normal: evolução pré e pós-natal. Rev. Assoc. Med. Bras. 2009; 55(5): 575-80.

11. Vieira LA. Evolução perinatal e pediátrica de crianças com translucência nucal aumentada e cariótipo normal RBGO 2013; 35(6): 274-80.

12. Emer CSC et al. Prevalência das malformações congênitas identificadas em fetos com trissomia dos cromossomos 13, 18 e 21. RBGO 2015; 37(7): 333-8

13. Pereira TM et al. Frequência das anormalidades cromossômicas: importância para o diagnóstico citogenético. Arq. Ciênc. Saúde 2009; 16(1): 31-3.

14. Sbragia L. Tratamento das malformações fetais intraútero. RBGO 2010; 32(1): 47-54

15. Henriques S. Rastreio pré-natal de cromossomopatias e defeitos do tubo neural. Como actuar? Revista Portuguesa de Medicina Geral e Familiar. 2009; 25(3): 320-31. 


\title{
PREVALENCIA DE LESIONES NEUROLÓGICAS DIAGNOSTICADAS POR ULTRASONOGRAFÍA
} TRANSFONTANELAR EN RECIÉN NACIDO A TÉRMINO

\author{
LORENA CABRAL DE CASTRO LOURENZO', MIDIÃ FONSECA LIMA', SIMONE CARRIJO SANTOS', \\ PATRÍCIA GONÇALVES EVANGELISTA²
}

\section{RESUMEN}

INTRODUCCIÓN: La ultrasonografía (USG) es el procedimiento de neuroimagen más ampliamente utilizado, pues proporciona informaciones sobre lesiones cerebrales perinatales para la previsión de resultados a largo plazo La USG transfontanelar (USTF) es un examen de rutina para aquellos con edad gestacional (EG) menor que 34 semanas y existen muchos estudios que hablan de la prevalencia de lesiones para ese grupo y pocos estudios relacionados a hallazgos en recién nacidos (RN) a término. Estudiar los hallazgos de la USTF es esencial en el cuidado de la salud de los bebés prematuros, con el objetivo de mejorar el pronóstico.

OBJETIVO: Medir los principales hallazgos de la USTF en recién nacidos a término.

MÉTODOS: Estudio transversal descriptivo, cuantitativo y retrospectivo, realizado en una maternidad pública de referencia en Goiânia-GO. RESULTADOS: Fueron analizados todos los RNs admitidos en la UCI de enero a diciembre de 2019 constituyendo un total de 265, 50 de los cuales se consideraron a término en relación con la edad gestacional y fueron indicados para que se sometieran a USTF (excluyendo seis casos con datos incompletos), totalizando 44 pacientes. . El perfil materno fue de mujeres entre 18 y 30 años (62\%), primíparas (50\%), menos de siete consultas prenatales (62\%), cesárea (62\%) con factores de riesgo asociados con enfermedad hipertensiva en el embarazo (EHE) e infecciones del tracto urinario (43\%). El perfil de los recién nacidos es femenino (75\%), 38 semanas (38\%), con una puntuación de apgar inferior a siete (65\%), con una puntuación de apgar superior a ocho (75\%), apropiado para la edad gestacional (AEG) (62\%) y por encima de 2.501 gramos (62\%). El 25\% de las muertes se registraron en el grupo de pacientes con alteraciones, el 100\% de los cuales fueron diagnosticados con leucomalacia.

CONCLUSIÓN: Se realizaron 44 exámenes, de los cuales el 82\% eran normales y el 18\% anormal, la principal alteración encontrada en este grupo fue la leucomalacia con el 50\%. El perfil materno fue de mujeres entre 18 y 30 años, primíparas que tuvieron menos de siete consultas prenatales y que tuvieron partos por cesárea con factores de riesgo asociados con EHE e infecciones del tracto urinario. El perfil de los recién nacidos es femenino, nacidos a las 38 semanas, con apgar $1^{\circ}$ menor que siete, apgar $5^{\circ}$ mayor que ocho, con peso adecuado para la edad gestacional con bebés arriba de 2,501 gramos.

\section{PALABRAS CLAVE: LESIONES, TRANSFONTANELA, ULTRASONOGRAFÍA, DIAGNÓSTICO}

\section{INTRODUCCIÓN}

Desde finales de la década de 1970, la ultrasonografía (USG) ha sido el procedimiento de neuroimagen más utilizado, puesto que proporciona información sobre la lesión cerebral perinatal para predecir resultados a largo plazo'. Los atributos favorables a la ultrasonografía que lo tornan casi indispensable para la atención de rutina del recién nacido incluyen fácil acceso, bajo costo, portabilidad, falta de radiación ionizante y exención de sedación o anestesia ${ }^{2}$.

Es muy útil en muchas situaciones clínicas, ya que permite seleccionar qué pacientes se beneficiarán de otras técnicas más invasivas o más caras, o que requieran sedación, como la resonancia magnética. Las desventajas de la técnica son que la misma depende del operador y que se requiere una ventana acústica adecuada. También posee limitaciones en el estudio del trauma obstétrico, en la evaluación de malformaciones complejas y en la evaluación del daño a la sustancia blanca ${ }^{3}$.

El examen de ultrasonografía craneal se sugiere en los primeros 4-7 días de vida con una repetición de la ecografía craneal de 10-14 días. Cuando se usa de esta manera, la ecografía craneal tiene una sensibilidad del $100 \%$ para la detección de lesiones hemorrágicas intraventriculares graves (HIV) y lesiones graves de la sustancia blanca. Si el examen de ultrasonografía es normal, se sugiere un examen de seguimiento a la edad gestacional corregida de 36 a 40 semanas (término equivalente) para rastrear la evidencia de lesiones más graves en la sustancia blanca ${ }^{4}$.

Se sabe que el embarazo se mide desde el primer día del
1. Médica residente en neonatología del Hospital e Maternidade Dona íris.

2. Doctoranda en Ciencias de la Salud de la UFG.
Dirección de correo electrónico:

Waldemar Naves do Amaral

Alameda Cel. Joaquim de Bastos, 243 - St. Marista

Goiânia - CEP 74175-150

Email: waldemar@sbus.org.br 
último período menstrual normal y puede contarse durante semanas gestacionales completas, donde los embarazos con menos de 37 semanas completas son considerados pretérmino y de 37 semanas a menos de 42 semanas completas se consideran a término 5 .

La US transfontanelar (USTF) es un examen de rutina para las personas con edad gestacional (EG) de menos de 34 semanas y hay muchos estudios que hablan sobre la prevalencia de lesiones para este grupo y pocos estudios relacionados con hallazgos en recién nacidos a término, que estudian los hallazgos de las USTF son esenciales en el cuidado de la salud de los bebés prematuros, por lo tanto, apuntan a un mejor pronóstico.

\section{MÉTODOS}

Estudio transversal descriptivo, cuantitativo y retrospectivo, realizado en una maternidad pública de referencia en Goiânia-GO. El hospital forma parte de la Red Municipal de Salud de Goiânia con UCI y UCIN exclusivamente para usuarios del Sistema Único de Salud (SUS).

La investigación se llevó a cabo de enero a diciembre de 2019, estando incluidos todos los recién nacidos que pasaron la UCIN en el período establecido (excluyendo los recién nacidos a término en los que el registro médico estaba incompleto y no tenía suficientes datos para el análisis).

Para la recolección de datos, se desarrolló un instrumento de recopilación de datos secundarios con las variables maternas: edad materna, número de niños, número de consultas prenatales, factores de riesgo maternos y tipo de parto. Ya las variables neonatales fueron el puntaje de Apgar en el primer y quinto minuto de vida, edad gestacional, sexo y peso y el USTF: tipo de lesión presentada. Los elementos recopilados se insertaron en una planilla de cálculo electrónica (Excel, Microsoft Corporation, EE. UU.) y se utilizó el sistema Epilnfo 2002 (Centers for Disease Control and Prevention, EE.UU) para el análisis de tablas y gráficos.

Este proyecto de investigación se basó en la Resolución N0. 466/2012, estando los derechos de los involucrados asegurados, aprobados por el Comité de Ética designado por la Plataforma Brasil.

\section{RESULTADOS}

Fueron analizados todos los RNs admitidos en la UCI de enero a diciembre de 2019 totalizando 265, 50 de los cuales se consideraron términos en relación a la edad gestacional y que fueron indicados para someterse a USTF (excluyendo seis pacientes que estaban incompletos), totalizando 44 registros médicos.

\begin{tabular}{ccc}
\hline USTF & N & $\%$ \\
\hline Normal & 36 & 82 \\
Cambiado & 8 & 18 \\
\hline Fuente: Dados de investigación, 2019. & &
\end{tabular}

Fuente: Dados de investigación, 2019.

Tabla 1 - Distribución de los resultados del USTF realizados en recién nacidos a término en HMDI, Goiânia (GO), Brasil, 2020.

\begin{tabular}{lcc}
\hline & \multicolumn{2}{c}{ Número de pacientes (N=8) } \\
\cline { 2 - 3 } & $\mathrm{N}$ & $\%$ \\
\hline EDAD MATERNA & 2 & 25 \\
$\leq 17$ & 5 & 62 \\
$18-30$ & 1 & 13 \\
$\geq 31$ & & \\
\hline NÚMERO DE EMBARAZOS & 4 & 50 \\
1 & 3 & 37 \\
$2-3$ & 1 & 13 \\
$\geq 4$ & & \\
\hline CONSULTAS PRENATALES & 5 & 62 \\
$<7$ & 3 & 38 \\
$\geq 8$ & & \\
TIPO DE NACIMIENTO INFANTIL & 5 & 62 \\
Cesárea & 3 & 38 \\
Normal & & \\
PRINCIPALES FACTORES DE RIESGO & 3 & 43 \\
DHEG & 3 & 14 \\
Infección del tracto urinario & 1 & \\
Diabetes & &
\end{tabular}

Fuente: Dados de investigación, 2019.

Tabla 2 - Distribución de las características maternas de los RNs en la UCIN que se sometieron a USTF en el HMDI, Goiânia (GO), Brasil, 2020.

\begin{tabular}{|c|c|c|}
\hline & \multicolumn{2}{|c|}{ Número de pacientes $(\mathrm{N}=8$ ) } \\
\hline & $\mathrm{N}$ & $\%$ \\
\hline \multicolumn{3}{|l|}{ SEXO } \\
\hline Femenino & 6 & 75 \\
\hline Masculino & 2 & 25 \\
\hline \multicolumn{3}{|c|}{ EDAD GESTACIONAL } \\
\hline 37 semanas & 1 & 12 \\
\hline 38 semanas & 3 & 38 \\
\hline 39 semanas & 2 & 25 \\
\hline 40 semanas & 2 & 25 \\
\hline \multicolumn{3}{|l|}{ APGAR $1^{\circ}$} \\
\hline$<7$ & 5 & 62 \\
\hline$\geq 8$ & 3 & 38 \\
\hline \multicolumn{3}{|l|}{ APGAR $5^{\circ}$} \\
\hline$<7$ & 2 & 25 \\
\hline$\geq 8$ & 6 & 75 \\
\hline \multicolumn{3}{|c|}{ PESO PARA LA EDAD GESTACIONAL } \\
\hline AIG & 5 & 62 \\
\hline GIG & - & 0 \\
\hline PIG & 3 & 38 \\
\hline \multicolumn{3}{|c|}{ FAIXA DE PESO (EM GRAMAS) } \\
\hline$<2.500$ & 3 & 38 \\
\hline$\geq 2.501$ & 5 & 62 \\
\hline
\end{tabular}

Tabla 3 - Distribución de las características de los RNs en la UCIN que se sometieron a USTF en el HMDI, Goiânia (GO), Brasil, 2020.

\begin{tabular}{ccc}
\hline Cambios encontrados & N & $\%$ \\
\hline Leucomalacia & 4 & 50 \\
Calcificaciones Talamicas & 3 & 38 \\
Hemorragia & 1 & 12 \\
\hline Fuente: Dados de investigación, 2019. & &
\end{tabular}

Tabla 4 - Distribución de los resultados de la USTF alteradas realizadas en RN término en HMDI, Goiânia (GO), Brasil, 2020. 
Fueron registrados $25 \%$ de muertes en el grupo de pacientes con alteraciones siendo que el $100 \%$ fueron diagnosticados con leucomalacia.

\section{DISCUSIÓN}

La ultrasonografía es una técnica de diagnóstico no invasiva y se ha utilizado para detectar lesiones intracraneales en recién nacidos durante mucho tiempo. Este estudio evaluó 44 exámenes USTF realizados en RNs a término, siendo que el $82 \%$ estaban dentro de los límites normales y el 18\% alterado.

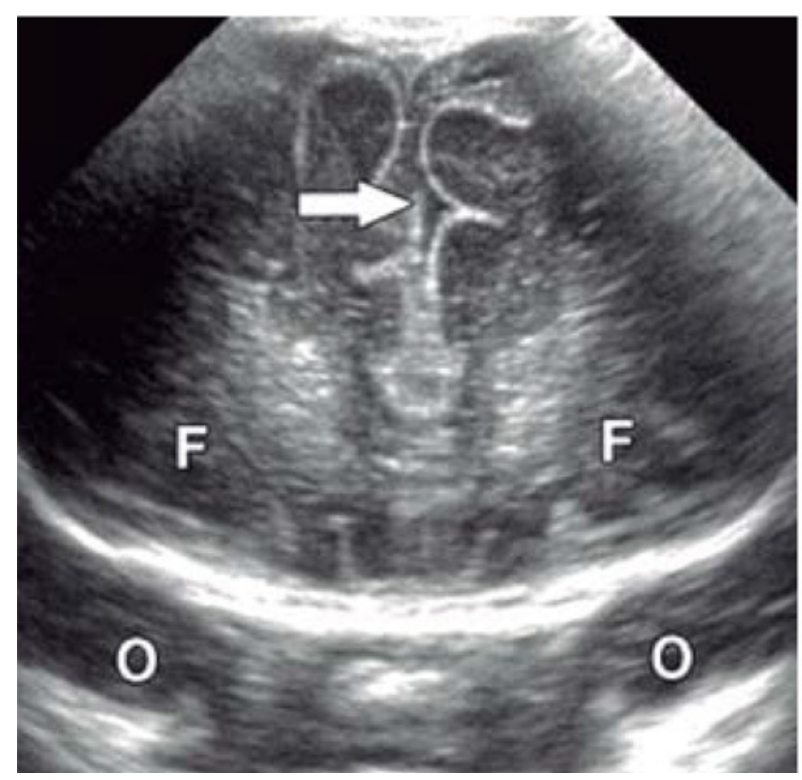

Figura 1 - Imagen de USTF en corte coronal del lóbulo frontal ${ }^{5}$

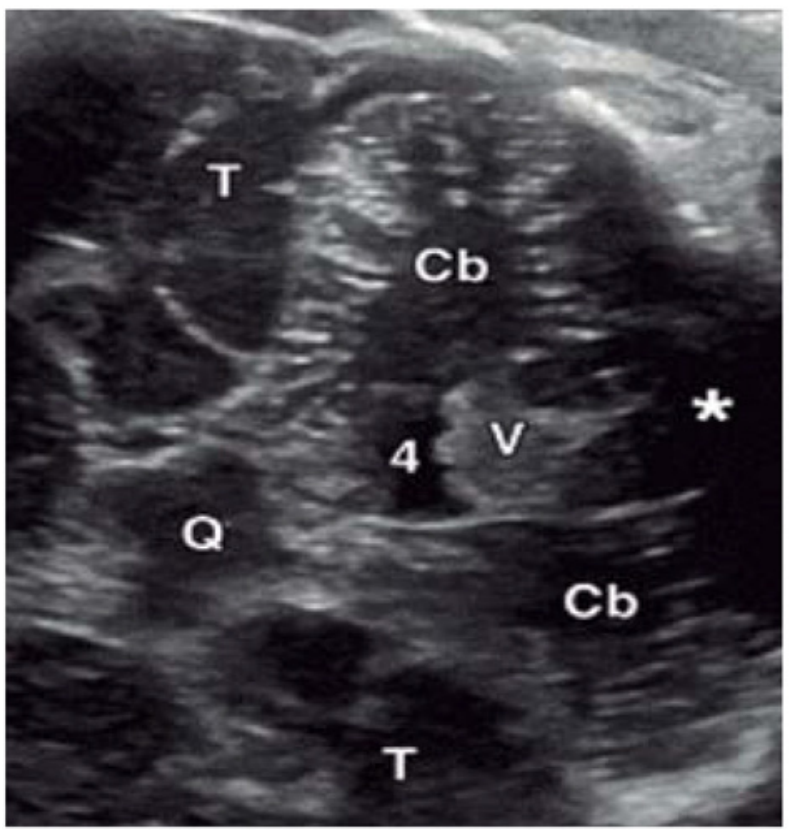

Figura 2 - Imagen de USTF exhibiendo hemisferios cerebelosos (Cb), cuarto ventrículo (4), cisterna magna (asterisco), placa cuadrigeminal $(\mathrm{Q})$, vermis $(\mathrm{V})$ y lóbulos temporales $(\mathrm{T})^{5}$
El cambio principal encontrado en este grupo fue leucomalacia con $50 \%$. Hsu et al., ${ }^{6}$ evaluaron entre septiembre de 2004 y agosto de 20093186 recién nacidos a término encontrando $93.6 \%$ dentro del rango normal con $6.3 \%$ de alteraciones menores y $0.1 \%$ de alteraciones mayores.

Santos y Prado ${ }^{7}$ investigaron 52 registros médicos de RN. En cuanto al diagnóstico ultrasonográfico, el 63\% de los recién nacidos presentaron un resultado normal. Las USTF anormales (37\%) se clasificaron en cinco tipos de lesiones: hemorragia intracraneal (HIC) y hemorragia peri-intraventricular (HPIV) que representan el 9\% de los afectados, encefalopatía hipóxico-isquémica (EHI, incluida la leucomalacia periventricular) con $17 \%$, dilatación ventricular (DV) con $9 \%$ y malformaciones cerebrales con $2 \%$ de la población.

El perfil materno fue de mujeres entre 18 y 30 años, primíparas, que tuvieron menos de siete consultas prenatales y que tuvieron partos por cesárea con factores de riesgo asociados con la EHE e infecciones del tracto urinario. El perfil de los recién nacidos es femenino, nacido a las 38 semanas, con Apgar 1 er min menos que siete, Apgar $5^{\circ}$ min mayor que ocho, con un peso apropiado para la edad gestacional y más de 2.500 gramos. Baumert et al., ${ }^{8}$ analizaron 2675 recién nacidos a término entre los años 2003-2005. La hemorragia periventricular / intraventricular se diagnosticó en 392 neonatos $(14,65 \%)$. La edad gestacional media del grupo fue de $39.11 \pm 1.26$ semanas y varió de 37 a 43 semanas y encontró una mayor prevalencia de varones y bajo peso al nacer, en desacuerdo con nuestros hallazgos.

Haataja et al., ${ }^{9}$ analizaron 103 bebés y revelaron que las anormalidades accidentales en la ecografía en recién nacidos a término, en particular la hemorragia intraventricular, aunque comunes, parecen tener un buen pronóstico y el médico debe observar con una mirada más atenta a aquellas personas con lesiones en la sustancia blanca. El daño de la sustancia blanca es un factor de riesgo importante para la parálisis cerebral, y la principal presentación es la leucomalacia periventricular. Aunque la etiología del daño a la sustancia blanca en los bebés prematuros está en gran medida relacionada con las alteraciones circulatorias, la etiología en los bebés nacidos a término es menos compreendida ${ }^{10}$.

Hsu et al., ${ }^{6}$ la prueba de detección ultrasonográfica craneal puede desempeñar un papel en el diagnóstico precoz de anomalías intracraneales de recién nacidos a término. Hayward ${ }^{11}$ sugiere que la ultrasonografía sea la investigación neuroradiológica inicial en este grupo etario y que todos los recién nacidos a término en una unidad de cuidados especiales sean examinados de manera rutinaria.

Se han encontrado pocos estudios que analicen la ultrasonografía transfontanelar en recién nacidos a término. Jensen y Holmer ${ }^{12}$ el hecho de que los recién nacidos a término aparentemente saludables no sean rastreados por imágenes de la cabeza se considera el eslabón perdido entre el insulto que escapa al diagnóstico y el desarrollo de retraso neuropsicomotor. 


\section{CONCLUSIÓN}

Se realizaron 44 exámenes, 82\% normales y 18\% alterados, la principal alteración encontrada en este grupo fue leucomalacia con 50\%. El perfil materno era de mujeres entre 18 y 30 años, primíparas, que tuvieron menos de 7 consultas prenatales y que tuvieron partos por cesárea con factores de riesgo asociados con EHE e infecciones del tracto urinario. El perfil de los recién nacidos es femenino, nacido a las 38 semanas, con Apgar al primer minuto menos de siete, Apgar al quinto minuto más de ocho, con un peso adecuado para la edad gestacional y más de 2.500 gramos.

\section{REFERENCIAS:}

1. Diwakar RK \& Khurana O. Cranial sonography in preterm infants with short review of literature. J Pediatr Neurosci., 2018; 13(2): 141-49.

2. Gupta P, Sodhi KS, Saxena AK, Khandelwal N, Singhi P. Neonatal cranial sonography: A concise review for clinicians. J Pediatr Neurosci., 2016; 11(1): 7-13.

3. Llorens-Salvador R \& Moreno-Flores A. The ABCs of transfontanellar ultrasound and more. Radiologia, 2016; 58(2): 129-41.

4. Riedesel EL. Neonatal cranial ultrasound: advanced techniques and image interpretation. J Pediatr Neurol., 2018; 16(1): 106-24.

5. Lowe LH \& Bailey Z. State-of-the-art cranial sonography: Part 1, Modern techniques and image interpretation. American Journal of Roentgenology, 2011; 196(1): 1028-33.

6. Hsu $\mathrm{CL}$, Lee $\mathrm{KL}$, Jeng $\mathrm{MJ}$ et al. Cranial ultrasonographic findings in healthy full-term neonates: A retrospective review. Journal of the Chinese Medical Association, 2012; 75(8): 389-95.

7. Santos DSS \& Prado MSG. Ocorrência de lesões neurológicas em recémnascidos diagnosticadas por ultrassonografia transfontanela. Rev Enferm UFPE 2017; 11 (10): 4081-8.

8. Baumentt M, G Brozek, M Paprotny, Z Walencka, H Sodowska, W Cnota, $\mathrm{K}$ Sodowski. Epidemiology of peri/intraventricular haemorrage in newborns at term. Journal Of Physiology And Pharmacology, 2008; 59(4): 67-75.

9. Haataja L, Mercuri E, Cowan F, Dubowitz L. Cranial ultrasound abnormalities in full term infants in a postnatal ward: outcome at 12 and 18 months. Arch Dis Child Fetal Neonatal., 2000; 82(1): 128-33.

10. Berger S, Bender S, Sefkow S, Klingmüller V, Künzel W, Jensen A. Peri / intraventricular haemorrhage: a cranial ultrasound study on 5286 neonates. Eur J Obst Gyn Reprod Biol, 1997; 75(2): 191-203.

11. Hayward C. Transfontanellar ultrasound of term infants. Clin Radiol., 1994; 35(5): 337-41.

12. Jensen LA \& Holmer B. White matter damage in 4,725 term-born infants is determined by head circumference at birth: the missing. Obst Gynecol Intern., 2018; 1(1). 


\title{
ULTRASONOGRAFÍA EN EL DIAGNÓSTICO DE LA OBSTRUCCIÓN INTESTINAL FETAL: UN CASO CLÍNICO
}

\author{
VALDIVINA ETERNA FALONE'; WALDEMAR NAVES DO AMARAL FILHO'; TARIK KASSEM SAIDAH4 ; PATRÍCIA MENDONÇA \\ LEITE', THAYNARA DE MORAES PACHECO'; LORENA TASSARA QUIRINO VIEIRA²; ANTÔNIO DE MORAIS JÚNIOR3, \\ WALDEMAR NAVES DO AMARAL'
}

\section{RESUMEN}

La obstrucción intestinal es la principal causa de emergencia quirúrgica en los recién nacidos, con la atresia como su entidad más prevalente. La atresia colónica es la más rara de ellas y el diagnóstico por ultrasonografía no es muy frecuente, especialmente debido a hallazgos inespecíficos que a menudo no representan patogenicidad en el feto. Este trabajo tiene como objetivo describir un caso de atresia colónica diagnosticada en la atención prenatal a través de ultrasonografía.

\section{PALABRAS CLAVE: ATRESIA COLÓNICA; ULTRASONOGRAFÍA; PRENATAL}

\section{INTRODUCCIÓN}

La obstrucción intestinal es la causa más común de emergencias neonatales, ocurriendo en 1 de cada 1.500 nacidos vivos. Sin embargo, hace unas décadas, los niños que nacían con tal afección casi siempre fallecían. Los avances en las técnicas quirúrgicas han contribuido enormemente desde entonces para reducir la mortalidad. Además, un papel importante en la reducción de este número debe atribuirse al avance de los métodos de diagnóstico en la atención prenatal, por ejemplo a través de la ultrasonografía (USG) ${ }^{1}$.

Entre las diversas causas de obstrucción, se destacan las atresias intestinales, meconio ileal, la enfermedad de Hirschprung y la malrotación intestinal, con o sin vólvulo, siendo las más comunes las atresias, seguidas de la malrotación y luego el îleo meconial'.

La atresia tiene una prevalencia de 1 caso por cada 2,500 nacimientos vivos y puede ser duodenal, yeyunal, ileal, yeyunoileal o colónica, siendo la duodenal la más comúnmente encontrada. En las ultrasonografías prenatales, se puede observar la presencia de polihidramnios, que se torna mayor cuanto más proximal sea la obstrucción, además de la dilatación de las asas intestinales ${ }^{2}$.

En la atresia duodenal, el diagnóstico debe sospecharse cuando hay un hallazgo de polihidramnios en casi la totalidad de los casos junto con una 'doble burbuja'. En esta condición, la asociación con defectos en otros sistemas es común, así como con la trisomía del cromosoma 21. La atresia del yeyuno ileal no está tan asociada con otras malformaciones como la duodenal y su multiplicidad es común. La ultrasonografía se caracteriza por la dilatación de asas delgadas en el aspecto de una burbuja triple o cuádruple. Finalmente, la atresia colónica, la más rara de ellas, generalmente no ocurre en multiplicidad y su evidencia en el cuidado prenatal se debe a la dilatación de las asas. Muchos casos, sin embargo, no pueden ser detectados con ultrasonografía ${ }^{3}$.

El îleo meconial es el resultado de la oclusión intestinal de un meconio más espeso, sugerido por hiperecogenicidad, acompañada o no de dilatación. Está presente en al menos el $15 \%$ de los pacientes con fibrosis quística ${ }^{4}$.

La enfermedad de Hirschprung, a su vez, es causada por una migración defectuosa de células ganglionares, aproximadamente en la semana 12 del embarazo, que culmina en una aganglionosis intestinal, reconocida por la dilatación del asa. El polihidramnios, en este caso, no es comúnmente visualizado 4 .

Finalmente, la malrotación intestinal es el resultado de una fijación embrionaria incorrecta, lo que causa la rotación de los vasos mesentéricos y puede culminar en una isquemia. La visualización ultrasonográfica es posible cuando ocurre el vólvulo intestinal, lo que resulta en la dilatación de las asas ${ }^{4}$.

\section{CASO CLÍNICO}

AFCA, mujer, G4P3A1, 30 años. La paciente fue sometida a una ultrasonografía morfológica durante la semana 33 de gestación. Tras el examen, se observó dilatación de las asas del intestino grueso, indicando sospecha de obstrucción debido a atresia (figuras 1-3). La paciente entró en trabajo de parto tres semanas después, al completar 36 semanas y 5 días de gestación. Poco después del nacimiento, el recién nacido fue sometido al primer abordaje para corrección quirúrgica. Después de 20 días, se realizó la segunda cirugía correctiva. El recién nacido permaneció en la UCI durante 56 días y se encuentra saludable.

\footnotetext{
1. Faculdade de Medicina da UFG

2. PUC- GOIÁS

3. Hospital UNIQUE

4. UniEvangélica
}

Dirección de correo electrónico:

Waldemar Naves do Amaral

Alameda Cel. Joaquim de Bastos, 243 - St. Marista

Goiânia - CEP 74175-150

Email:waldemar@sbus.org.br 


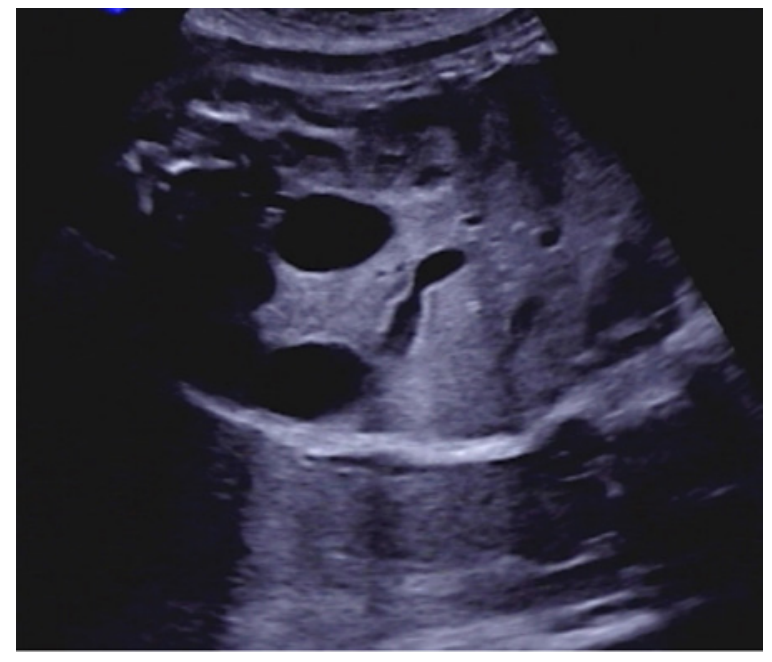

Figura 1: Ultrasonografía obstétrica: distensión de intestino grueso (contenido anecoico)

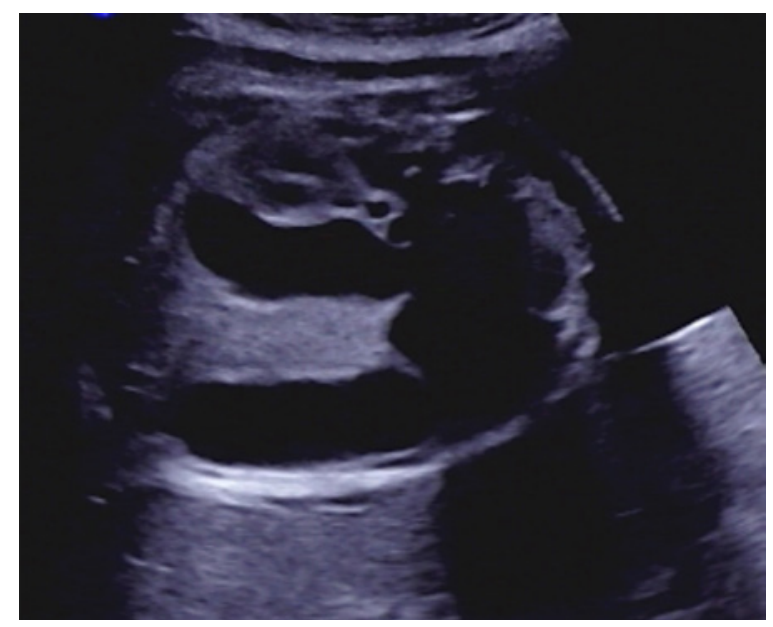

Figura 2: Ultrasonografía obstétrica: distensión de intestino grueso (contenido anecoico)

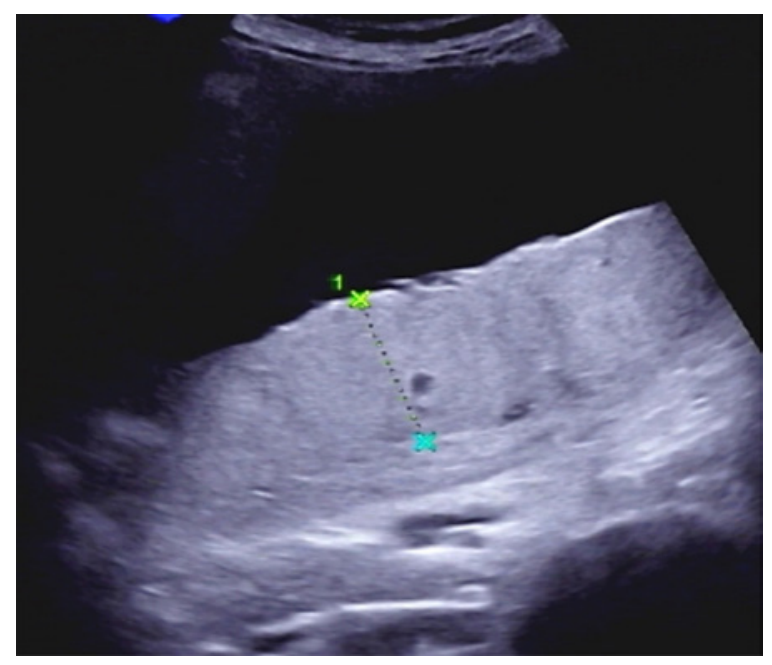

Figura 3: Ultrasonografía obstétrica: polihidramnios.

\section{DISCUSIÓN}

La atresia colónica se presenta en la vida neonatal con vómitos, distensión de asa y dificultad para eliminación del meconio. Es una afección poco frecuente que constituye apenas del 1,8 al 15\% de las atresias intestinales y puede confundirse con otras afecciones, como la enfermedad de Hirschsprung, el síndrome del tapón meconial y el îleo meconial $^{3}$.

El diagnóstico prenatal por USG de obstrucciones intestinales en general, generalmente ocurre en el tercer trimestre del embarazo, no obstante, la precisión es variable. Este método puede llegar a ser limitante porque depende del operador y de su técnica y porque tiene un campo de visión restringido. Además, muchos hallazgos no son muy específicos y otros constituyen variantes no patológicas ${ }^{5}$.

Como mencionado, por ejemplo, el polihidramnios e incluso la dilatación de las asas pueden estar presentes en otras condiciones de obstrucción. Sin embargo, la localización de la dilatación e incluso la ausencia de signos típicos de otras atresias, como el signo de burbuja doble, triple o cuádruple, hablan a favor de un diagnóstico de atresia colónica.

Aunque la ultrasonografía no siempre puede proporcionar el diagnóstico correcto y excluir diferenciales, a través del diagnóstico temprano, se puede ofrecer a los padres del niño consejos sobre su condición, especialmente en los casos en que la obstrucción sea parte de algún otro diagnóstico , como es el caso del íleo meconial en la fibrosis quística ${ }^{6}$.

Además, cuando una obstrucción intestinal se diagnostica precozmente, es posible desarrollar un plan terapéutico para el niño, que involucre un equipo multidisciplinario y un centro de asistencia capaz de atender cualquier complicación durante el parto o después del nacimiento del niño. La planificación de la intervención temprana puede reducir las tasas de mortalidad y las complicaciones en el período neonatal ${ }^{6}$.

Un estudio retrospectivo fue realizado en el Texas Children's Fetal Center en Houston, en Texas, desde enero de 2006 hasta febrero de 2016, para mostrar el resultado del diagnóstico prenatal de obstrucción gastrointestinal fetal. Las tasas de supervivencia encontradas fueron del $88 \%$, siendo que en casos de obstrucción del intestino grueso fue del $100 \%{ }^{5}$. Dicha información difiere mucho de la mortalidad extremadamente alta de décadas atrás. Los datos sugieren que hasta 1950, apenas 125 niños habían sobrevivido a obstrucciones intestinales congénitas ${ }^{1}$.

En medicina se sabe que el diagnóstico precoz en diversas áreas es responsable de mejorar el pronóstico del paciente e incluso reducir los costos para el Sistema de Salud. Por lo tanto, los avances en el método ultrasonográfico, así como la capacitación adecuada de profesionales de la salud y estudios en el campo son aspectos de gran valor en la obstetricia y la medicina fetal.

\section{REFERENCIAS:}

1. Verma A, Rattan KN, Yadav R. Neonatal intestinal obstruction: A 15 year experience in a tertiary care hospital. Journal of Clinical and Diagnostic 
Research 2016; 10: 10-13.

2. Durante AP, Baratella JRS, Velhote MCP, Hercowitz B, Napolitano-Neto P, Salgado-Filho H, Lira JOO; Mari JA, Monteiro RP. Obstrução intestinal neonatal : Diagnóstico e Tratamento. Projeto Diretrizes Associação Médica Brasileira e Conselho Federal de Medicina 2005; 1-12.

3. Figueiredo S, Helena L, Ribeiro V, Barcelos B, Augusto M, Costa B, Oliveira GL, Esteves E, Silveira S. Atresia do trato gastrointestinal: avaliação por métodos de imagem. Radiologia Brasileira 2005; 38: 141-50.

4. Barnewolt, CE. Congenital abnormalities of the gastrointestinal tract. Seminars in Roetgenology2004; 39: 263-81.

5. Lau P, Cruz S, Cassady CI, Mehollin-Ray AR, Ruano R, Keswani S, Lee TC, Olutoye OO, Cass D. Prenatal diagnosis and outcome of fetal gastrointestinal obstruction. Journal of Pediatric Surgery 2017; 52: 722-25.

6. Rubesova, E. Fetal bowel anomalies - US and MR assessment. Pediatric Radiology 2012; 42: 101-06. 


\title{
ASPECTO ULTRASONOGRÁFICO DEL DISPOSITIVO ANTICONCEPCIONAL FEMENINO PERMANENTE ESSURE ${ }^{\circledR}$ - RELATO DE CASO
}

\author{
LEONARDO DE SOUZA PIBER ${ }^{1,2}$, CAIO VINÍCIUS DA FONSECA SILVA ${ }^{1}$, GEORGIA DE SÁ CAVALCANTE TEIXEIRA ${ }^{1}$, \\ GABRIELA RAMOS REZENDE DEL CASTILHO1 , MATHEUS FLORENTINO DOS SANTOS ${ }^{1}$, REBECA GUIMARÃES RIBEIRO \\ DE ALMEIDA ${ }^{2}$, MARIA TERESA NATEL DE ALMEIDA ${ }^{2}$, MARIA ELENA GUIMARÃES RIBEIRO DE ALMEIDA²
}

\section{RESUMEN}

El Essure ${ }^{\circledR}$ es un método anticonceptivo que actúa a través de la oclusión tubárica histeroscópica. El propósito de este relato de caso es mostrar las imágenes ultrasonográficas del dispositivo Essure ${ }^{\circledR}$ bien posicionado, por ser un caso inusual en la práctica diaria del diagnóstico por imagen.

\section{PALABRAS CLAVE: ANTICONCEPCIÓN, DISPOSITIVOS ANTICONCEPCIONALES FEMENINOS, ULTRASONOGRAFÍA, GINECOLOGÍA, SALUD DE LA MUJER.}

\section{INTRODUCCIÓN}

La esterilización femenina, por ligadura u oclusión tubárica, es el método más eficaz y utilizado para la planificación familiar en el mundo ${ }^{1}$. Los métodos para la esterilización femenina incluyen salpingectomía, ligadura de trompas, oclusión tubárica laparoscópica y oclusión tubárica histeroscópica ${ }^{2}$. El último, comercializado como Essure ${ }^{\circledR}$ por Bayer AG (Leverkusen, Alemania), implica la inserción de bobinas de aleación de níquel/titanio que contienen fibras de polietileno en las trompas de Falopio, lo que provoca una reacción fibrótica que obstruye las trompas y evita la fertilización ${ }^{3}$. Las ventajas presentadas del procedimiento incluyen el hecho de no requerir incisiones y/o anestesia general ${ }^{4}$. La figura 1 muestra el dispositivo; la figura 2 muestra la posición intratubárica del dispositivo y la figura 3, el aspecto histeroscópico después de la implantación.

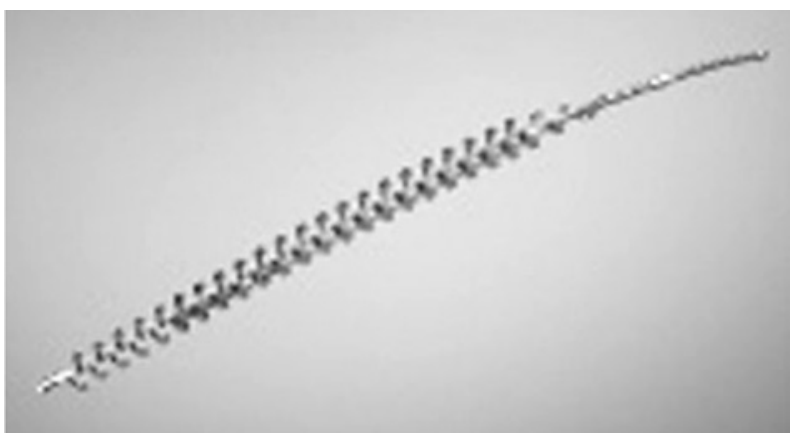

Figura 1 - El dispositivo intratubárico Essure ${ }^{\oplus .}{ }^{5}$

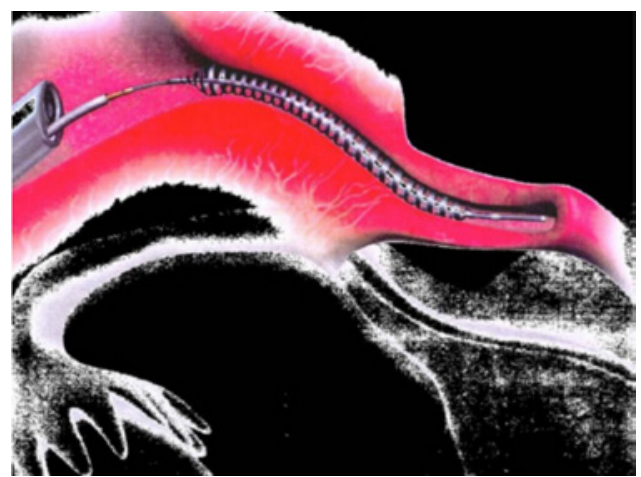

Figura 2 - Dibujo que muestra la colocación del Essure ${ }^{\circledast}$.

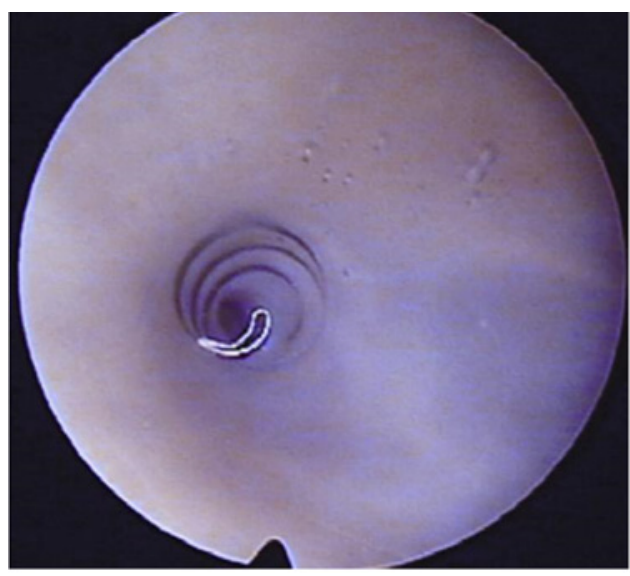

Figura 3 - Aspecto histeroscópico del Essure ${ }^{\circledR}$ después de la inserción.
1. Faculdade de Medicina da Universidade Santo Amaro

2. CDB Inteligência Diagnóstica
Dirección para correspondencia:

Leonardo Piber

Rua Marechal Deodoro, 135 apt. 62B - Santo Amaro

São Paulo - CEP 04738-000

Email: lpiber@prof.unisa.br 
El Essure ${ }^{\circledR}$ de Bayer AG (Leverkusen, Alemania) fue el primer dispositivo mecánico aprobado por la Food and Drug Administration (FDA), en 2002, para la esterilización transcervical, y en 2009, la Agencia Nacional de Vigilancia Sanitaria (ANVISA) lo aprobó en Brasil ${ }^{6}$.

El sistema está compuesto por un dispositivo intratubárico, un sistema de liberación y un catéter para acceder a cada trompa por la vía transcervical. El microdispositivo es un resorte de expansión dinámico compuesto por un anillo interno de acero inoxidable rodeado por un anillo externo de níquel y titanio que, al ser expandible, mantiene el dispositivo en la unión útero-tubárica durante el tiempo necesario para que ocurra la fibrosis.

Las fibras de poliéster se encuentran alrededor de la estructura central y provocan una reacción del tejido circundante, seguida de fibrosis, ocasionando una oclusión irreversible de las trompas. Este proceso lleva aproximadamente tres meses y, durante este período, la mujer debe mantener el método anticonceptivo que utilizaba anteriormente ${ }^{7}$.

La revisión después de la implantación del dispositivo se considera la parte final del procedimiento, siendo obligatoria a los tres meses, para verificar que el implante esté en la pelvis y en la posición adecuada. En los Estados Unidos, se solicita la histerosalpingografía (HSG) y, en otros países, se realiza una radiografía o ultrasonido pélvico simple. Si los dispositivos estuvieren satisfactoriamente colocados en la unión útero-tubárica, la paciente puede abandonar el método anticoncepcional alternativo utilizado. Si la posición no fuere satisfactoria, se solicita un $\mathrm{HSG}^{8}$. Sin embargo, la ultrasonografía transvaginal realizada tres meses después de la inserción de Essure ${ }^{\circledR}$ mostró la misma precisión que la histerosalpingografía para detectar el posicionamiento correcto del dispositivo?.

El propósito de este relato de caso es mostrar las imágenes ultrasonográficas del dispositivo Essure ${ }^{\circledR}$ bien posicionadas, por ser un caso inusual en la práctica diaria del ultrasonografista.

\section{RELATO DE CASO}

Paciente del sexo femenino, 38 años, asintomática, sometida a exámenes de rutina. Se ilustra el aspecto ultrasonográfico del dispositivo Essure, característicamente ecogénico, en la topografía de las tubas uterinas, lo que permite evaluar su relación con las estructuras de tejidos blandos adyacentes. Como la serosa está bien delimitada y es fácilmente identificable, la ultrasonografía permite la identificación de la unión utero-tubárica, el punto donde la trompa de Falopio cruza la serosa uterina, que es un punto anatómico importante para evaluar la ubicación de la inserción del Essure. Las figuras 4, 5 y 6 muestran la posición de los dispositivos bilateralmente.

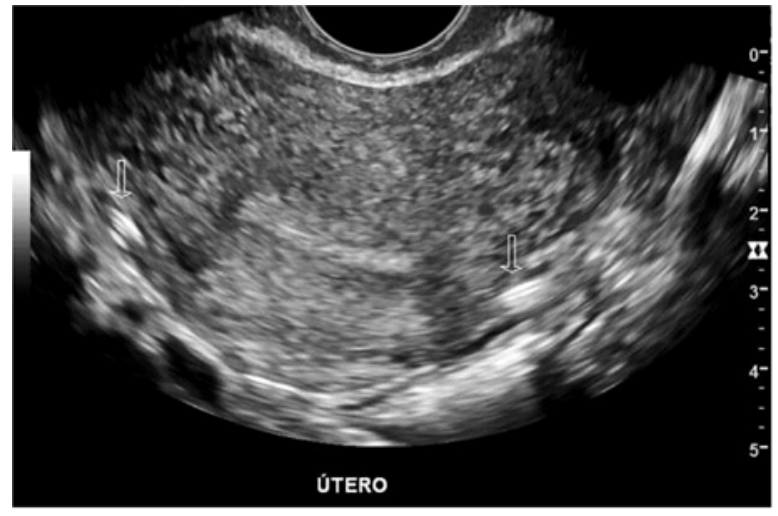

Figura 4 - Imagen ecogénica tubuliforme en la topografía de las tubas uterinas, identificada en la unión utero-tubárica, simétrica y bilateralmente.

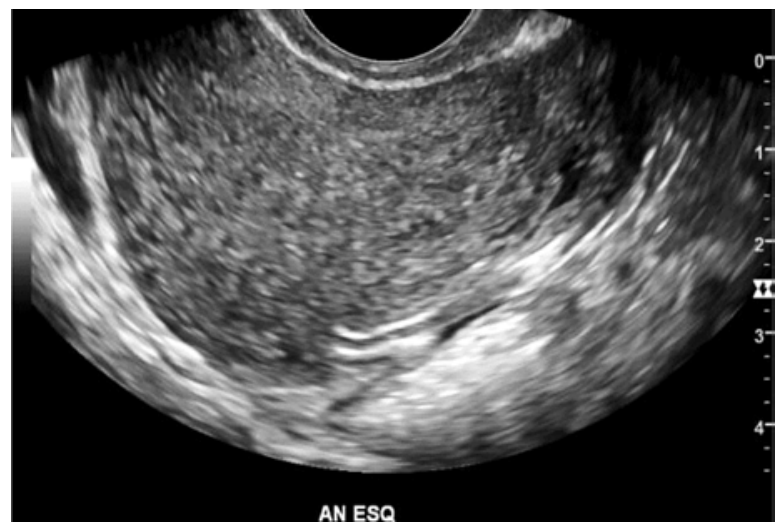

Figura 5 - Imagen ecogénica tubuliforme en la topografía de la tuba uterina izquierda, evidenciada como dos líneas hiperecogénicas paralelas.

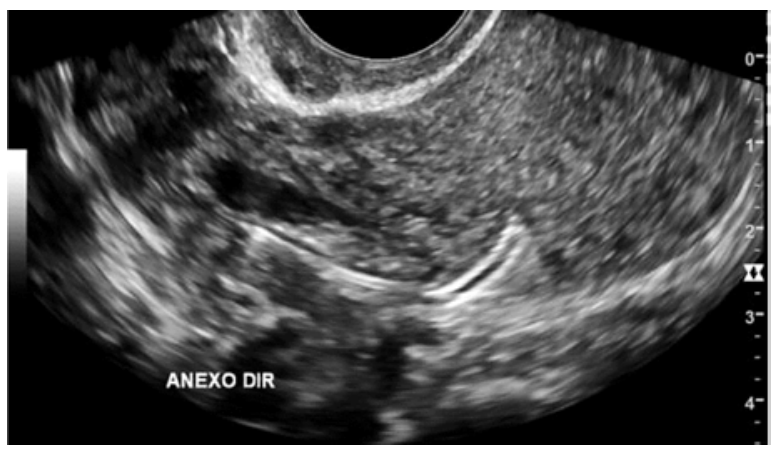

Figura 6 - Imagen ecogénica tubuliforme en la topografía de la tuba uterina derecha, evidenciada como dos líneas hiperecogénicas paralelas. 


\section{DISCUSIÓN}

El Essure ${ }^{\circledR}$ revolucionó la esterilización femenina al permitir la anticoncepción definitiva a través de un procedimiento rápido, mínimamente invasivo y ambulatorio, sin necesidad de anestesia, con un retorno rápido a la actividad laboral e igualmente eficaz ${ }^{10}$.

Varios estudios han confirmado la seguridad, efectividad y baja tasa de eventos adversos de la técnica; sin embargo, desde 2013, el producto ha sido objeto de controversia, con muchas mujeres informando complicaciones que requieren una nueva operación ${ }^{11}$. En 2015, se publicó una revisión que confirma la efectividad similar de Essure ${ }^{\circledR}$ en la prevención del embarazo, pero con un riesgo 10 veces mayor de reintervención, en comparación con la esterilización laparoscópica ${ }^{12}$.

Desde agosto de 2017, el certificado CE de conformidad Essure ${ }^{\circledR}$ está suspendido en la Unión Europea por el organismo National Standards Authority of Ireland, con Infarmed emitiendo una circular informativa en el mismo mes recomendando "como medida de precaución, que el dispositivo médico Essure ${ }^{\circledR}$ no sea adquirido ni utilizado mientras dure la suspensión del certificado" 13 .

Después de que varias publicaciones mundiales relataron posibles eventos adversos ${ }^{14-16}$, en julio de 2018, Bayer decidió suspender voluntariamente la venta y distribución del dispositivo hasta finales de diciembre, para finalizar su comercialización ${ }^{17}$.

La ultrasonografía se muestra adecuada para la localización temprana posterior a la inserción, ya que el escaneo puede garantizar la colocación correcta del dispositivo y aliviar la ansiedad del paciente, o incluso diagnosticar una mala posición tempranamente.

Este caso resalta la importancia de la educación continua a través de la documentación fotográfica de diagnóstico y la integración entre ultrasonografistas y ginecólogos.

\section{REFERENCIAS}

1. Harrington EK, Gordon D, Osgood-Roach I, Jensen JT, Aengst J. Conceptualizing risk and effectiveness: a qualitative study of women's and providers' perceptions of nonsurgical female permanent contraception. Contraception. 2015; 92(2): 128-34.

2. Ahlborg J, Cordero C, Cullins V et al. Female sterilization. In: Landry E, ed. Contraceptive sterilization: global issues and trends. New York, NY: Engender Health, 2002: 139-60.

3. Bayer Health Care Pharmaceuticals. Essure permanent birth control: Instructions for use. Milpitas, CA: Bayer Healthcare LLC, 2002.

4. Dhruva SS, Ross JS, Gariepy AM. Revisiting Essure-toward safe and effective sterilization. N Engl J Med 2015; 373: e17.

5. Shah, V, Panay N, Williamson R, Hemingway A. Hysterosalpingogram: an essential examination following Essure hysteroscopic sterilisation. The British Journal of Radiology 2011; 1005(84): 805-12.

6. Munro MG, Nichols JE, Levy B, Vleugels MP, Veersema S. Hysteroscopic sterilization: 10-year retrospective analysis of worldwide pregnancy reports. J Minim Invasive Gynecol. 2014; 21 (2): 245-51.

7. Chapelle CF, Veersema S, Brölmann HA, Jansen FW. Effectiveness and feasibility of hysteroscopic sterilization techniques: a systematic review and meta-analysis. Fertil Steril. 2015; 103(6): 1516-25.

8. Veersema S. Hysteroscopy and contraception. Best Pract Res Clin Obstet Gynaecol. 2015; 29(7): 940-50.

9. Kerin JF, Munday D, Ritossa M, Rosen D. Tissue encapsulation of the proximal Essure micro-insert from the uterine cavity following hystero- scopic sterilization. J Minim Invasive Gynecol 2007; 14: 202-04.

10. Félix N, Carvalho C, Amaral PI, Sousa F, Delgado E, Machado AI et al . Essure ${ }^{\circledR}$ : efetividade, complicações e satisfação em 13 anos de experiência. Acta Obstet Ginecol Port 2019; 13(1): 20-6.

11. "Women report complications from Essure birth control" Acessado em Março 2020; http://articles.chicagotribune.com/2013-12-22/health/ctessure-safety-met-20131222_1_essure-conceptus-fallopian- -tubes.

12. Mao J, Pfeiter S, Schlegel P, Sedrakyan P. Safety and efficacy of hysteroscopic sterilization compared with laparoscopic sterilization: an observational cohort study. BMJ. 2015; 351: h5162.

13. Infarmed, Autoridade Nacional do Medicamentos e Produtos de Saúde, I.P. Acessado Março de 2020. http://www.infarmed.pt/documents/15786/1878969/Suspens\%C3\%A3o+do+dispositivo+m\%C3\%A9dico+Essure+do+fabricante+Bayer+Healthcare\%2C+LLC/4a ca2815-9e93-4e72-8a4e-864548873072.

14. Summary safety review - ESSURE permanente birth control system - assessing the risk of complications and the potencial need for device removal. Acessado em Março de 2020. https://www.canada.ca/ en/ health-canada/services/drugs-health-products/medeffect-canada/ safety-reviews/summary-safety-essure-permanent-birth-control-systemassesing-risk.html.

15. French National Agency for Medicines and Health Products Safety. Temporary Specialist Scientific Committee for permanent sterilization device Essure. Acessado em Março de 2020 http://ansm.sante. fr/LANSM/Comites-scientifiques-specialists-temporaires/Comites- -scientifiques-temporaires/Comites-scientifiques-temporaires/CSST- -Dispositif-de-sterilisation-definitive-Essure

16. Bouillon K, Bertrand M, Beder G, et al. Association of hysteroscopic vs laparoscopic sterilization with procedual, gynecological, and medical outcomes. JAMA. 20158; 319(4): 375-87.

17. Bayer to voluntarily discontinue U.S. sales of Essure at end of 2018 for business reasons. Acessado em Março de 2020. https://www. bayer.us/ en/newsroom/press-releases/article/?id=123229 


\title{
LINFOMA EN EMBARAZO CON FETO VIVO: UN CASO CLÍNICO
}

\author{
VALDIVINA ETERNA FALONE'; WALDEMAR NAVES DO AMARAL FILHO'; TARIK KASSEM SAIDAH3 ; ADRIELLY JOICE \\ MENDES SANTANA BRANDÃO', THAYNARA DE MORAES PACHECO'; LORENA TASSARA QUIRINO VIEIRA²; \\ MATHEUS FERREIRA GONÇALVES ${ }^{1}$, WALDEMAR NAVES DO AMARAL'
}

\section{RESUMEN}

Los linfomas son neoplasias del sistema inmune que se originan en las células B, To Natural Killer que causan la aparición de masas tumorales. Se pueden clasificar como Hodgkin y no Hodgkin. El cáncer es la segunda causa de muerte en mujeres en edad reproductiva, siendo que los linfomas son la cuarta neoplasia más diagnosticada en mujeres embarazadas, dada la incidencia máxima de la enfermedad durante la fase reproductiva femenina. El propósito de este informe es presentar un caso de linfoma durante el embarazo con un feto vivo.

\section{PALABRAS CLAVE: LINFOMA, EMBARAZO, LINFOMA EN EL EMBARAZO}

\section{INTRODUCCIÓN}

Los linfomas son neoplasias del sistema inmunitario que se originan en las células B, T o Natural Killer que provocan la aparición de masas tumorales. Se pueden clasificar como Hodgkin y no Hodgkin. La estimación brasileña para 2018 era de 2.530 nuevos casos de linfoma de Hodgkin y 10.180 no Hodgkin, afectando a 1.050 y 4.810 mujeres, respectivamente ${ }^{1}$. El cáncer es la segunda causa principal de muerte en mujeres en edad reproductiva, siendo que los linfomas son la cuarta neoplasia más diagnosticada en mujeres embarazadas, dada la incidencia máxima de la enfermedad durante la fase reproductiva femenina ${ }^{2}$.

El diagnóstico de linfoma de Hodgkin y no Hodgkin se realiza con el examen histopatológico de la biopsia de ganglio linfático. El linfoma de Hodgkin se clasifica como Clásico, con cuatro subtipos (esclerosis nodular, celularidad mixta, depleción linfocítica y rico en linfocitos) y linfoma de Hodgkin con predominio linfocítico nodular. El linfoma no Hodgkin se clasifica como indolente (40\%) o agresivo (60\%) 1 .

La escisión del ganglio linfático solo se puede hacer de manera segura para el feto en el primer trimestre. Además, la estadificación se realiza con anamnesis, examen físico, de laboratorio y biopsia de médula ósea. Se debe evitar el uso de exámenes de imagen con alta carga de radiación. Se debe considerar la resonancia magnética nuclear siempre que sea posible. El tratamiento con radioterapia y quimioterapia durante el embarazo debe tener en cuenta el riesgo-beneficio para la salud de la embarazada y del feto. Los riesgos de la quimioterapia en el primer trimestre van desde el aborto espontáneo hasta las malformaciones ${ }^{3}$.

\section{CASO CLÍNICO}

Paciente de 33 años, G5P2A2, con antecedentes personales de tiroiditis de Hashimoto y diabetes gestacional en embarazos previos. En la semana 30 de gestación notó la aparición de nódulos en ambas axilas. Buscó un servicio médico donde fue realizada una biopsia de ganglios linfáticos, que reveló la presencia de linfoma el 02/03/19. También fueron identificados nódulos afectados en las mamas. A pesar de la enfermedad materna, feto de 34.5 semanas con signos vitales normales (ver figuras 1 y 2). Feto a término con recién nacido y placenta sanos. Quimioterapia poco después del parto, seguida de radioterapia con muerte materna después de 6 meses.

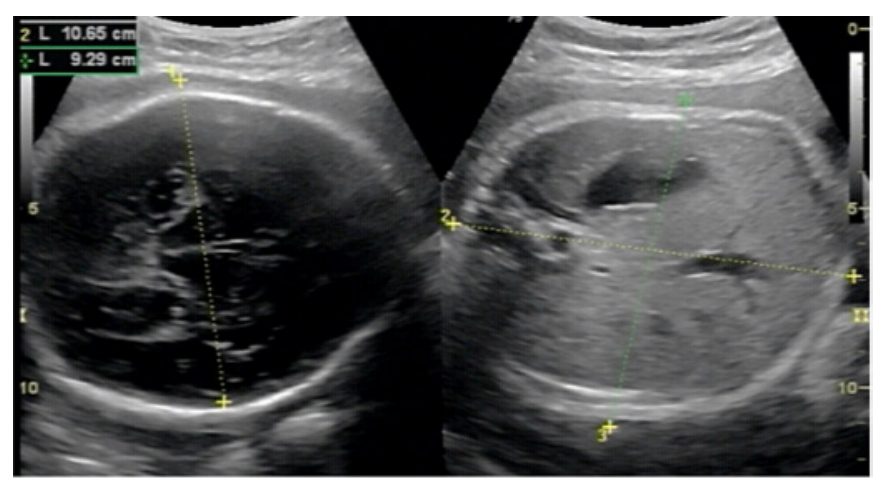

Figura 1: Ultrasonografía obstétrica que muestra un feto normal. Fuente: Clínica Fértile

\footnotetext{
1. Faculdade de Medicina da UFG

2. PUC- GOIÁS

3. UniEvangélica
}

Dirección de correo electrónico:

Waldemar Naves do Amaral

Alameda Cel. Joaquim de Bastos, 243 - St. Marista

Goiânia - CEP 74175-150

Email: waldemar@sbus.org.br 


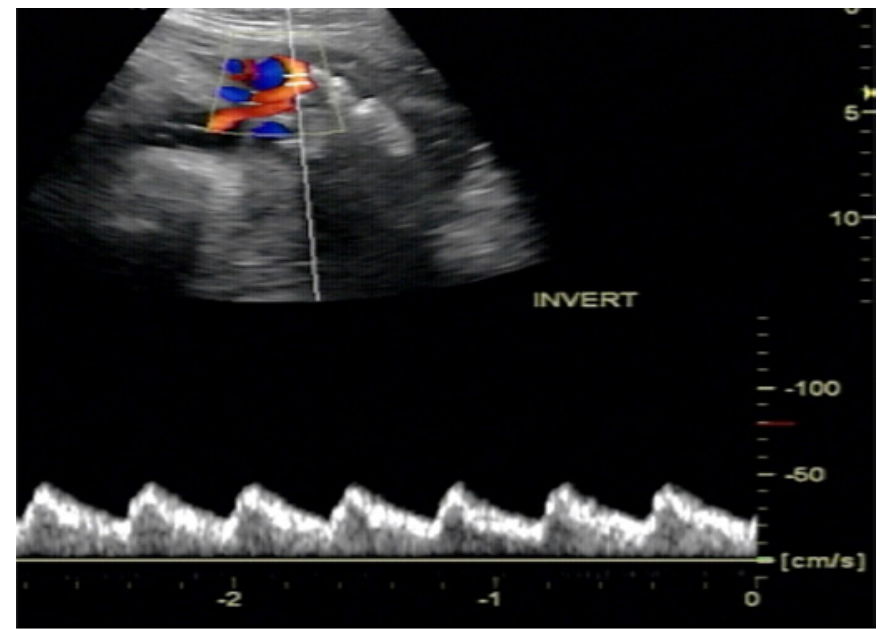

Figura 2: Doppler obstétrico evidenciando una arteria umbilical normal. Fuente: Clínica Fértile

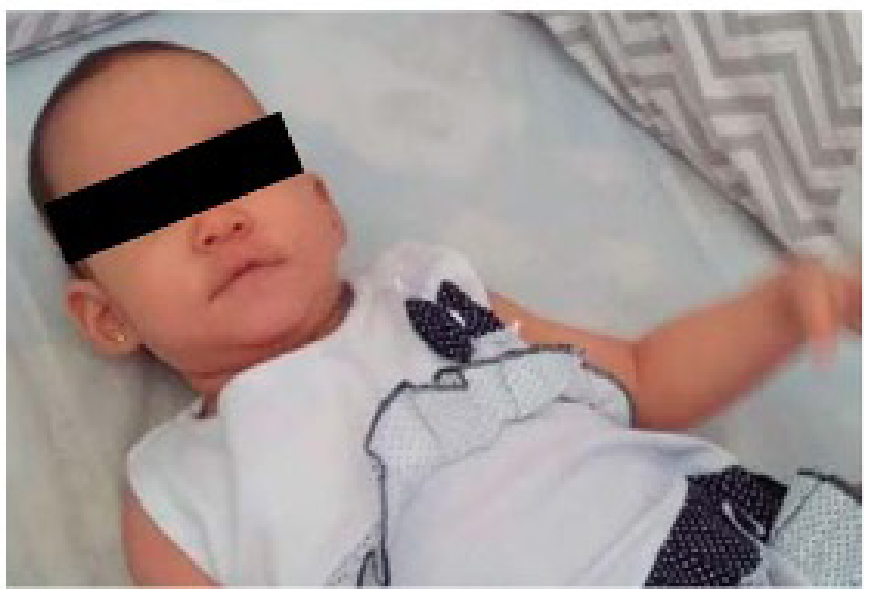

Figura 3: ¡Bebé sano con 7 meses de vida! Fuente: Archivos del autor

\section{DISCUSIÓN}

Entre los exámenes para la estadificación del LH se encuentran los exámenes de imágenes como la radiografía y la tomografía computarizada de tórax, abdomen y pelvis, con alta emisión de radiación ionizante. Por lo tanto, los exámenes alternativos son la resonancia magnética nuclear y la ultrasonografía (USG), que son más adecuados para la fase de gestación, aunque la ultrasonografía sea un examen operador dependiente ${ }^{2}$.

Aunque se cuestione sobre un mayor riesgo de parto prematuro, bajo peso al nacer y un mayor número de abortos de fetos, los estudios muestran que no se puede descartar la posibilidad de anomalías congénitas en los hijos de madres Hodgkin. En este caso, la USG morfológica es una aliada para detectar malformaciones y aneuploidías fetales. El seguimiento ultrasonográfico garantiza una mayor precisión de la edad gestacional y la evaluación de la anatomía y el desarrollo del feto, lo que permite la seguridad en la toma de decisiones con respecto al tratamiento del paciente y la seguridad del feto ${ }^{4}$.

En un estudio inglés que comparó a 129 hijos de madres que tuvieron cáncer durante el embarazo y se sometieron a algún tipo de tratamiento después del segundo trimestre de embarazo con hijos de madres sanas, se puede observar que no hubo diferencias significativas entre el desarrollo inicial y la evaluación cardíaca entre los niños ${ }^{5}$. Un estudio danés mostró un alto grado de prematuridad entre los recién nacidos de madres con LH en comparación con los bebés de madres saludables ${ }^{2}$.

\section{CONSIDERACIONES}

El tratamiento en mujeres embarazadas con cáncer es posible, siempre que se eviten retrasos en el diagnóstico. A pesar de las complicaciones asociadas, la ventaja del tratamiento ya es evidente y debe ser discutida y debidamente aclarada con la paciente para que pueda ejercer su autonomía al tomar las decisiones sobre su tratamiento ${ }^{3}$.

\section{REFERENCIAS}

1. INCA. Estimativa 2018: incidência de câncer no Brasil / Instituto Nacional de Câncer José Alencar Gomes da Silva. Coordenação de Prevenção e Vigilância. - Rio de Janeiro: INCA, 2017. http://www1.inca.gov. br/estimativa/2018/index.asp. acessado em 30 de ago. 2019.

2. Kassab C, Perini GF, Bollmann PW, Kerbauy FR, Hamerschlak N. Linfoma de Hodgkin e gestação: série de casos e proposta de protocolo para tratamento. Einstein (São Paulo). 2011;9 (2 Pt 1): 216-9. https:// doi. org/10.1590/S1679-45082011RC1992.

3. Atala A, Neto AEH, Riani LR, Soares GMT, Miranda MAV, Gomide BO, Silva MN, Silva RN. Linfoma de Hodgkin e gestação. Relato de caso e revisão de literatura. Universidade Federal de Juiz de Fora (Minas Gerais). Ver Bras Clin Med 2010; 8(3): 276-82.

4. Peralta CFA; Barini R. Ultrassonografia obstétrica entre a $11^{\mathrm{a}}$ e a $14^{\mathrm{a}}$ semanas: além do rastreamento de anomalias cromossômicas. Rev. Bras. Ginecol. Obstet. 2011; 33 (1): 49-57.

5. INCA. Terapia antineoplásica em situações clínicas especiais: uma visão integral do cuidado. Pacientes gestantes. https://www.inca.gov.br/ bvscontrolecancer/publicacoes/Boukai_Terapia_antineoplasica_clinicas_especiais_cuidado_pacientes_gestantes.pdf 


\title{
FASCITIS NODULAR: UN CASO SIMULANDO PATOLOGÍA SOSPECHOSA A ULTRASONOGRAFÍA
}

\author{
ANA CAROLINA SILVA ${ }^{1,2}$, LUIZA CAIXETA ${ }^{1,2}$, GABRIEL TOFANI ${ }^{1,2}$, LAIO RASPANTEE ${ }^{1,2}$, ELIZABETH DE AYUB ${ }^{2}$, \\ LETICIA AZEREDO ${ }^{2}$, LEONARDO PEREIRA ${ }^{2}$, CARLOS HENRIQUE SILVA ${ }^{2}$
}

\begin{abstract}
RESUMEN
La fascitis nodular es un tumor benigno que afecta los tejidos subcutáneos, cuya etiología aún no fue completamente elucidada. Afecta predominantemente las extremidades superiores de los pacientes que se encuentran entre la segunda y cuarta décadas de la vida. Su presentación clínica y a través del diagnóstico por imagen puede parecerse a un tumor maligno, especialmente debido a su rápido crecimiento, convirtiéndose así en un desafío para su diagnóstico. El tratamiento suele ser la escisión quirúrgica de la lesión. El objetivo de este estudio es relatar un caso de fascitis nodular, que se presentó en una ubicación inusual y simuló un tumor sospechoso en la ultrasonografía, además de hacer una breve revisión de la literatura sobre esta patología y sus aspectos ecográficos.
\end{abstract}

\section{PALABRAS CLAVE: FASCIITIS NODULAR, ULTRASONOGRAFÍA, ELASTOGRAFÍA, RESONANCIA MAGNÉTICA, NÓDULO.}

\section{INTRODUCCIÓN}

La fascitis nodular (FN) es una afección benigna en la que existe una proliferación autolimitada de fibroblastos y miofibroblastos, que fue descrita por primera vez en 1955 por Konwaler et. al ${ }^{1}$. Característicamente, presenta un rápido crecimiento, alta celularidad y alta actividad mitótica ${ }^{1-3}$, que luego puede ser confundida con tumores malignos como los sarcomas ${ }^{1-5}$.

Preferentemente afecta a adultos jóvenes, entre 20 y 45 años, sin predilección de género2,6. Las regiones anatómicas más afectadas según la literatura son las miembros superiores, especialmente los antebrazos 1,2,7. A menudo se encuentra en la región subcutánea, pero hay relatos de haber sido identificados en planos más profundos como los intramusculares e intraarticulares ${ }^{4,6}$.

\section{RELATO DE CASO}

Paciente de 30 años de edad, sexo femenino, negra, fue derivada al servicio de ultrasonografía debido a la aparición de un nódulo palpable, ubicado debajo de la fúrcula esternal, con un informe de crecimiento rápido y progresivo. En el examen físico, se encontró una lesión nodular endurecida, midiendo aproximadamente $5 \mathrm{~mm}$.

El examen ultrasonográfico de tejidos blandos con Doppler reveló un nódulo con límites precisos, contornos irregulares, espiculado, marcadamente hipoecoico, con un ligero aumento en la ecogenicidad de los tejidos circundantes, ubicados en el plano subcutáneo, mostrado en la figura 1 . El nódulo midió aproximadamente $6 \times 3 \times 5 \mathrm{~mm}$ (figura 2), con su centro a $4 \mathrm{~mm}$ del plano de la piel y $26 \mathrm{~mm}$ por debajo de la fúrcula esternal (figura 3). Durante el estudio con Doppler color, el nódulo mostró vascularización interna de fácil captura y el estudio con Doppler espectral reveló flujo pulsátil, con patrón arterial de baja resistencia (IR: 0,61), como muestra la figura 4. En un estudio complementario con elastografía dinámica por compresión (strain elastography), el nódulo se evidenció duro, con una rigidez aproximadamente 5,3 veces mayor que la de los tejidos circundantes (figura 5).

Después de la realización del estudio ultrasonográfico, la paciente fue derivada al servicio de cirugía plástica, que procedió a extirpar la lesión. Este procedimiento se realizó sin complicaciones y la muestra quirúrgica se envió al laboratorio de anatomía patológica. El análisis anatomopatológico reveló una proliferación fusocelular relativamente monomórfica, sin atipia significativa y con extravasación de glóbulos rojos, como mostrado en las láminas de la figura 6 .

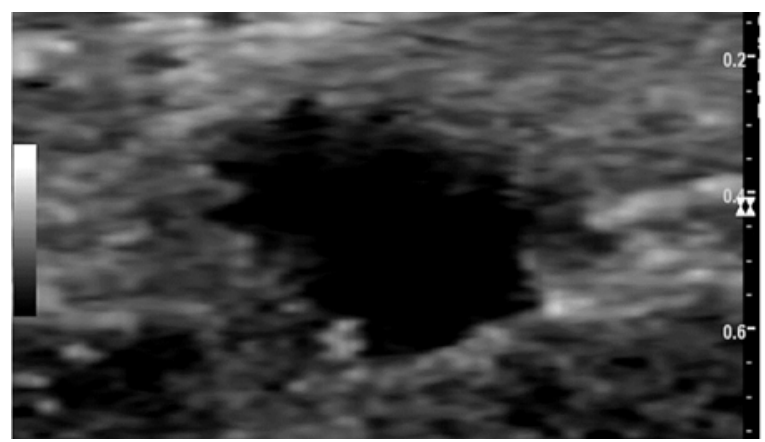

Figura 1: Nódulo sólido, marcadamente hipoecoico, con contornos irregulares y límites poco precisos.
1 Ciências Médicas de Minas Gerais (PGCM-MG) Fundação Educacional Lucas Machado (FELUMA). 2 Rede Mater Dei de Saúde
Dirección para correspondencia:

Ana Carolina de Faria e Silva

Rua Venezuela, 610, apt.404 - Sion

Belo Horizonte - CEP 30.315-250

E-mail: sfaria.carol@gmail.com 


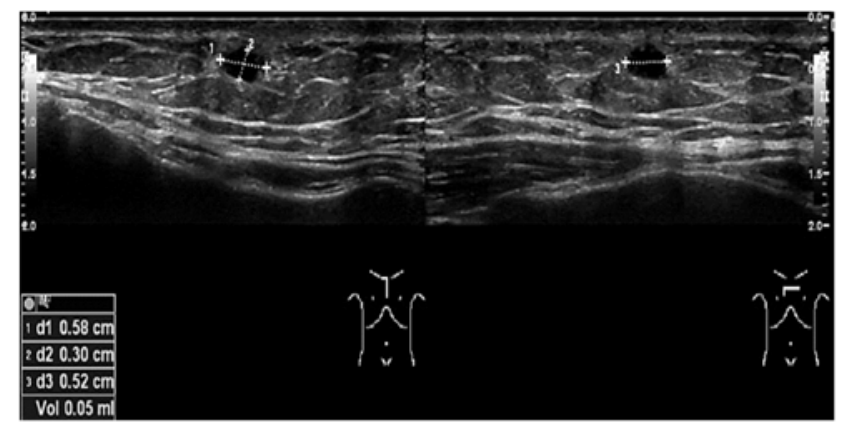

Figura 2: Medidas del nódulo en los planos longitudinal (izquierda) y transversal (derecha), con un volumen estimado de $0,05 \mathrm{~cm}^{3}$.

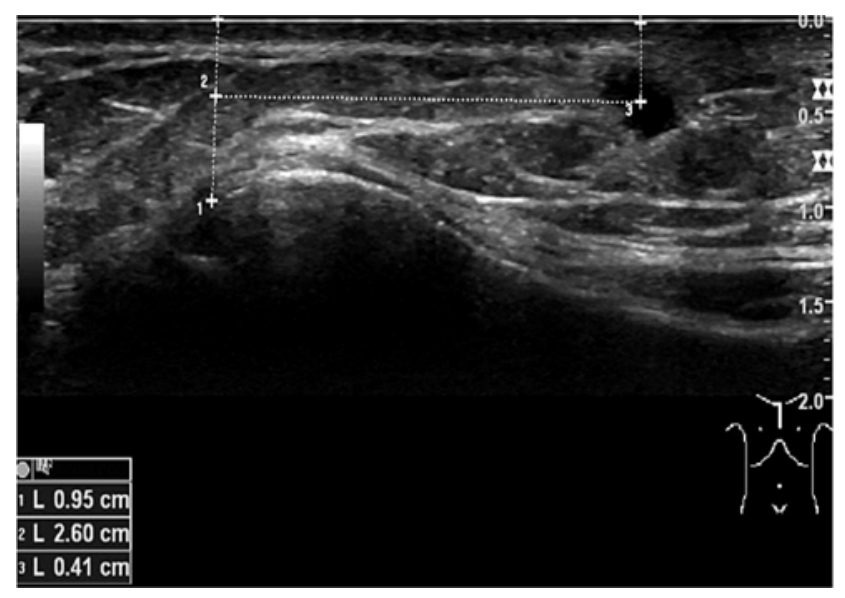

Figura 3: el centro de la lesión se encuentra aproximadamente a $4 \mathrm{~mm}$ de la piel y $26 \mathrm{~mm}$ caudal a la fúrcula esternal.

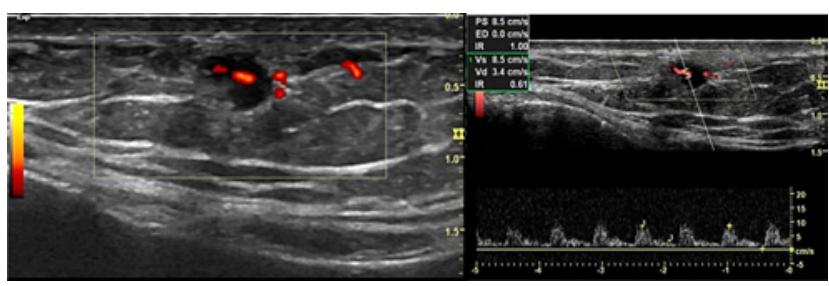

Figura 4: el nódulo muestra una fácil captación del flujo central en el estudio Power Doppler (izquierda), con un patrón de flujo arterial de baja resistencia al estudio Doppler Espectral (derecha).

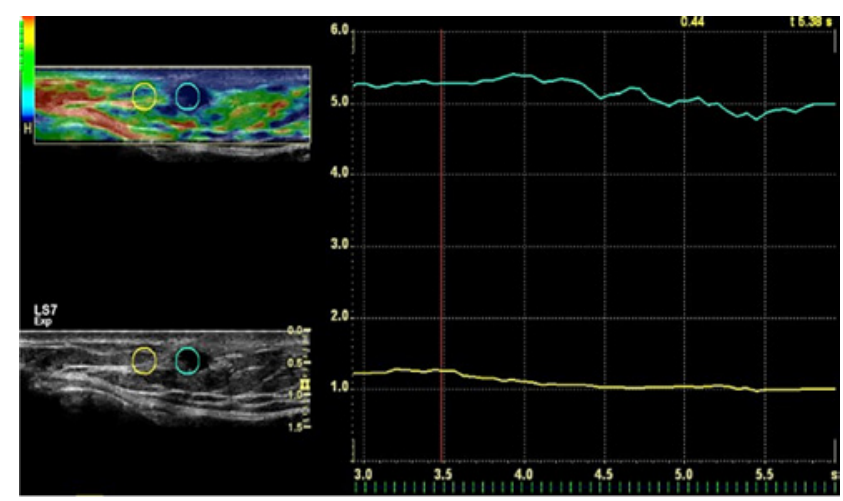

Figura 5 - La elastografía de compresión mostró la rigidez de nódulo (círculo azul)
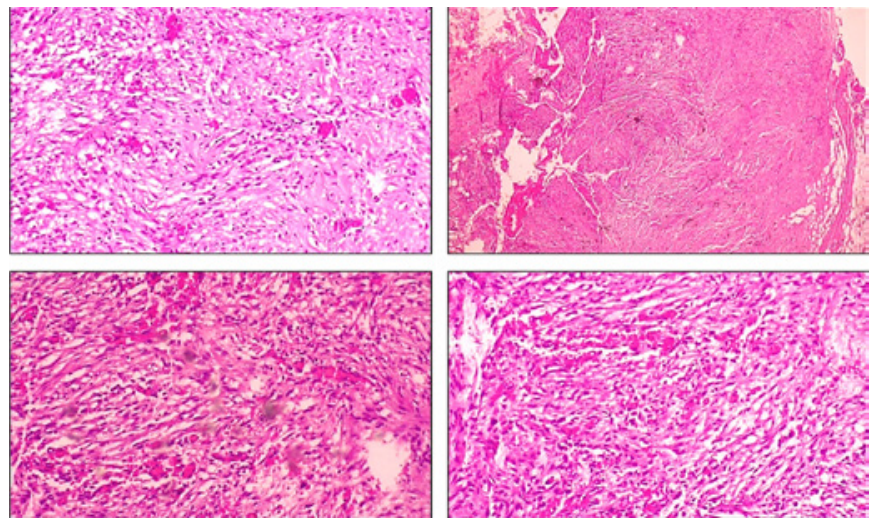

Figura 6 - Proliferación fusocelular relativamente monomórfica, sin atipia significativa y con extravasación de glóbulos rojos.

\section{DISCUSIÓN}

La fascitis nodular es una lesión benigna, caracterizada por la proliferación de fibroblastos y constantemente confundida histológicamente con sarcomas ${ }^{1-5}$.

Su etiología no se ha aclarado por completo, pero Velagaleti et al., revisaron publicaciones que señalan la participación de anomalías clonales en los mecanismos de reparación de tejidos relacionados con el gen FGR7 (factor de crecimiento de fibroblastos) ubicado en el cromosoma $15^{8}$. Ya Oliveira, AM y Chou, MM. (2013) observaron una alta expresión de ARNm del gen USP6 (proteasa específica de ubiquitina) en estas lesiones y plantearon la hipótesis de un mecanismo oncogénico que implica reordenamientos genómicos en el locus de este gene ${ }^{6}$.

La FN se presenta comúnmente como un nódulo único de rápido crecimiento ( 2 a 4 semanas), con un diámetro que raramente excede los $5 \mathrm{~cm}^{6,7,9}$ y puede o no estar acompañado de dolor ${ }^{4,7}$. Hay relatos de asociación con trauma local en 10 a $15 \%$ de los $\operatorname{casos}^{1,2,6}$. Las regiones anatómicas más afectadas son las extremidades superiores y el tronco, seguidas de la cabeza y el cuello y las extremidades inferiores $1,2,4,7,9$, pero pueden afectar cualquier parte del cuerpo1,9. En la población pediátrica, en cambio, la cabeza y el cuello son las regiones más afectadas ${ }^{1,2}$. Los síntomas como entumecimiento, parestesia e irradiación de dolor son poco frecuentes y denotan la compresión de los nervios periféricos ${ }^{4}$.

Puede tomar tres formas principales, que se basan en su ubicación anatómica: la forma subcutánea (que es la más común); la forma intramuscular (que simula lesiones malignas) y la forma fascial 2,4 .

Microscópicamente, la FN consiste básicamente en fibroblastos dispuestos en haces cortos y fascículos diseminados dentro de un estroma mixoide o fibroso ${ }^{6}$. Según la composición histológica predominante, la lesión puede ser: fibrosa, mixoide o celular ${ }^{6}$. Células gigantes de hábito osteoclástico pueden estar presentes, así como una infiltración de linfocitos y extravasación de eritrocitos, sin depósito de hemosiderina $^{2}$. Tiene una amplia variación en el patrón morfo- 
lógico y a menudo puede ser mixta, constituida por células fusiformes, delgadas, similares a los fibroblastos? ${ }^{7}$. En el caso descrito, la macroscopia de la lesión resultó ser predominantemente fibrosa.

La ultrasonografía generalmente muestra hallazgos bastante inespecíficos, como una masa sólida, bien definida, ovoide o lobulada, isoecogénica o hipoecogénica'. En algunos casos, también puede presentar un tono acústico posterior $^{2}$. Al igual que con los hallazgos de la ecografía, la FN generalmente se presenta, en la resonancia magnética, como una lesión bien definida, redondeada u ovalada, pero sin un patrón específico de intensidad de señal en las diferentes secuencias ${ }^{4,9}$. En la secuencia ponderada en T1, la FN generalmente se presenta con una señal aumentada en relación con el tejido muscular adyacente y ligeramente heterogénea. Ya en la ponderación T2, las lesiones son relativamente homogéneas e hiperintensas en relación con el tejido adiposo subcutáneo ${ }^{4}$. Sin embargo, dependiendo de los componentes histológicos de las lesiones, estas pueden ser ligeramente hipointensas en todas las secuencias ${ }^{9}$. Debido a este hecho, algunos autores ${ }^{9}$ defienden que los subtipos mixoides y celulares muestran una señal más intensa que el músculo en $\mathrm{T} 1$ y también son hiperintensos en relación con la grasa en secuencias potenciadas en $\mathrm{T} 2$, mientras que en el subtipo fibroso, la lesión es hipointensa en relación con el tejido muscular en todas las ponderaciones. Tales propiedades de los diferentes subtipos histológicos y la ubicación de la lesión influirán en el patrón de realce al medio de contraste con el gadolinio9. La alta celularidad y la vascularización densa están relacionadas con un realce precoz después de la inyección intravenosa de gadolinio, que se mostró homogénea principalmente cuando la lesión estaba localizada en la topografía del subcutâneo' ${ }^{9}$. Considerando solo aspectos de imagen, los diagnósticos diferenciales son diversos e incluyen fibromatosis agresiva, adenomegalia, dermatofibroma, fibrosarcoma y fibrohistiocitoma maligno ${ }^{2,4}$. Por lo tanto, el diagnóstico de FN no puede ser realizado usando apenas los resultados de los exámenes de imagen ${ }^{2}$.

La elastografía de compresión (strain elastography) es una técnica ultrasonográfica basada en la deformación estática de un material lineal, isotrópico y elástico ${ }^{10,11}$. De una manera más simple, la misma puede describir el desplazamiento (compresión) o la rigidez de un determinado tejido en respuesta a la aplicación de una fuerza en el local y con ella los tejidos rígidos tienden a deformarse menos y presentan menos tensión que los tejidos blandos cuando la misma fuerza es aplicada ${ }^{12}$.

Estudios recientes muestran que la elastografía tiene una alta sensibilidad y especificidad para diferenciar las lesiones benignas de las malignas, cuando la técnica se aplica adecuadamente ${ }^{13}$.

El tratamiento de elección es la escisión quirúrgica de la lesión ${ }^{2,4,7}$, pero algunos autores sugieren alternativas como la observación y la inyección de corticoides en la lesión ${ }^{4}$. La recurrencia es bastante rara, siendo reportada en $1-2 \%$ a $10 \%{ }^{2,4,7}$, probablemente debido a una resección incom- pleta $^{2}$. En esta paciente, el tratamiento ofrecido fue la extirpación quirúrgica completa de la lesión, sin necesidad de tratamiento adicional.

La fascitis nodular es un tumor benigno relativamente infrecuente, con características clínicas y de imagen poco comunes, con varios diagnósticos diferenciales, que incluyen patologías de naturaleza maligna.

La ultrasonografía puede ser considerada como un método inicial para evaluar estas lesiones debido a su amplia accesibilidad, disponibilidad y no utilización de radiación ionizante, pudiendo ofrecer información valiosa para la elaboración de una hipótesis diagnóstica. Las herramientas como el Doppler color, el Doppler pulsado y la elastografía son útiles para aumentar la sensibilidad de la ecografía en modo $\mathrm{B}$.

El diagnóstico final es realizado después de una biopsia o escisión quirúrgica de la lesión. La muestra extraída se envía para análisis anatomopatológico y, en algunas situaciones, el estudio inmunohistoquímico debe ser realizado para la confirmación del diagnóstico.

\section{REFERENCIAS}

1. Di Serafino M, Maurea S, Vallone G. Nodular fasciitis of the chest: case report of a rare presentation. Musculoskeletal surgery. 2011; 95(3): 251-3.

2. Roberti A, Roberti MdRF, Carneiro SdS, rapoport A, Dedivitis RA. Fasciíte nodular em região cervical: relato de caso. Revista Paraense de Medicina. 2007; 21: 41-4.

3. Aydin O, Oztuna V, Polat A. Three cases of nodular fasciitis: primary diagnoses by fine needle aspiration cytology. Cytopathology: official journal of the British Society for Clinical Cytology. 2001; 12(5): 346-7.

4. Leung LY, Shu SJ, Chan AC, Chan MK, Chan CH. Nodular fasciitis: MRI appearance and literature review. Skeletal radiology. 2002; 31 (1): 9-13.

5. Wirman JA. Nodular fasciitis, a lesion of myofibroblasts: an ultrastructural study. Cancer. 1976; 38(6): 2378-89.

6. Oliveira AM, Chou MM. USP6-induced neoplasms: the biologic spec trum of aneurysmal bone cyst and nodular fasciitis. Human pathology. 2014; 45(1): 1-11

7. Souza LS, Almeida WLd, Costa ALD, Silva APS, Souza LLd. Fasceíte nodular. Rev Bras Cir Cabeça Pescoço. 2009; 38(4): 274-5.

8. Velagaleti GV, Tapper JK, Panova NE, Miettinen M, Gatalica Z. Cytogenetic findings in a case of nodular fasciitis of subclavicular region. Cancer genetics and cytogenetics. 2003; 141(2): 160-3.

9. Wang XL, De Schepper AMA, Vanhoenacker F, De Raeve H, Gielen J, Aparisi F, L Rausin, Somville J. Nodular fasciitis: correlation of MRI findings and histopathology. Skeletal radiology. 2002; 31 (3): 155-61.

10. Ophir I, Cespedes I, Ponnekanti H, Yazdi Y, Li X. Elastography: a quan titative method for imaging the elasticity of biological tissues. Ultrasonic imaging. $1991 ; 13(2): 111-34$.

11. Gao L, Parker KJ, Lerner RM, Levinson SF. Imaging of the elastic properties of tissue--a review. Ultrasound in medicine $E$ biology. 1996; 22(8): 959-77.

12. Choi YJ, Lee JH, Baek JH. Ultrasound elastography for evaluation of cervical lymph nodes. Ultrasonography. 2015; 34(3): 157-64.

13. Qiong Xie, Yi Bing Li, Haoping Li, Hongli Ji. Elastography for the differentiation of benign and malignant cervical lymph node: a meta-analy sis. Int J Clin Exp Me. 2016; 9(8): 16094-101. 


\title{
DIAGNÓSTICO PRENATAL DE ESQUIZENCEFALIA CON EVOLUCIÓN PROGRESIVA UNILATERAL A BILATERAL - UN CASO CLÍNICO
}

\author{
RENATO MURTA, MARCOS FARIA, LUCCA PENNA FARIA, BRUNO PENNA FARIA, HEVERTON PETTERSEN
}

\begin{abstract}
RESUMEN
La esquizencefalia es una malformación congénita rara del sistema nervioso central (SNC). Perteneciente al grupo de defectos de migración de células del SNC, aparece entre el $2^{\circ}$ y el $5^{\circ}$ mes de gestación, caracterizada por una sustancia gris dismórfica que delinea las hendiduras en la corteza cerebral que se extienden medialmente desde el espacio subaracnoideo comunicando con el ventrículo cerebral ipsolateral. Este caso clínico es de un feto que fue derivado con el diagnóstico de ventriculomegalia y en el examen morfológico fue identificada una patología rara del SNC, la esquizencefalia unilateral tipo II.

Durante el monitoreo, evolucionó para una forma bilateral con aumento progresivo de la hendidura, espacio subaracnoideo, ventrículo cerebral e identificación de anomalías cerebrales asociadas. Esta evolución de la forma unilateral a la bilateral no está descrita en la literatura médica. Puede presumirse que el diagnóstico fue muy precoz y, aunque el evento hubiese sido bilateral, su manifestación tardó un cierto tiempo para tornarse identificable en el examen ultrasonográfico. Será abordada la etiología, las anomalías asociadas, el diagnóstico diferencial y los factores pronósticos en la esquizencefalia.
\end{abstract}

\section{PALABRAS CLAVE: ESQUIZENFALIA, DIAGNÓSTICO, PRENATAL, ULTRASONIDO, EVOLUCIÓN, ETIOLOGÍA, FACTORES PROGNÓSTICOS.}

\section{INTRODUCCIÓN}

La esquizencefalia es una malformación congénita rara del sistema nervioso central (SNC), con una prevalencia de 1.5: 100.000 nacimientos vivos ${ }^{1,2}$. Fue descrita por primera vez en 1946 por Yakovlev y Wadworth cuando definieron la esquizencefalia como una hendidura congénita en el manto cerebral en un estudio post mortem ${ }^{3}$.

Perteneciente al grupo de defectos de migración celular del SNC, surge entre el $2^{\circ}$ y el $5^{\circ}$ mes de gestación, y se caracteriza por una sustancia gris dismórfica delineando las hendiduras en la corteza cerebral. Estas hendiduras se extienden medialmente desde el espacio subaracnoideo, comunicándose con el ventrículo cerebral ipsilateral. La identificación de la sustancia gris que bordea la hendidura es una característica patognomónica de la lesión, que la diferencia de la porencefalia severa.

La esquizencefalia unilateral es más frecuente (60\%) que la hendidura bilateral y en el $75-95 \%$ de los casos la ubicación anatómica predominante es en los lóbulos frontal y parietal ${ }^{3-5}$.

\section{ETIOLOGÍA}

La mayoría de los casos de esquizencefalia son esporádi- cos y desconocidos, sin una causa etiológica reconocida. Se han sugerido teorías como la migración neuronal anómala y la obstrucción de la arteria cerebral media como resultado de un proceso inflamatorio intrauterino, como en la infección por citomegalovirus ${ }^{3,4}$.

La teoría de la migración neuronal anormal precoz implica el plisado y la fusión de las capas de la piamadre con el epéndimo. La Figura 1 ilustra la sección histológica coronal a las 10, 17 y 28 semanas de gestación, exhibiendo el plegamiento y la fusión de las capas de la piamadre con el epéndimo, y el posterior desarrollo de la corteza cerebral ${ }^{5}$.

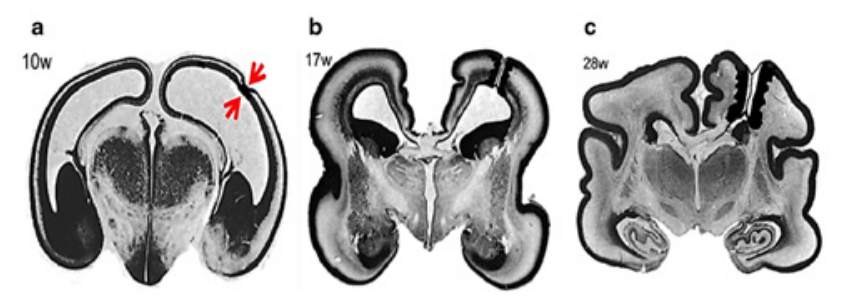

Figura 1. llustra el plisado y la fusión de las capas de la piamadre y del epéndimo en la corteza cerebral a las 1, 17 y 28 semanas de gestación ${ }^{5}$.
GENUS - Grupo de Ensino em Ultrassonografia -

Belo Horizonte

GENNUS - Núcleo de Medicina Fetal

Faculdade Ciências Médicas de Minas Gerais
Dirección para correspondencia:

Renato Murta

Rua Jaceguai, 208, sl.1022 - Prado

Belo Horizonte - CEP 30.411-040

Email: renato.jardim@hotmail.com 
La figura 2 ilustra los cambios en la corteza cerebral y su evolución durante el embarazo. En la figura, el cuadrado rojo representa el daño focal de toda la espesura de la corteza cerebral precoz y la posterior destrucción del tejido cerebral. Durante el período de migración neuronal, aproximadamente en la semana 28 , se forman regiones de polimicrogiria, que se observan en los bordes de la hendidura de la esquizencefalia ${ }^{5}$.

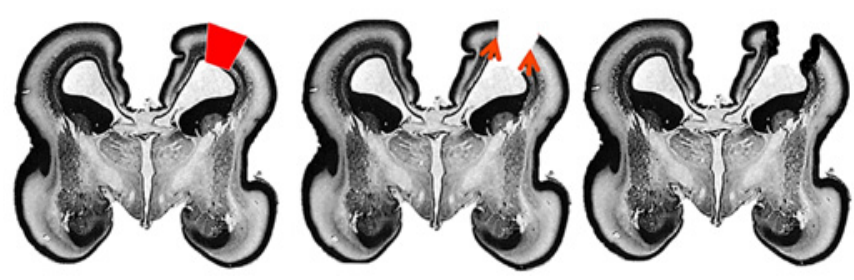

Figura 2. Ilustra las modificaciones en la corteza cerebral y su evolución en el transcurso de la gestación ${ }^{5}$.

Por otro lado, si el evento ocurre después del sexto mes de gestación, no existe migración neuronal adecuadamente suficiente para contornar la lesión existente y, por lo tanto, no hay suficiente organización para desarrollar polimicrogiria.

De esta forma, el daño cerebral se produce por la reabsorción del tejido lesionado y, debido a la migración neuronal inadecuada, hay una ausencia de sustancia gris en los bordes de las lesiones, lo que resulta en la formación de quistes porencefálicos, diferentes de la esquizencefalia. Por otro lado, la teoría de la obstrucción vascular de la arteria cerebral media corrobora el hecho de que la mayoría de la esquizencefalia es vista en la región del surco lateral del cerebro, territorio irrigado por la arteria cerebral media, incluso en las formas bilaterales ${ }^{3,4}$.

Algunos autores señalan ciertos factores genéticos como etiología, como las mutaciones en el gen EMX2 que regulan el desarrollo estructural del prosencéfalo. La mutación causa una lesión en la matriz germinativa periventricular, lo que afecta la migración celular entre las semanas $6-7^{\mathrm{a}}$ del embarazo ${ }^{4,6}$.

Otros genes como el EPG5 y el COL4A1 que causan vulnerabilidad en la pared vascular se consideran responsables de la esquizencefalia ${ }^{7,8}$.

Otros factores relacionados fueron la edad menor de 20 años, abuso de alcohol, estupefacientes, exposición a solventes orgánicos, muerte de un gemelo, trombocitopenia aloinmune, trombofilia, infecciones congénitas, trauma materno y warfarina ${ }^{8}$.

\section{PRESENTACIÓN CLÍNICA}

La esquizencefalia se divide en dos tipos clínicos: tipo I o de labio cerrado donde la hendidura cerebral no se comunica con el ventrículo y el diagnóstico prenatal es difícil. Griffiths PD realizó una revisión con 11 fetos y encontró esquizencefalia tipo I (cerrada) en el $45 \%$ de los casos al utilizar estudio de resonancia magnética ${ }^{5}$.
La tipo II o de labio abierto, donde la hendidura se comunica con el ventrículo siendo llenada por líquido y con características que pueden ser descritas en la atención prenatal, ocurriendo en el 55-60\% de los casos 5 . Los márgenes de la hendidura están rodeados por sustancia gris displásica y heterotópica ${ }^{1,8}$.

Ambos tipos de esquizencefalia pueden ser unilaterales o bilaterales. La forma unilateral se caracteriza por un curso notablemente más suave; pudiendo ser asintomática o presentar crisis epilépticas, defectos motores leves y visión anormal. La bilateral es una malformación grave e irreversible del SNC que se manifiesta con crisis convulsivas difíciles de controlar, retraso mental severo, ceguera, diversos grados de defectos motores ${ }^{8}$.

No existen relatos de esquizencefalia diagnosticada por ultrasonografía antes de las 20 semanas de gestación. Howe et al evaluaron 18 casos de esquizencefalia prenatal y todos tenían una edad gestacional mayor que 21 semanas de gestación ${ }^{8}$.

\section{ANOMALÍAS ASOCIADAS}

La literatura describe la asociación de la esquizencefalia con anomalías cromosómicas, síndromes genéticos, infecciones congénitas y muerte gemelar monocoriónica. Otras patologías cerebrales concomitantes han sido descritas como hidrocefalia $(30 \%$ de los casos y casi exclusivamente con tipo II), ventriculomegalia (85\%), agenesia del cuerpo calloso y septo pelúcido (40-70\%), atrofia del nervio óptico (30\%) , quiste aracnoideo y malformaciones cerebelosas, displasia cortical, heterotopia, paquigiria, polimicrogiria, leucomalacia periventricular ${ }^{1,8}$.

Griffiths PD reportó ausencia o interrupción del septo pelúcido en el $64 \%$ de los fetos con tendencia a su ausencia en fetos con esquizencefalia tipo II (abierta) ${ }^{5}$.

\section{DIAGNÓSTICO DIFERENCIAL}

El diagnóstico diferencial debe hacerse con agenesia del cuerpo calloso, hidrocefalia, holoprosencefalia, encefalocele, quiste aracnoideo y porencefalia. La lesión porencefálica es un desafío aparte, especialmente en el tipo I, que se diferencia de la esquizencefalia, en la resonancia magnética, debido a la ausencia de sustancia gris en el contorno de la lesión.

\section{RELATO DE CASO:}

Paciente con ARSC, 19 años, blanca, ciclo regular, concepción natural, primípara, fecha de la última menstruación desconocida; sin antecedentes de patologías previas. Fue derivada a nuestro servicio con un diagnóstico de ventriculomegalia unilateral severa.

El 31.12.2019, fue realizado el primer examen ultrasonográfico en la gestante, identificando una hendidura unilateral izquierda que comunicaba el sistema ventricular con el espacio subaracnoideo en la región del lóbulo parietal - (figuras 3). El diagnóstico fue de esquizencefalia unilateral tipo II. No se observó ninguna otra anomalía estructural mayor asociada. 

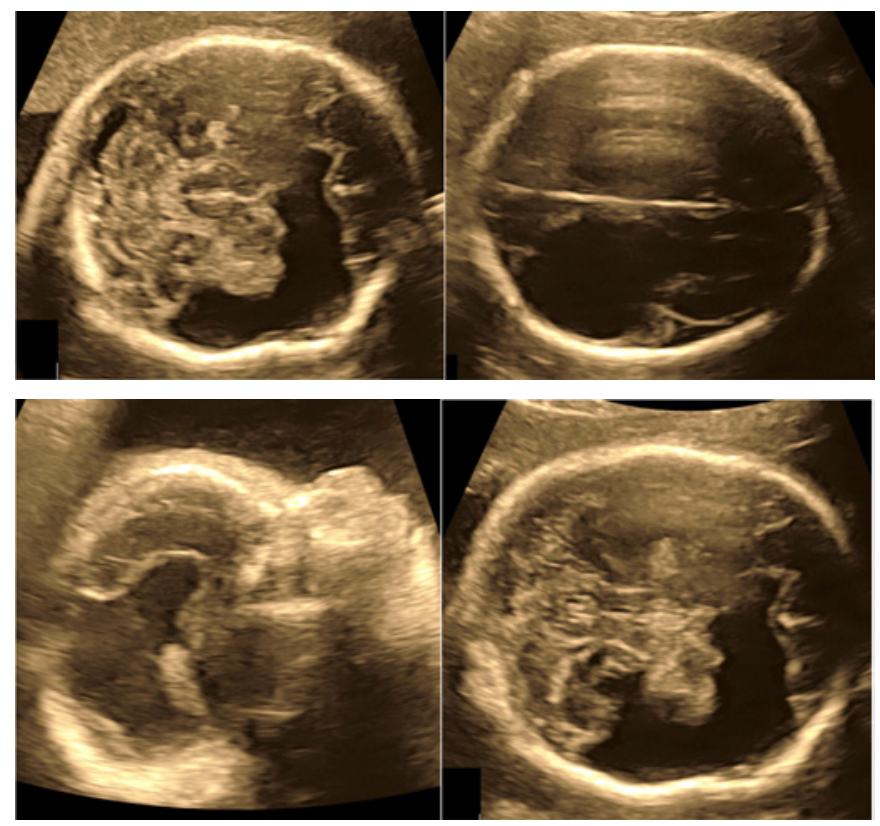

Figura 3. Imágenes ultrasonográficas exhiben área anecoica en región del lóbulo parietal izquierdo (esquizencefalia tipo Il unilateral).

El 28.01.2020, fue realizado el segundo examen, siendo observada una evolución de unilateral a bilateral; comunicando los sistemas ventriculares a los espacios subaracnoideos bilateralmente - (figuras 4). No se ha identificado ninguna otra anomalía estructural importante asociada.
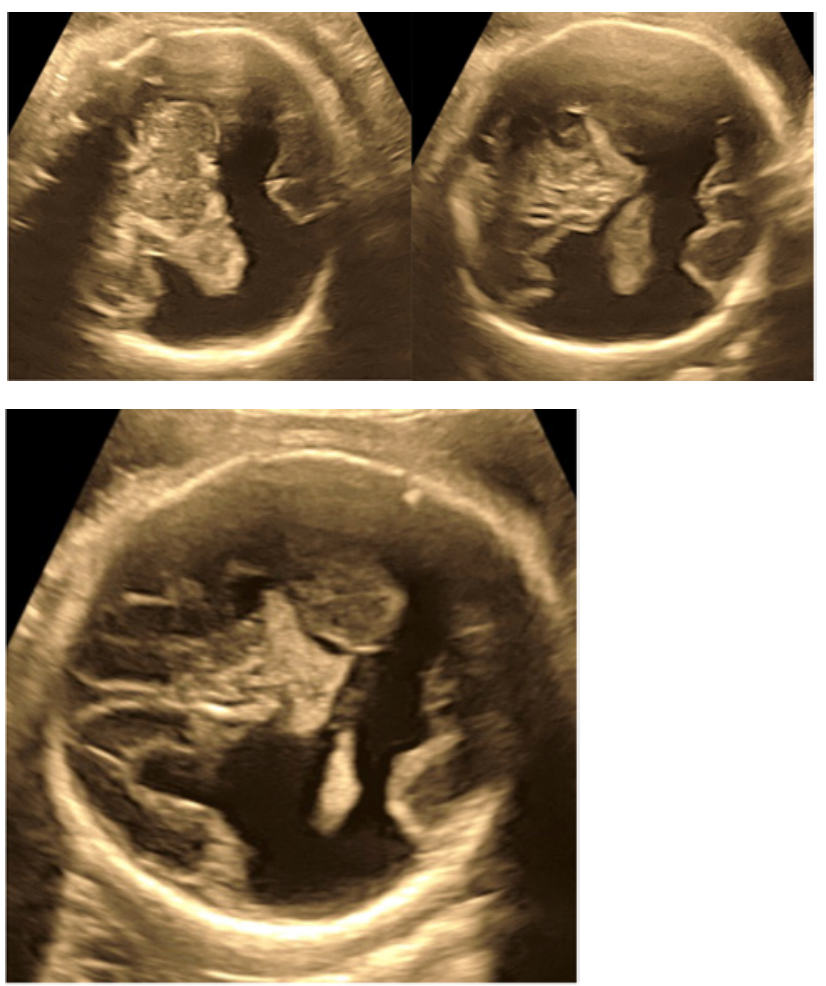

Figura 4. Imágenes ultrasonográficas exhiben área anecoica en región del lóbulo parietal bilateral (esquizencefalia tipo II bilateral).
El 14.02.2020, fue realizado un tercer examen ultrasonográfico, en el que se observó una imagen anecoica, comunicando el espacio subaracnoideo derecho al ventrículo derecho, imagen anecoica de las mismas características comunicando el espacio subaracnoideo izquierdo al ventrículo izquierdo y la ausencia de cavidad del septo pelúcido, observándose aumento de las comunicaciones desde los espacios subaracnoideos a los ventrículos. Sin otras anomalías estructurales importantes asociadas.

El 10.03.2020, se realizó un cuarto examen de ultrasonográfico, que reveló un aumento progresivo en el espacio subaracnoideo, de la hendidura y de los ventrículos cerebrales, ausencia de cavidad del septo pelúcido. El plexo coroideo se ve flotando en la cavidad ventricular - (figuras 5).
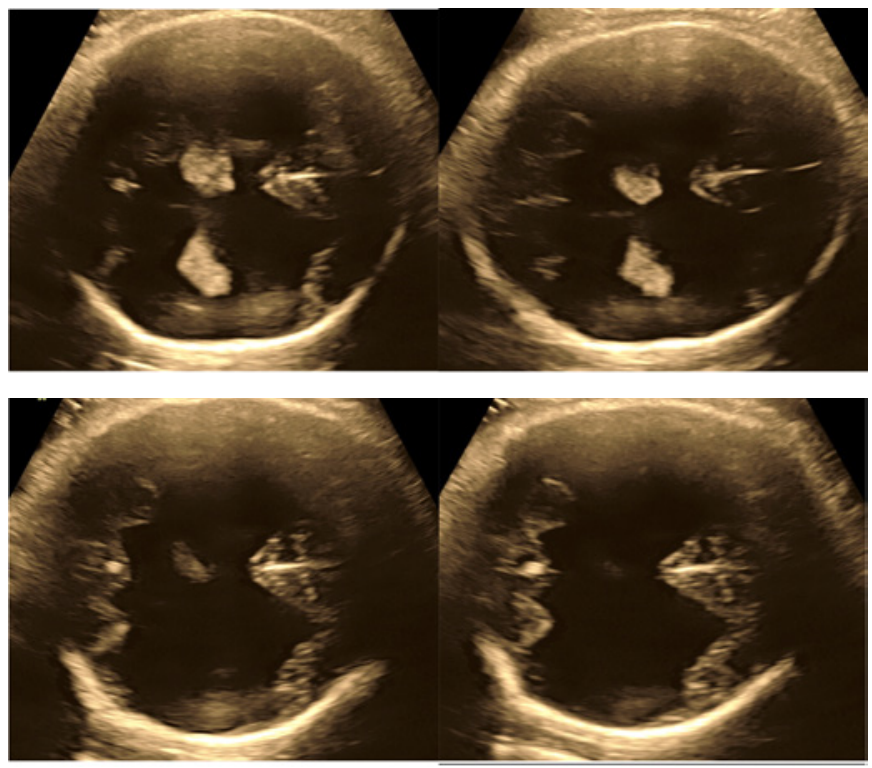

Figura 5. Imágenes ultrasonográficas exhiben área anecoica en región del lóbulo parietal bilateral (esquizencefalia tipo II bilateral).

\section{DISCUSIÓN:}

La esquizencefalia generalmente se asocia con otras malformaciones del SNC, como ventriculomegalia, polimicrogiria, paquigiria, heterotopia, lisencefalia, ausencia de cavidad del septo pelúcido, agenesia del cuerpo calloso, hipoplasia del nervio óptico. Aunque el estándar de oro para el diagnóstico de esquizencefalia se estudie mediante resonancia magnética, existen casos raros descritos en la literatura. La serie más grande fue descrita por Nabavizadeh et al, quienes estudiaron 10 fetos con resonancia magnética intrauterina y confirmaron con un estudio postnatal, que incluyó ocho casos bilaterales. Un hallazgo interesante fue la discordancia en la clasificación entre prenatal y posnatal con el $47 \%$ de las esquizencefalia tipo II (abierta) detectadas intraútero convirtiéndose en tipo I (cerrada) en el período posnatal. Informaron que alrededor del 26\% de las polimicrogirias fetales no fueron detectadas ${ }^{10}$.

Otra evidencia circunstancial en este trabajo de Nabavizadeh et al, es el hallazgo de depósito de hemosiderina y/o 
hemorragia en la hendidura y en los ventrículos de fetos afectados por esquizencefalia en el estudio por resonancia magnética. Además, más de la mitad de los fetos presentaban microcefalia debido a la destrucción del tejido cerebral. Estos hallazgos corroboran la teoría de que la etiología principal para los casos de esquizencefalia se debe a hemorragia y/o destrucción de la matriz cerebral ${ }^{10}$.

Las manifestaciones clínicas de la esquizencefalia incluyen diferentes niveles de retraso en el desarrollo, convulsiones neuropsicomotores y diferentes grados de alteraciones en la visión y el habla. Hunt et al estudiaron a 21 pacientes con esquizencefalia ( 16 unilaterales y 5 bilaterales). La mayoría de los pacientes con déficit neurológicos se detectaron antes del año de edad, especialmente en hendiduras bilaterales. La presentación clínica principal fue hemiparesia en esquizencefalia unilateral y convulsiones en la forma bilateral.

Alrededor del $81 \%$ de los pacientes manifestaron convulsión epiléptica tónicoclónica generalizada, siendo que el 38\% de los casos desarrollaron epilepsia refractaria. La mayoría de los pacientes desarrollaron deficiencias motoras, intelectuales y de lenguaje, especialmente en la esquizencefalia bilateral ${ }^{11}$.

Este caso clínico es de un feto que fue derivado con diagnóstico de ventriculomegalia y el examen morfológico identificó una patología rara del SNC a la esquizencefalia tipo II unilateral. Durante el monitoreo, evolucionó para una forma bilateral con un aumento progresivo de la hendidura, el espacio subaracnoideo, el ventrículo cerebral y la identificación de anomalías asociadas con la ausencia de cavidad del septo pelúcido y del cuerpo calloso. Esa evolución de forma unilateral a bilateral no está descrita en la literatura médica.

Puede suponerse que el diagnóstico fue muy precoz y, aunque el evento hubiese sido bilateral, su manifestación necesitó de un cierto tiempo para tornarse identificable en el examen de ultrasonográfico. El diagnóstico diferencial es realizado para distinguir este trastorno de la holoprosencefalia, la hidranencefalia y los quistes aracnoideos bilaterales. Los casos de esquizencefalia tipo I y porencefalia la mayoría de las veces solo podrán ser distinguidos en el examen de resonancia magnética en el que la sustancia gris displásica y heterotrópica rodea la lesión quística en la esquizencefalia tipo I.

En la mayoría de los casos la etiología no será identificada. El pronóstico a largo plazo dependerá del tamaño y la ubicación de la lesión, ya sea unilateral o bilateral y si existen malformaciones cerebrales asociadas. El recién nacido deberá ser evaluado por un neurólogo pediátrico y el seguimiento con resonancia magnética es recomendado.

Por lo tanto, un diagnóstico prenatal preciso es importante para una adecuada asesoría genético-reproductiva de los padres.

\section{REFERENCIAS:}

1. Howe DT, Rankin J, Draper ES. Schizencephaly prevalence, prenatal diagnosis and clues to etiology: A register based study. Ultrasound Obstet Gynecol 2012; 39: 75 82.
2. Brant WE, Helms CA. Fundamentals of Diagnostic Radiology. 3rd ed. Philadelphia: Lippincott Williams \& Wilkins; 2007. p. 2267.

3. Yakovlev PI, Wadsworth RC. Schizencephalies: a study of the congenital clefts in the cerebral mantle; clefts with hydrocephalus and lips separated. J Neuropathol Exp Neurol 1946; 5: 169206.

4. Barkovich AJ, Norman D. MR imaging of schizencephaly. AJR Am J Roentgenol 1988; 150: 13916.

5. Griffiths PD. Schizencephaly revisited. Neuroradiology. 2018; 60(9): 945-60.

6. Tietjen I, Erdogan F, Currier S, Apse K, Chang BS, Hill RS et al. EMX- 2 independent familial schizencephaly: Clinical and genetic analyses. Am J Med Genet A 2005; 135: 16670.

7. Sato Y, Shibasaki J, Aida N, Hiiragi K, Kimura Y, Akahira-Azuma M, Enomoto Y, Tsurusaki Y, Kurosawa K. Novel COL4A1 mutation in a fetus with early prenatal onset of schizencephaly. Hum Genome Var. 2018; 24(5): 4.

8. Halabuda A, Klasa L, Kwiatkowski S, Wyrobek L, Milczarek O, Gergont A. Schizencephaly - diagnostics and clinical dilemmas. Childs

Nerv Syst. 2015; 31(4): 551-6.

9. Dies KA, Bodell A, Hisama FM, Guo CY, Barry B, Chang BS, Barkovich AJ, Walsh CA. Schizencephaly: association with young maternal age, alcohol use, and lack of prenatal care. J Child Neurol. 2013; 28(2): 198-203.

10. Nabavizadeh SA, Zarnow D, Bilaniuk LT, Schwartz ES, Zimmerman RA, Vossough A. Correlation of prenatal and postnatal MRI findings in schizencephaly. Am J Neuroradiol 2014; 35(7): 1418-24.

11. Hung PC, Wanga HS, Choua ML, Lina KL, Hsieha MY, Choua IJ, Wongb AMC. Schizencephaly in children: A single medical center retrospective study. Pediatrics \& Neonatology, 2018; 59(6): 573-80. 


\title{
SINOVITIS VELLONODULAR PIGMENTADA: UN CASO CLÍNICO
}

\author{
JORGE GARCIA, ANA CLAUDIA PEREIRA LIMA, PROCÓPIO DE FREITAS, AUGUSTO CESAR SAAB BENEDETI, \\ FERNANDO MARUM MAUAD, FRANCISCO MAUAD FILHO
}

\section{RESUMEN}

La sinovitis vellonodular pigmentada es una enfermedad sinovial proliferativa, benigna, caracterizada por nódulo, sésil, pedunculado de etiología desconocida. Su incidencia anual es de 1.8/100.000 y afecta a la $3^{a}$ y $4^{a}$ década. En la mayoría de los casos, los síntomas son inespecíficos, es monoarticular y la rodilla es el segmento más afectado. Se concluye que la ultrasonografía demostró ser una técnica de imagen efectiva para detectar lesiones vellonodulares.

PALABRAS CLAVE: SINOVIA, INTRAARTICULAR, HUESO, VILLONODULAR, HOFFA.

\section{INTRODUCCIÓN}

La sinovitis vellonodular pigmentada (SVNP) es una enfermedad clínica benigna e inusual de etiología desconocida, caracterizada por una proliferación excesiva de la membrana sinovial de las articulaciones, las vainas sinoviales y las bursas ${ }^{1-4}$.

En 1852, Chassaignac informó el primer caso de lesión nodular en la vaina del tendón flexor de los dedos índice y medio1. Recientemente, la Organización Mundial de la Salud definió que SVNP y tumor de células gigantes son términos equivalentes ${ }^{2,4}$.

\section{RELATO DE CASO}

Paciente femenina, de 26 años, con inflamación en la región anterolateral de la rodilla derecha durante tres meses ( $\mathrm{Fi}^{-}$ gura 1), sin quejas de dolor o bloqueo articular. Examen físico ortopédico con buena alineación de las extremidades inferiores, pruebas de los meniscos y ligamentos negativos y ausencia de signos de inestabilidad articular.

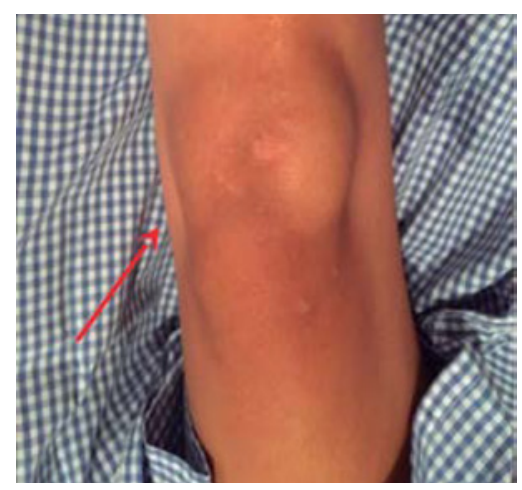

Figura. 1. Inflamación anterolateral rodilla derecha.
Se realizó una ultrasonografía que mostró una formación sólida hipoecogénica intraarticular con dimensiones de 3.5 x 1.6 x $3.8 \mathrm{~cm}$, expandiéndose a la grasa de Hoffa (Figs. 2 y 3), examen Doppler espectral y de amplitud mostrando vascularización (Figura 4 y 5).

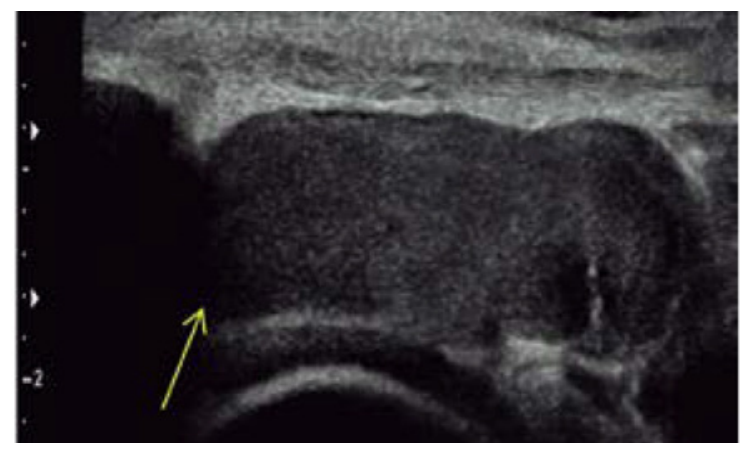

Figura2. Nódulo transversal hipoecogénico.

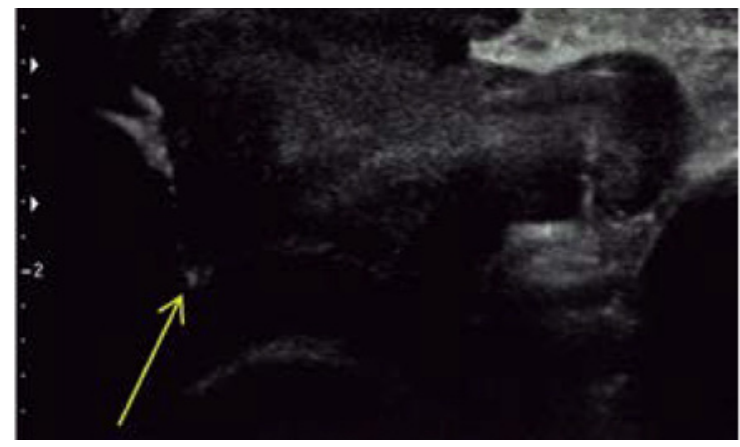

Figura3. Nódulo longitudinal hipoecogénico
Faculdade de Tecnologia em Saúde. FATESA/ EURP. Ribeirão Preto. SP.

Faculdade de Medicina e Odontologia Mandic de Campinas.
Dirección para correspondencia:

Augusto César Saab Benedeti

Email: augusto@fatesa.edu.br 


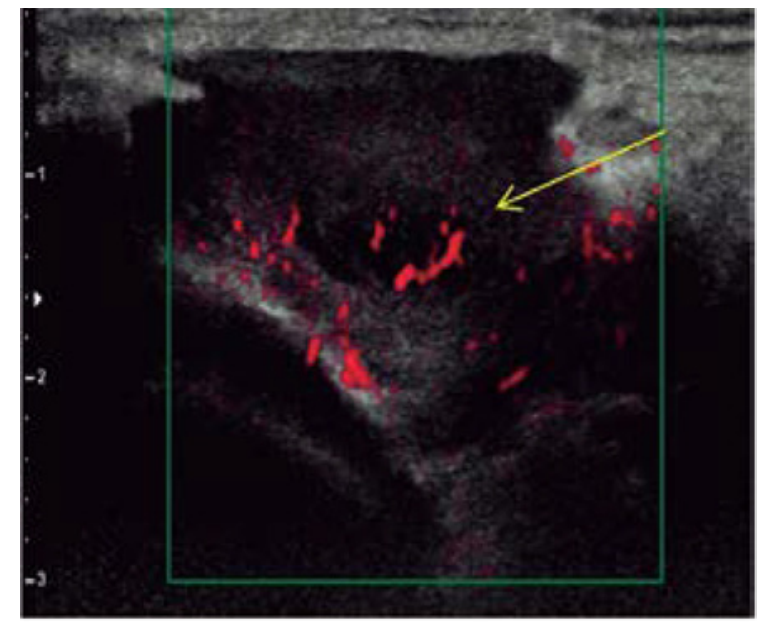

Figura4. Nódulo vascularizado con Doppler de amplitud.

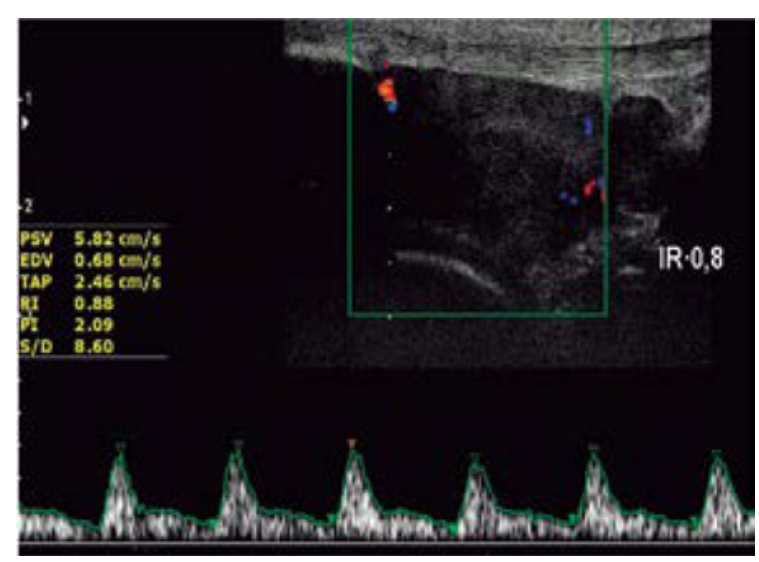

Figura5. Nódulo con pico de velocidad sistólico elevado.

\section{DISCUSIÓN}

La SVNP es una enfermedad rara, generalmente monoarticular, siendo la rodilla la articulación más afectada en el $80 \%$ de los casos, seguida de la cadera y el tobillo. Incidencia de 1.8/100.000 personas, en la $3^{\mathrm{a}}$ e $4^{\mathrm{a}}$ década ${ }^{1,3,6}$.

La sintomatología clínica más frecuente es la aparición lenta e insidiosa de dolor, edema y rigidez articular ${ }^{6}$. Tiene dos presentaciones:

a) difusa: involucra completamente el revestimiento sinovial de articulaciones grandes, como la rodilla y la cadera; b) localizada: vellonodular, sésil, afectando pequeñas articulaciones de manos y pies 5,7 .

Se realiza el diagnóstico diferencial con sarcoma sinovial, condromatosis sinovial, hemangioma, lipoma arborescente sinovial $^{4}$.

El método de imagen más apropiado para su diagnóstico es la resonancia magnética, ya que la extensión intraarticular y la afectación ósea no pueden evaluarse con precisión mediante ultrasonido. La ultrasonografía puede ayudar en el diagnóstico, pero no es específica ${ }^{4,7}$.

\section{CONCLUSIÓN}

La sinovitis vellonodular pigmentada, a pesar de ser poco común, es benigna y su diagnóstico es histopatológico. Sin embargo, la ultrasonografía ha demostrado ser un método sensible para la detección del proceso expansivo intraarticular.

\section{REFERENCIAS:}

1. Chassaignac EP. Câncer de lagainedestendons. Gaz Hop CivMilit. 1852; 25:185-6.

2. Rodriguez-Merchan EC. Review article: open versus arthroscopic synovectomy for pigmented villonodular synovitis of the knee. J OrthopSurg (Hong Kong), 2014; 22(3): 406-8.

3. Yang B, Liu D, Lin J, Jin J, Weng XS, Qian WW, et al. Surgical treatment of diffuse pigmented villonodular synovitis of the knee. Zhongguo $Y i$ XueKeXue Yuan XueBao. 2015; 37(2):234-9.

4. Jendrissek KA, Hotfiel T, Swoboda B, Soder S, Janka R. Pigmented villonodular synovitis: a rare differential diagnosis of synovial joint swelling. Z Rheumatolog, 2016; 75 (2):157-65.

5. Kramer DE, Frassic FJ, Cosgarea AJ. Total arthroscopic synovectomy for pigmented villonodular synovitis of the knee. Tech Knee Surg 2004, 3(1): 36-45

6. Myers B, Masi A. Pigmented villonodular synovitis and tenosynovitis: A clinical epidemiologic study of 166 cases and literature review. Medicine (Baltimore). 1980; 59: 223-38.

7. Kim SJ, Shin SJ, Choi NH, Choo ET. Arthroscopic treatment for localized pigmented vilonodular synovitis of the knee. Clin Orthop. 2000. 379: 224-30. 


\title{
ULTRASONOGRAFÍA DOPPLER EN LA EVALUACIÓN DEL REFLUJO GASTROESOFÁGICO
}

\author{
THALITA BARBOSA DUTRA DE MIRANDA, ARIELA MAULLER VIEIRA PARENTE, LARISSA BARBOSA DUTRA DE MIRANDA, \\ MÔNICA SILVA CARNEIRO, AVELINO PEIXOTO NETO, HAYTHAM LOAIY IBRAHIM KARAJAH, \\ WALDEMAR NAVES DO AMARAL
}

\section{RESUMEN}

El reflujo gastroesofágico (RGE) es el paso involuntario de contenido gástrico hacia la luz esofágica. Es una condición común en bebés y niños pequeños, siendo, en la mayoría de los casos, considerado fisiológica, sin embargo, puede determinar manifestaciones clínicas y conducir a la enfermedad por reflujo gastroesofágico. El objetivo general de este trabajo fue analizar el papel de la ultrasonografía en el diagnóstico y monitoreo del reflujo gastroesofágico. La metodología utilizada en este trabajo fue una revisión de la literatura. La metodología utilizada fue una revisión bibliográfica de artículos publicados en español, inglés y portugués en los últimos 20 años, siendo la base de datos PubMed, SciElo, Bireme, Lilacs. Lo que se puede concluir es que la ultrasonografía en el diagnóstico del reflujo gastroesofágico es un examen no invasivo, rápido, accesible y económico.

\section{PALABRAS CLAVE: REFLUJO GASTROESOFÁGICO, ULTRASONOGRAFÍA, DIAGNÓSTICO DE IMÁGENES}

\section{INTRODUCCIÓN}

El reflujo gastroesofágico (RGE) es la situación que más ataca al esófago, una de las quejas más comunes en los consultorios ${ }^{1}$.

La expresión enfermedad por reflujo gastroesofágico sintomática se refiere a aquellos pacientes que presentan signos pépticos (pirosis y regurgitación), con o sin evidencia endoscópica de esofagitis. Los pacientes más complejos de entender son aquellos que presentan amplia sintomatología, pero sin evidencia de daño tisular al esófago (enfermedad por reflujo gastroesofágico no erosivo) ${ }^{2}$.

El número de hospitalizaciones asociadas con la enfermedad por reflujo gastroesofágico (ERGE) en los EE. UU. aumentó de 710.000 a 3.100.000 de 2002 a 2004. Un episodio de ERGE ocurre cuando el esfínter esofágico inferior (EEI) se abre espontáneamente y el contenido gástrico afecta el esófago ${ }^{3}$.

La ERGE es uno de los trastornos más comunes en la práctica médica. Los datos de América del Norte indican que la acidez estomacal, el síntoma más frecuente del trastorno, ocurre al menos una vez por semana en el 20\% de la población estudiada. Datos similares han sido reportados en Inglaterra y en Escocia. En Brasil, un estudio de base poblacional mostró una prevalencia de al menos $12 \%$ en la población general ${ }^{4}$.

Es una de las afecciones más comunes que acometen al tracto gastrointestinal y generalmente es considerada la causa de una variedad de síntomas esofágicos. En un individuo que padece ERGE, pueden estar presentes síntomas como acidez estomacal o sensación de ardor en el pecho. La ERGE no tratada puede conducir a otras consecuencias, como el esófago de Barrett, que se ha considerado un precursor del cáncer de esófago ${ }^{5}$.

La ERGE tiene una etiología multifactorial, y tanto el daño tisular como los síntomas resultan del contacto de la mucosa con el contenido de reflujo. Tal contacto se debe a la falla de las defensas esofágicas. La barrera antirreflujo, considerada la principal protección contra el reflujo gastroesofágico, está formada por el esfínter interno (o esfínter esofágico inferior) y el esfínter externo (formado por la porción crural del diafragma). El mecanismo principal de esta falla es la relajación transitoria del esfínter esofágico inferior, sin relación con la deglución, siendo responsable por aproximadamente el 70\% de los episodios de RGE ${ }^{6}$.

El diagnóstico de ERGE debe comenzar identificando la historia clínica completa del paciente. El enfoque diagnóstico debe variar según la presentación clínica. Las manifestaciones clínicas de la RGE son variables y se refieren no solo al tracto digestivo. Por lo tanto, el diagnóstico diferencial es amplio, abarca causas clínicas y quirúrgicas de vómitos y regurgitación, causas de broncoespasmo y síntomas atípicos, como asma, otitis, laringitis y sinusitis. Otro factor significati- 
vo es la edad del paciente, ya que las enfermedades varían según la edad ${ }^{7}$.

La enfermedad por reflujo gastroesofágico puede diagnosticarse por sus manifestaciones clínicas subjetivas. La acidez estomacal (o pirosis), la regurgitación y la disfagia representan los síntomas comunes de la ERGE. La endoscopia está indicada en pacientes en los que el tratamiento clínico común no es eficiente y presenta síntomas de ERGE, disfagia, odinofagia, hemorragia gastrointestinal (GI) microscópica o macroscópica o en pacientes con anemia por deficiencia de hierro detectada ${ }^{6}$.

Teniendo en cuenta las características no invasivas y no oncogénicas de la ultrasonografía transabdominal (US), este método puede eliminar las principales desventajas de la endoscopia digestiva alta. Varios estudios han sugerido la utilidad de la US transabdominal en la detección de ERGE en pacientes pediátricos. Sin embargo, parece haber pocos estudios que investiguen la utilidad de los US en la detección de la esofagitis inducida por ERGE en la población adulta ${ }^{6}$.

Recientemente, Savino et al. ${ }^{8}$ publicó un artículo sobre US para el diagnóstico de ERGE pediátrica. Los autores analizaron otras causas de síntomas, como vómitos, que no sean ERGE; y midieron la longitud del esófago abdominal, el diámetro del esófago, el grosor de la pared esofágica y el ángulo de Hiss para obtener datos anatómicos y funcionales. Los autores también destacaron la necesidad de definir criterios de diagnóstico, para estandarizar los exámenes y las medidas referidas. El análisis tradicional para el estudio de la RGE es la seriagrafía del esófago, el estómago y el duodeno (SEED) con bario y, más recientemente, la ecografía del esófago intraabdominal (USEI) - figura 1.

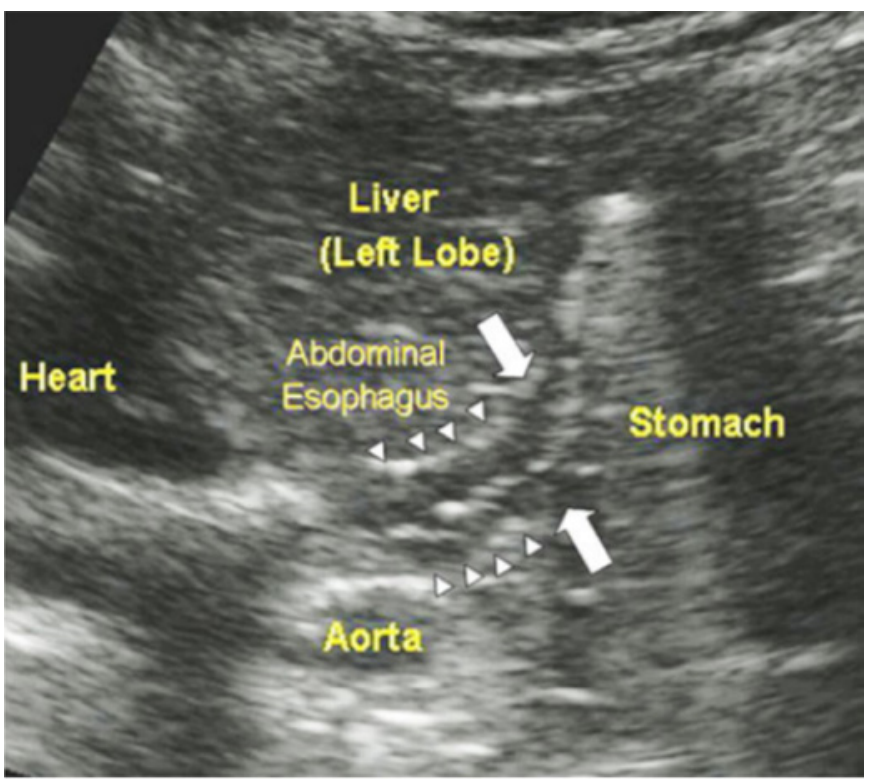

Figura 1. Ultrasonografía oblicua transversal de la unión gastroesofágica (flechas). El esófago visto como una estructura tubular (puntas de flecha) con una pared hipoecogénica (capa muscular) y un centro hiperecogénico (mucosa y lumen) ${ }^{8}$.
Hoy en día, existen varios métodos que permiten el análisis de trastornos esofágicos, como radiografías contrastadas con fluoroscopia, cintilografía, manometría, endoscopia digestiva alta y monitoreo prolongado del $\mathrm{pH}$ esofágico (24 horas). Sin embargo, los exámenes simples, rápidos, económicos y no invasivos que no usan radiación ionizante son esenciales. El US transabdominal para analizar el esófago intraabdominal, dentro de este contexto, representa un buen recurso e incorpora ventajas inmediatas, como distinguirse como un estudio inicial, dirigir mejor el examen complementario y presentar el equilibrio del efecto del tratamiento de individuos con disfagia ${ }^{9}$.

La USEI proporciona, de manera similar a la SEED, la posibilidad de clasificar detalles anatómicos estructurales, y puede constatar varios métodos patológicos, incluso el RGE, en tiempo real. Es un método no invasivo, seguro y no utiliza radiación ionizante 10 .

Con esto en mente, este artículo tuvo como objetivo describir el papel de la ultrasonografía en el diagnóstico y monitoreo del reflujo gastroesofágico.

\section{METODOLOGÍA}

Este es un estudio de revisión de literatura. Después de la definición del tema fue realizada una búsqueda de artículos científicos en las siguientes bases de datos científicos: Pubmed, Scielo, Lilacs y Bireme.

La búsqueda fue realizada utilizando las siguientes palabras clave: reflujo gastroesofágico / gastroesophagealreflux, ultrasonografia / ultrasonography, reflujo gastroesofágico / diagnóstico por imagen / gastroesophagealreflux/ diagnosticimaging.

Esta investigación incluyó: artículos publicados en español, inglés y portugués en los últimos 20 años. Los artículos de revisión, sistemáticos o no, y aquellos que usaron modelos animales fueron excluidos de esta investigación.

\section{RESULTADOS}

Concepto de reflujo gastroesofágico - RGE El término enfermedad por reflujo gastroesofágico sintomático se refiere a aquellos pacientes que presentan síntomas pépticos (pirosis y regurgitación), con o sin evidencia endoscópica de esofagitis. Los pacientes más difíciles de entender son aquellos que presentan gran sintomatología, pero sin evidencia de lesión en el tejido esofágico (enfermedad por reflujo gastroesofágico no erosiva) y también aquellos con síntomas llamados reflujo oculto extra digestivo y con mínimas alteraciones en la motilidad esofágica ${ }^{11}$. El reflujo gastroesofágico (RGE) se refiere al pasaje involuntario de contenido gástrico hacia el esófago.

En los niños, a menudo representa un fenómeno fisiológico, especialmente en niños con regurgitación inocente. Por otro lado, la enfermedad de ERGE (ERGE) ocurre cuando el reflujo del contenido gástrico causa síntomas incómodos y/o complicaciones. Es una de las causas más comunes de síntomas intestinales en todos las categorías de 
edad pediátricas ${ }^{12}$.

Aunque la fisiopatología y los síntomas, especialmente en los niños mayores, de la ERGE pediátrica sean similares en los adultos, los niños pueden presentar una diferencia entre los diferentes síntomas gastroesofágicos y extraesofágicos y las posibles complicaciones ${ }^{13}$.

La enfermedad por reflujo gastroesofágico (ERGE) es el trastorno esofágico más común en lactantes y niños, causando regurgitación intermitente o vómitos. Aunque es un evento fisiológico en la mayoría de los adultos y niños, se torna patológico cuando la intensidad y/o frecuencia aumentan ${ }^{14}$.

El flujo retrógrado de contenido gástrico hacia el esófago se denomina reflujo gastroesofágico (RGE). Esta condición clínica, resultante de la inmadurez de los mecanismos naturales de defensa antirreflujo, es común en los lactantes, siendo autolimitada y exenta de complicaciones. Cuando acompañada de repercusiones clínicas como anemia, hemorragia digestiva, dificultad para ganar o peso o pérdida ponderal, manifestaciones respiratorias y otorrinolaringológicas, retraso del desarrollo, entre otras, pasa a ser caracterizada como enfermedad de reflujo gastroesofágico (ERGE) ${ }^{15}$.

El reflujo del contenido gástrico puede ocurrir en mayor o menor grado y con frecuencia variable. En la mayoría de los casos es pasajero, en pequeño volumen y sin consecuencias particulares. Sin embargo, si es persistente, el reflujo patológico se configura ${ }^{16}$.

\section{EPIDEMIOLOGÍA}

El RGE es sin duda una de las principales condiciones gastroenterológicas entre los niños. A pesar de predominar en los hombres, la diferencia entre los sexos no tiene significación estadística. Un estudio reciente con una muestra de 1,447 madres en los Estados Unidos, utilizando los criterios definidos por el Consenso de Roma III, mostró una prevalencia de regurgitación entre los lactantes del 26\%. También se estima que las regurgitaciones ocurren más de una vez al día en 41 a $67 \%$ de los lactantes saludables de cuatro meses de edad. Afortunadamente, solo la minoría de estos niños que regurgitan necesitará alguna investigación clínica y/o intervención terapéutica ${ }^{17}$.

Otra asociación alarmante fue propuesta por un estudio epidemiológico reciente que sugiere que la aparición de ERGE, en recién nacidos prematuros o pequeños para la edad gestacional, puede ser el factor responsable de la mayor frecuencia de adenocarcinoma esofágico en adultos que nacieron prematuramente ${ }^{18}$.

Otro estudio epidemiológico reciente sugirió que la aparición de ERGE, en nacimientos prematuros o pequeños para la edad gestacional, podría ser el factor responsable de la mayor frecuencia de adenocarcinoma esofágico en adultos que murieron prematuramente ${ }^{18}$.

Las tasas de prevalencia de la ERGE, caracterizadas por la presencia de síntomas de pirosis y regurgitación ácida, son bastante variables, pero, especialmente en los países occidentales, casi siempre son altas. En España, un estudio transversal publicado en 2004, identificó una prevalencia del 31,6\% de ERGE por año. En Bélgica, también es elevada, habiendo sido del 28\% en 2002. En un estudio realizado en Australia en 1996, el 56\% de las personas informaron haber tenido síntomas de ERGE al menos una vez en sus vidas, siendo que el $37 \%$ los tuvo al menos una vez cada cuatro meses, En Dinamarca, en 1994, la prevalencia era del 38\% entre los hombres y del 30\% entre las mujeres. En Brasil, en 2001 fue del 48,2\%. En un estudio de revisión publicado en 1997, la variación en la prevalencia varía del $10 \%$ al $48 \%$ para pirosis, del $9 \%$ al $45 \%$ para la regurgitación ácida y del 21\% al 59\% para ambos síntomas ${ }^{19}$.

La prevalencia de la enfermedad por reflujo gastroesofágico (ERGE) está aumentando en Japón, así como en los países occidentales, lo que puede estar relacionado con el estilo de vida occidentalizado y la dieta, el aumento de la edad, la disminución de la prevalencia de la infección por Helicobacterpylori y demás. La ERGE afecta las actividades de la vida diaria y reduce la calidad de vida del paciente, por lo que el diagnóstico y el manejo de esta afección son clínicamente cruciales ${ }^{20}$.

Exámenes de diagnóstico: ultrasonografía Doppler El diagnóstico de RGE debe comenzar con la elaboración de la historia clínica completa. El enfoque diagnóstico del RGE debe cambiar de acuerdo con la presentación clínica. Las pruebas de diagnóstico son útiles para documentar el reflujo patológico o sus dificultades, para constituir una relación causal entre el reflujo y los síntomas, para analizar la terapia y para excluir otras especies patológicas. Como ningún examen considera todas estas cuestiones, deben elegirse cuidadosamente de acuerdo con el historial obtenido y sus limitaciones deben ser reconocidas ${ }^{7}$.

El reflujo gastroesofágico (RGE) es una afección común en la primera infancia, caracterizada por el flujo retrógrado de contenido gástrico hacia el esófago. Debido a las secuelas potencialmente graves, el diagnóstico y tratamiento tempranos en estos pacientes son extremadamente importantes. Aunque la monitorización continua del $\mathrm{pH}$, la cintilografía y los exámenes de contraste del tracto gastrointestinal superior han sido los métodos primarios para evaluar el RGE, la ultrasonografía también se ha utilizado para diagnosticar esta afección, especialmente en niños y bebés a término. La sensibilidad y la especificidad de la ultrasonografía en el diagnóstico de reflujo en niños son de alrededor del 95 y 60\%, respectivamente, y recientemente se ha demostrado que la sensibilidad puede ser aumentada mediante el uso de imágenes Doppler en color. Varios estudios han comparado el monitoreo del $\mathrm{pH}$ con exámenes de ultrasonido en el diagnóstico de ERGE en niños, dando 
diferentes resultados ${ }^{21}$

Un estudio de Manabe et al. ${ }^{22}$, se ha especulado que la disminución del flujo salival contribuye a la eliminación anormal de ácido en pacientes con esofagitis erosiva (EE). Para una evaluación fácil y objetiva de la función salival, hemos desarrollado una técnica para medir el flujo sanguíneo en las glándulas salivales mediante ecografía Doppler de onda continua. En el presente estudio, evaluamos la función secretora de la saliva en pacientes con EE y aquellos con enfermedad por reflujo no erosiva (ERNE) usando este método. Se realizó un análisis de la forma de onda Doppler en la arteria facial para evaluar el flujo sanguíneo hacia la glándula submandibular de 30 individuos sanos (HS). El flujo sanguíneo fue comparado antes y después de la estimulación secretora con $1 \mathrm{ml}$ de jugo de limón. La saliva se recolectó y se pesó simultáneamente antes y después de la estimulación. La ecografía con Doppler de onda continua también se realizó en pacientes con EE y ERNE. El tamaño de la glándula submandibular se comparó en 26 pacientes con EE, 41 pacientes con ERNE y 86 del grupo de control. El flujo sanguíneo de la glándula submandibular aumentó después de la estimulación en todos los HS. Tanto la reproducibilidad en el día como en el día a día fue buena. Hubo una correlación significativa entre el aumento porcentual en la velocidad máxima y el aumento porcentual en la secreción salival. Aunque el tamaño de la glándula submandibular no haya sido significativamente diferente entre los tres grupos, el aumento porcentual en la velocidad máxima en pacientes con EE fue significativamente menor que en el HS. Lo que este estudio reveló es que una disminución en la función secretora salival está involucrada en la patología de EE. Manabe et al. ${ }^{22}$, desarrollaron un nuevo método para medir el flujo sanguíneo de la glándula submandibular mediante ecografía con Doppler cefalométrico para evaluar la secreción salival. Usando este método, demostramos que los pacientes con EE tuvieron significativamente menos reactividad a la secreción salival después de la estimulación que el gripo de control (HS).

Sakuno ${ }^{23}$, en disertación presentada a la Universidad Federal de Santa Catarina, 76 comparó la US con la SEED. Examinaron a 102 niños con sospecha clínica de ERGE usando SEED, US y US con Doppler. La US mostró ser más sensible que la SEED en la detección del RGE (83.3\% de la US frente a $62.7 \%$ de SEED), con un alto valor predictivo negativo, cercano al 100\%, siendo que la adición del Doppler a la US no aumentó su sensibilidad. Riccabona et al. ${ }^{24}$ comparando la US con la medición de $\mathrm{pH}$ encontraron una sensibilidad del $100 \%$ de una especificidad del $87,5 \%$, sin embargo, su población era exclusivamente de recién nacidos y lactantes. Jang et $\mathrm{al}^{25}$ usando el US con Doppler también encontraron una sensibilidad del 95.5\%, pero una baja especificidad, del 11.0\%, en comparación con la medición de pH (figura 2).
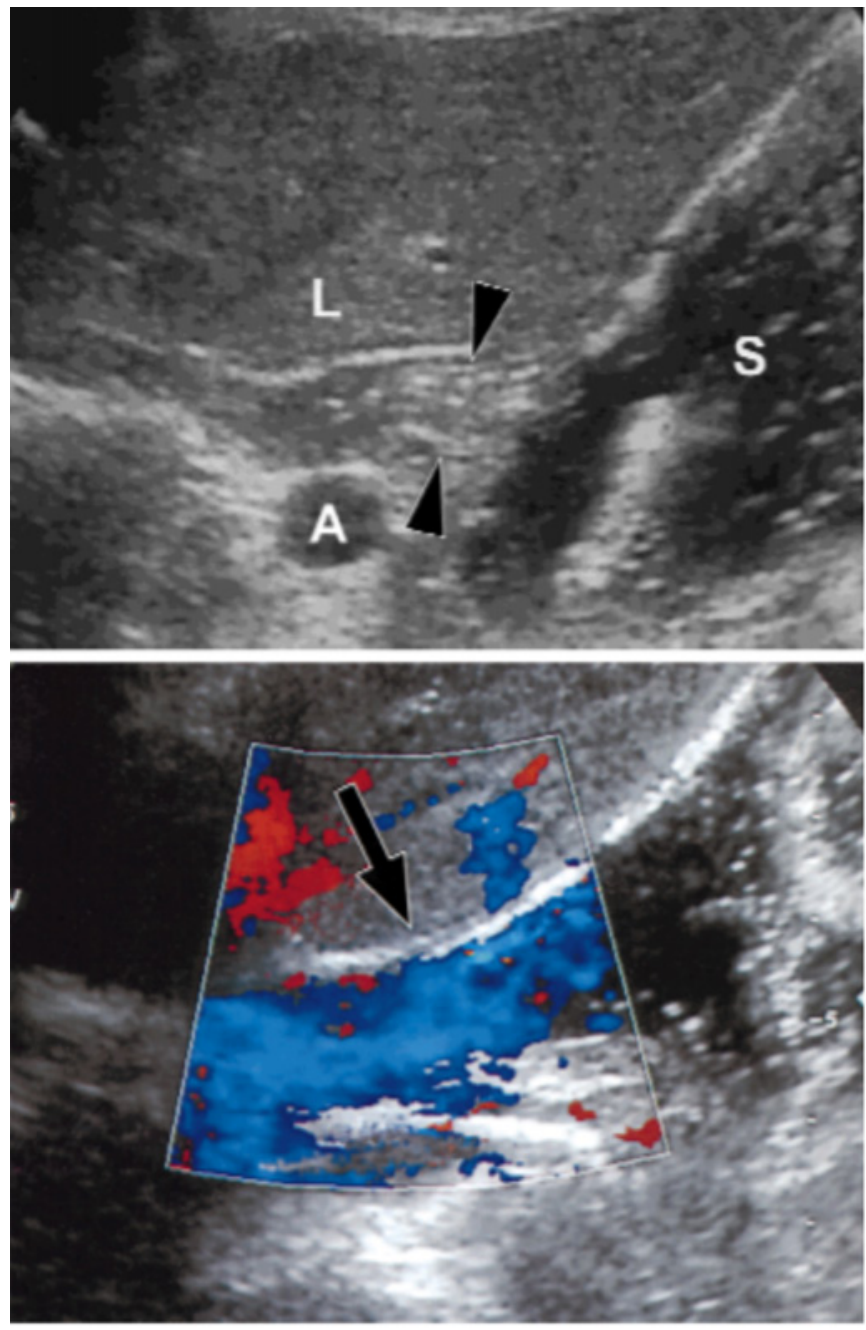

Figura 2. A - La ultrasonografía oblicua longitudinal del epigastrio muestra la unión gastroesofágica (puntas de flecha). B - El color azul en el estudio Doppler ilustra un episodio de reflujo (flecha) en la unión gastroesofágica. $\mathrm{A}=$ aorta, $\mathrm{S}=$ estómago, $\mathrm{L}=$ hígado $^{25}$.

Fue realizado un análisis de comparación de algunos artículos que hablan sobre sensibilidad y especificidad, como se muestra en la tabla a continuación:

\begin{tabular}{lll}
\hline Autor & Sensibilidade & Especificidade \\
\hline Pezzati et al., 2005 & $38 \%$ & $100 \%$
\end{tabular}

Sakuno T, $2002 \quad 87,5 \% \quad 97,4 \%$

Riccabona et al., $1992 \quad 100 \% \quad 87,5 \% \mathrm{p}<0,001$. 
Un estudio de Pezzati et al. ${ }^{21}$ (2005), mostró que la ultrasonografía tiene una baja sensibilidad en la detección del RGE en bebés prematuros y no debe reemplazar la monitorización del $\mathrm{pH}$ en 24 horas como la herramienta de diagnóstico definitivo. Sin embargo, la ultrasonografía tiene una especificidad muy alta y un valor predictivo positivo del $100 \%$. En un estudio realizado por Sakuno ${ }^{23}$ se concluye que la ultrasonografía puede diagnosticar el reflujo gastroesofágico, su número y duración, evaluando adecuadamente la anatomía de la unión esofagogástrica y determinando con precisión la longitud del esófago intraabdominal y el ángulo de His. En comparación con la seriagrafía esofagogástrica duodenal, tiene una mayor sensibilidad y un alto valor predictivo negativo. Otro estudio de Riccabona et al. 24 (1992), comparó la ultrasonografía con la medición de $\mathrm{pH}$ y/o la manometría esofágica para evaluar la precisión de la ultrasonografía en el diagnóstico temprano del reflujo gastroesofágico. Se estudiaron treinta niños con una edad media de 72 días (21-252 días). Los resultados mostraron que la especificidad del diagnóstico por ultrasonido fue del $87.5 \%$ y la sensibilidad fue del $100 \%$ (con $\mathrm{P}<0.001$ ). La ultrasonografía ha demostrado ser útil para proporcionar datos tanto funcionales como morfológicos, además de los resultados métricos del $\mathrm{pH}$.

\section{CONSIDERACIONES}

La ultrasonografía Doppler se puede utilizar como el procedimiento de elección en la investigación y el control de la ERGE. Es capaz de diagnosticar el reflujo gastroesofágico, su número y duración, evaluar adecuadamente la anatomía de la unión esofagogástrica y determinar con precisión la longitud del esófago intraabdominal y el ángulo de Hiss.

\section{REFERENCIAS}

1. Lightdale JR; Gremse DA. Gastroesophageal reflux: management guidance for the pediatrician. Pediatrics, 2013; 131(5): 1684-95.

2. Junqueira JCF. Doença do refluxo gastroesofágico: diagnóstico e tratamento. Rev Pediatria SOPERJ, 2007; 8(2).

3. Everhart JE. Gastroesophageal reflux disease. In: Everhart JE, editor. The burden of digestive diseases in the United States.US Department of Health and Human Services, Public Health Service, National Institutes of Health, National Institute of Diabetes and Digestive and Kidney Diseases. Washington, DC: US Government Printing Office. NIH Publication 2008; 09-6443: 96-72.

4. Moraes-Filho JPP et al. Guidelines for the diagnosis and management of gastroesophageal reflux disease: an evidence-based consensus. Arq. Gastroenterol., 2010; 47(1): 99-115.

5. Barlow WJ, Orlando RC. The pathogenesis of heartburn in nonerosive reflux disease: a unifying hypothesis. Gastroenterol, 2005; 128(3): 771-8.

6. Mohammadi A et al. Lack of utility of transabdominal ultrasound in the detection of gastroesophageal reflux disease-induced esophagitis in comparison with endoscopy. Ultrasound Q., 2011; 27 (2): 121-5.

7. Pimenta JR et al. Refluxo gastroesofágico. Rev Med Minas Gerais, 2016; 26(6): S76-S81.

8. Savino A et al. US in the diagnosis of gastroesophageal reflux in children. Pediatr Radiol., 2012; 42 (5): 515-24

9. Sakate $M$ et al. Avaliação do tempo de trânsito esofágico pelo ultrassom: influência do gênero e índice de massa corpórea. Radiol Bras, 2011; 44(6): 360-62.

10. Sakate $M$ et al. Refluxo gastroesofágico: estudo comparativo da recep- tividade e sensibilidade entre seriografia e ultrassonografia. Radiol Bras, 2009; 42(4): 245-8.

11. Fass $\mathrm{R}$ et al. Review article: supra-oesophageal manifestations of gastro-oesophageal reflux disease and the role of night-time gastro oesophageal reflux. Aliment Pharmacol Ther. 2004; 20(9): 26-38.

12. Gold BD. Review article: epidemiology and management of gastro-oesophageal reflux in children. Aliment Pharmacol Ther, 2004; 19(1): 22-7.

13. Nelson SP et al. Prevalence of symptoms of gastroesophageal reflux during childhood: a pediatricpractice-based survey. Pediatric Practice Research Group. Arch Pediatr Adolesc Med, 2000. 15(2): 150-4.

14. Matrunola M et Al. Role of radiography and ultrasonography In: The diagnosis of the pediatric gastro-esophageal reflux disease. Eur Rev Med Pharmacol Sci, 2003; 7(5): 147-9.

15. Rosen R. Gastroesophageal reflux in infants: more than just a phenomenon. JAMA Pediatr, 2014; 168(1): 83-9.

16. Sakate $M$ et al. Um novo método de avaliação do "tempo esofágico" com ultrassonografia por abordagem externa. Radiol Bras, 2008; 41 (5): 309-12.

17. Benninga MA et al. Childhood functional gastrointestinal disorders: neonate / toddler. Gastroenterol., 2016; 15 pii: S0016-5085(16)00182-7.

18. Kaijser $\mathrm{M}$ et al. Preterm birth, low birth weight, and risk for esophageal adenocarcinoma. Gastroenterol. 2005; 128(3): 607-9.

19. Diaz-Rubio M et al. Symptoms of gastro-oesophageal reflux: prevalence, severity, duration and associated factors in a Spanish population. Aliment Pharmacol Ther., 2004; 19(1): 95-105.

20. Moki $\mathrm{F}$ et al. Association between reflux oesophagitis and features of the metabolic syndrome in Japan. Aliment Pharmacol Ther., 2007 26(7): 1069-75.

21. Pezzati $M$ et al. Diagnosis of gastro-oesophageal reflux in preterm infants: sonography vs.pH-monitoring. Neonatology, 2007; 91(3): 162-6.

22. Manabe $\mathrm{N}$ et al. Differences in salivary secretory function between patients with erosive esophagitis and those with nonerosive reflux disease J Gastroenterol Hepatol., 2018; 33(4): 807-13.

23. Sakuno T. A Ultrassonografia no diagnóstico do refluxo gastroesofágico em crianças [Mestrado]. Florianópolis: Universidade Federal de Santa Catarina; 2002.

24. Riccabona $\mathrm{M}$ et al. The role of sonography in the evaluation of gas tro- oesophageal reflux--correlation to pH-metry. Eur J Pediatr., 1992, 151 (9): 655-7.

25. Jang HS et al. Correlation of color Doppler sonographic findings with $\mathrm{pH}$ measurements in gastroesophageal reflux in children. J Clin Ultrasound . 2001; 29(4): 212-7. 


\title{
FORMULARIO DE CONSENTIMIENTO INFORMADO: CONCEPTOS QUE EL ECOGRAFISTA DEBE SABER
}

\author{
LEONARDO DE SOUZA PIBER ${ }^{1}$, MARCELO IVANDER ANDRADE WANDERLEY' ${ }^{1}$, CARLA MICAELE DE FREITAS², \\ ARTHUR SOUSA BEZERRA², RONALDO SOUZA PIBER
}

\section{RESUMEN}

OBJETIVO: Presentar conceptos sobre el término de consentimiento informado que son importantes para la práctica médica diaria. MÉTODO: Esta es una revisión narrativa de literatura sobre el término de consentimiento informado. Los conceptos discutidos fueron seleccionados de artículos disponibles para acceso gratuito online, libros sobre doctrina legal, legislación brasileña, así como pautas y resoluciones del Consejo Federal de Medicina.

RESULTADOS: La práctica o la obtención del consentimiento informado en la práctica de la medicina son características de las últimas décadas y caracterizan la mejora de la ética biomédica. Se debe seguir la legislación, las orientaciones y las resoluciones brasileñas que rigen la relación médico-paciente y el consentimiento informado. Sin embargo, no hay reglas establecidas que definan la forma de este término.

CONCLUSIONES: La validez del formulario de consentimiento informado dependerá de que el profesional informe y aclare, además de los deseos del paciente.

\section{PALABRAS CLAVE: CONSENTIMIENTO INFORMADO, LEGISLACIÓN BRASILEÑA, ÉTICA MÉDICA, BIOÉTICA, DERECHO MÉDICO}

\section{INTRODUCCIÓN}

Desde la antigüedad, se observan pocos y escasos relatos y referencias de situaciones en las que el paciente era informado y advertido sobre los procedimientos médicos que le eran indicados. También hay poca mención de la consideración e importancia dadas por el médico a la manifestación de la voluntad del paciente para aceptar el procedimiento recomendado o rechazarlo.

En la década de 1950, algunos eventos jurídicos de gran repercusión tuvieron lugar en los Estados Unidos, lo que resultó en cambios de comportamiento en la relación médico-paciente. La expresión informed consent provino de la decisión judicial en el Salgo v. Leland Stanford Jr. University Board of Trustees, en 1957.

También se observa que los documentos éticos y legales más expresivos se concretizaron a partir de la década de 1970, coincidiendo con la caída de los regímenes dictatoriales en Europa, entre estos documentos se destacan los siguientes: el Código de Nuremberg (1947), el Informe Belmont (1978), la Declaración de Helsinki (1964) y la Declaración Universal de Derechos Humanos (1948).

En la realidad actual, los profesionales de la salud se basan tanto en el Código de Ética Médica como en la legislación nacional para garantizar mejor la autonomía del paciente.

El Código de Ética Médica se refiere al consentimiento informado del paciente, en diversas oportunidades: califica la autonomía del paciente, en las elecciones relacionadas con la atención médica, como un principio deontológico fundamental de la ética médica, y prohíbe que el médico deje de obtener el consentimiento del paciente, o de su representante legal, después de informarle sobre el procedimiento a realizar, excepto en caso de riesgo inminente de muerte. ${ }^{2}$

Por lo tanto, es importante mencionar que la causa principal del litigio rotulado como error médico proviene de la relación insatisfactoria médico-paciente, resultado de la incapacidad del profesional de proporcionar una comunicación interpersonal adecuada proporcionando una atención de buena calidad. Hoy, esta relación tiende a ser impersonal, de desconfianza, mutua y recíproca. ${ }^{3}$

La elaboración del formulario de consentimiento informado (FCI) es una obligación del profesional de la salud que prestará el servicio, siendo un acto médico y no del hospital, clínica o laboratorio, donde se informará al paciente sobre los beneficios, los riesgos de los procedimientos y tratamientos médicos a los que será sometido, lo que fortalece su confianza. ${ }^{3}$

Lo que es seguro es que, de no hacerlo, el profesional puede caracterizarse como un agente de mala fe, culposa o dolosa, pues solamente a partir del conocimiento exacto de lo que le es ofrecido, así como de los riesgos y beneficios a los que será sometido, es que el paciente está de acuerdo o no con la realización del procedimiento, contemplando así el

\footnotetext{
1. CDB Inteligência Diagnóstica.

2. Universidade Santo Amaro, São Paulo, Brasil.

3. Faculdade de Direito, da Universidade de

São Paulo, Brasil.
}

\author{
Dirección para correspondencia: \\ Leonardo Piber \\ Rua Marechal Deodoro, 135 apto 62B Santo Amaro \\ São Paulo - CEP 04738-000 \\ Email: lpiber@prof.unisa.br
}


principio bioético de autonomía. ${ }^{4}$

Vale la pena mencionar que, el incumplimiento en el deber de informar o en la obtención del consentimiento, hoy se convierte en el punto focal de las demandas contra los médicos en muchos países. ${ }^{5}$

Cuando se trata de un procedimiento invasivo, especialmente aquellos realizados a través del diagnóstico por imágenes intervencionista, que pueden causar al paciente, además de ansiedad, incomodidad, es extremadamente necesario que los efectos secundarios enumerados en la literatura médica estén muy bien aclarados ${ }^{5}$, lo que motiva, así, la importancia del aprendizaje y el reciclaje de la clase médica a través de este artículo.

\section{OBJETIVO}

Presentar conceptos sobre el formulario de consentimiento informado que son importantes para la práctica cotidiana de los médicos ecografistas.

\section{MÉTODO}

Esta es una revisión narrativa de la literatura sobre el formulario de consentimiento informado. Fueron seleccionados artículos disponibles para acceso gratuito online, libros de doctrina jurídica, legislación brasileña, así como pautas y resoluciones del Consejo Federal de Medicina.

\section{RESULTADOS Y DISCUSIÓN}

El Consejo Federal de Medicina proporcionó a la clase médica la Recomendación $n^{\circ} 1 / 2016$ que trata sobre la obtención del consentimiento en la atención médica, justificando la iniciativa de desarrollar pautas para los médicos sobre el tema, a través de los siguientes hechos:

a) La evolución, desarrollo y expansión del catálogo de derechos humanos, reconstruido en base al conocimiento de las atrocidades perpetradas durante la Segunda Guerra Mundial, incluidos los experimentos con seres humanos; ${ }^{6}$

b) Documentos que respaldan y estipulan garantías, derechos, deberes y referencias éticas en relación con los seres humanos; ${ }^{6}$

c) Las cuatro referencias básicas de la bioética: los principios de (i) autonomía, (ii) no maleficencia, (iii) beneficencia y (iv) justicia; ${ }^{6}$

d) La garantía de la dignidad de la persona humana; ${ }^{6}$

e) El Código de Ética Médica y la necesidad de complementar las pautas contenidas en él; ${ }^{6}$

f) La necesidad de establecer, para todos los profesionales e instituciones de salud, el hecho de que el paciente tiene derechos, incluso para decidir, libre y autónoma, después de estar suficientemente informado y aclarado, sobre su sumisión a cualquier terapia, procedimiento clínico o quirúrgico que le sea recomendado. ${ }^{7}$

Por lo tanto, el consentimiento informado se ha convertido en una práctica médica obligatoria, igualándose al estatus legal de libertad, igualdad y dignidad humana, por tratarse de derecho fundamental del paciente. ${ }^{8}$
El formulario de consentimiento informado es más que una simple opción para que el paciente rechace o no al médico o un tratamiento. Es un proceso de diálogo, de intercambios recíprocos de información entre el médico y el paciente para, así, iniciar el tratamiento.

En el diálogo médico-paciente, el médico aclarará toda la información sobre el tratamiento al que se someterá al paciente, informando todos los riesgos, los efectos secundarios y las consecuencias del tratamiento. Además, es necesario que el médico no solo informe el tratamiento, sino que proporcione información sobre otros posibles procedimientos, o que el paciente reciba incluso una segunda opinión. ${ }^{10}$

Para que el formulario de consentimiento informado sea completo, es necesario que el paciente obtenga el derecho de elegir la forma de intervención basada en la información recibida durante el diálogo. ${ }^{10}$

El fallo de la Corte de Nuremberg de 1947 resume específicamente cuál es el formulario de consentimiento informado y voluntario, demostrando que esto es esencial, ya que es el medio por el cual el paciente ejerce su derecho de elección después de recibir todo la información del procedimiento al que se someterá. ${ }^{10}$

Por lo tanto, el formulario de consentimiento informado constituye el derecho del paciente a participar en las decisiones relevantes para su tratamiento, y el médico debe alertarlo sobre los beneficios y riesgos del procedimiento. ${ }^{11}$

Dada la subjetividad de esta relación, la forma se vuelve secundaria al objetivo real del instituto. Sin embargo, en vista de la necesidad de defensa documental en un proceso judicial, debe tenerse en cuenta la práctica habitual de exigir formularios escritos en las instituciones de salud $1^{2}$.

Así, teniendo en cuenta la necesidad de prueba documental, las características principales son ${ }^{13}$ :

a) Escrito: contiene todos los riesgos y todos los beneficios escritos, no siendo suficiente contener la información "el paciente es consciente de todos los riesgos y beneficios";

b) Comprensible: comprensible para el paciente (ser claro, por el principio de la información, sin términos puramente técnicos);

c) Informativo: con los riesgos y beneficios de alcance a las diferentes culturas y clases sociales de los pacientes;

d) Ausencia de vicios: libre de cualquier tipo de dolo, coerción, intimidación, amenaza, lesión, simulación, error, etc. El formulario de consentimiento informado tiene como objetivo proteger: (i) la dignidad humana, (ii) la autonomía privada, (iii) la beneficencia, (iv) la no maleficencia y (v) la justicia; estos principios deben usarse como moldes en la actuación del médico. ${ }^{14}$

El principio de autonomía es la esencia del formulario de consentimiento informado, ya que prescribe el respeto por la autonomía legítima de las personas, por sus elecciones y decisiones; estas deben ser verdaderamente autónomas o libres. Por lo tanto, para tener autonomía, es necesario el libre albedrío de la persona, sin defectos o vicios que puedan empañar su voluntad. ${ }^{14}$ 
El principio de beneficencia, por otro lado, describe que el médico debe buscar el mejor tratamiento sin tener en cuenta las manifestaciones personales de los pacientes y el principio de no maleficencia, corresponde a hacer solo bien al paciente. 15

El formulario de consentimiento informado, desde la perspectiva de los principios de dignidad humana y justicia, tiene como objetivo ejercer el derecho fundamental a la integridad física y moral de la persona/paciente. ${ }^{15}$

Es discutible, cuando el paciente no puede hablar por sí mismo o es incapaz de entender el acto que se va a ejecutar, estando el médico obligado a obtener el consentimiento de sus tutores legales, cuyo nombre es el consentimiento sustituto.

La capacidad civil definida como aptitud para realizar actos de la vida civil se define en los artículos $3^{\circ}$ y $4^{\circ}$ del Código Civil brasileño, que excluye absolutamente a los menores de 16 años y aquellos con enfermedades mentales y de manera relativa a los mayores de 16 y menores de 18 años. En ausencia de capacidad civil, es necesario obtener un consentimiento sustituto para la realización de procedimientos médicos. El titular de este derecho varía según la situación objetiva presentada y no todo tipo de relación otorga esa prerrogativa ${ }^{16}$.

Si el menor ha sido emancipado por sus padres, mediante un instrumento público o una sentencia del juez, ya no dependerá de los responsables del consentimiento. Se debe alentar la participación del menor en la obtención del consentimiento. Incluso se sugiere que el consentimiento se obtenga de una manera lúdica, con figuras e historietas, para ejercicio de una mejor comprensión del paciente. ${ }^{17}$

En los otros casos de discapacidad, también debe alentarse la participación de los involucrados, en función de la evaluación del grado de deterioro de la capacidad de comprensión de los pacientes.

Los pacientes que, por cualquier razón, tienen mayor dificultad para comprender la información deben recibir explicaciones más detalladas y adecuadas a su grado de comprensión. El criterio para determinar la capacidad de consentir, o incluso de rechazar, comprende la evaluación de la capacidad del individuo para, al recibir informaciones,

procesarlas para comprender las preguntas planteadas y evaluar racionalmente las posibilidades presentadas, es decir, evaluar valores, comprender los riesgos, las consecuencias y los beneficios del tratamiento quirúrgico o terapéutico al que será sometido. ${ }^{18}$

Puede haber situaciones en las que el paciente niegue su consentimiento para realizar un determinado procedimiento médico, con graves consecuencias para su salud. En estos casos, si hay dudas sobre su capacidad para tomar decisiones, el médico debe solicitar una evaluación especializada. Si el paciente es capaz y niega su consentimiento, el médico debe registrar su decisión por escrito; proponer alternativas, si las hay; darle tiempo para reflexionar; explicar el pronóstico y las consecuencias; y finalmente, completar un formulario de rechazo.
En relación a la legislación, se destacan los siguientes artículos:

a) Artículo $1^{\circ}$ de la Constitución Federal: la República Federativa de Brasil, formada por la unión indisoluble de Estados y Municipios y el Distrito Federal, constituye un Estado de derecho democrático y se basa en: (...) III - la dignidad de persona humana. ${ }^{19}$

b) Artículo $5^{\circ}$, inciso X, de la Constitución Federal: Todos son iguales ante la ley, sin distinción de cualquier naturaleza, garantizando a los brasileños y extranjeros que residen en el País la inviolabilidad del derecho a la vida, a la libertad, a la igualdad, a la seguridad y a la propiedad, en los siguientes términos: (...) X - son inviolables la intimidad, la vida privada, el honor y la imagen de las personas, asegurado el derecho a una indemnización por daños materiales o morales resultantes de su violación. ${ }^{19}$

c) Artículo 15 del Código Civil: nadie puede ser obligado a someterse, en riesgo de muerte, a tratamiento médico o intervención quirúrgica. ${ }^{20}$

d) Artículo $6^{\circ}$ del Código de Defensa del Consumidor: Los derechos básicos del consumidor son: (...) III - información adecuada y clara sobre los diferentes productos y servicios, con la especificación correcta de cantidad, características, composición, calidad, tributos incidentes y precio, así como sobre los riesgos que presenten. ${ }^{21}$

e) Artículo. ${ }^{22}$ de la Resolución CFM no. 2.217/2018: el médico tiene prohibido: Dejar de obtener el consentimiento del paciente o de su representante legal después de informarle sobre el procedimiento a realizar, excepto en caso de riesgo inminente de muerte. ${ }^{22}$

f) Artículo. 24 de la Resolución CFM no. 2.217/2018: está prohibido que el médico: No garantice al paciente el ejercicio del derecho de decidir libremente sobre su persona o bienestar, así como ejercer su autoridad para limitarlo.22

g) Artículo. 31 de la Resolución CFM no. 2.217/2018: está prohibido que el médico: No respete el derecho del paciente o su representante legal a decidir libremente sobre la ejecución de prácticas de diagnóstico o terapéuticas, excepto en caso de riesgo inminente de muerte. ${ }^{22}$

\section{CONCLUSIONES}

Por lo tanto, el consentimiento para el acto médico es la anuencia otorgada por el paciente al profesional que observa los requisitos anteriores. Por lo tanto, su validez dependerá del cumplimiento del deber del profesional de informar y del esclarecimiento y voluntad del paciente.

No existe una forma definida, en una ley específica o en el Código de Ética Médica, para el consentimiento informado en general. Esto se basa en la idea de proporcionar contacto entre el profesional y el paciente, fortaleciendo así la relación.

\section{REFERENCIAS}

1. Beauchamp TL, Faden RR. History of informed consent. In: Reich WT editor. Encyclopedia of Bioethics. New York: Simon \& Shuster MacMillan; 1995. 
2. Vaz W, Reis C. Consentimento informado na relação médico-paciente. Revista Jurídica Cesumar - Mestrado. 2008; 7(2): 489-514.

3. Pereira AGD. O dever de esclarecimento e a responsabilidade médica. Revista dos Tribunais, São Paulo. 2005; 94(839):69-109.

4. Kfouri Neto M. Responsabilidade Civil do Médico. $8^{\circ}$ ed. São Paulo: Ed. Revista dos Tribunais, 2013.

5. Tsuji FH. Grau de satisfação e intensidade da dor dos pacientes submetidos à biópsia prostática transretal guiada por ultrassom com uso de sedação e analgesia endovenosa com midazolam e citrato de fentanila. 2012. Disponível em: https://repositorio.unesp.br/handle/ 11449/97710, acessado 20 de Março 2020.

6. Brasil. Conselho Federal de Medicina - Recomendação n¹/2016 - Disponível em: https://sistemas.cfm.org.br/normas/visualizar/recomendacoes/ BR/2016/1, acessado 20 de Março de 2020.

7. Junges, JR. Exigências éticas do consentimento informado. Revista bioética. 2007; 15(1):77-82.

8. Oliveira V, Pimentel D, Vieira M. O uso do termo de consentimento livre e esclarecido na prática médica. Revista Bioética. 2010; 18(3): 705-24.

9. Fernandes $\mathrm{CF}$, Pithan LH. O consentimento informado na assistência médica e o contrato de adesão: uma perspectiva jurídica e bioética. Revista HCPA. 2007; 27(2): 78-82.

10. Clotet J - O Consentimento informado nos comitês de ética em pesquisa e na prática médica: conceituação, origens e atualidade. Bioética, 1995.

11. Albuquerque A. Violação aos direitos dos pacientes: análise da jurisprudência no Brasil. Revista Direitos Fundamentais e Alteridade. 2019; 3(1): 7-33.

12. Duarte R. Consentimento informado: um conceito incompreendido breve ensaio sobre a judicialização da medicina e suas consequências na relação médico-paciente. Revista de Estudos Jurídicos UNESP. 2015; 19(29): 1-10.

13. Pereira AG - A capacidade para consentir: um novo ramo da capacidade jurídica, em: Pereira AG. Comemorações dos 35 anos do Código Civil e dos 25 anos da Reforma de 1977, $1^{\text {a }}$ Ed, Coimbra, Coimbra Ed, 2004.

14. Nunes LNBT. O consentimento informado na relação médico-paciente: respeitando a dignidade da pessoa. Ed. Padma LTDA, RTDC, 2007.

15. Rodrigues JV. O consentimento informado para o acto médico no ordenamento jurídico português (elementos para o estudo da manifestação da vontade do paciente). Coimbra Ed., 2001.

16. França GV. Direito Médico. $1^{\circ}$ ed. Rio de Janeiro: Forense, 2014: 277.

17. Aguiar M, Barboza AS. Autonomia bioética de crianças e adolescentes e o processo de assentimento livre e esclarecido. Revista Brasileiro de Direito Animal. 2017; 12(2): 17-42.

18. Sampaio CV, Menezes JB. Autonomia da pessoa com deficiência e os atos de disposição do próprio corpo. Revista Jurídica Cesumar - Mestrado. 2018; 18(1): 133-157.

19. Brasil. Constituição Federal. Constituição da República Federativa do Brasil de 1988. Disponível em: http://www.planalto.gov.br/ccivil_ 03/ constituicao/constituicaocompilado.htm, acessado dia 20 de Março de 2020.

20. Brasil. Código Civil. Disponível em: https://www.jusbrasil.com. br/topicos/10729769/artigo-15-da-lei-n-10406-de-10-de-janeiro- -de-2002

21. Brasil. Código de Defesa do Consumidor. Disponível em: https:// www.jusbrasil.com.br/topicos/10607666/artigo-6-da-lei-n-8078-de-11-de-setembro-de-1990

22. Brasil. Conselho Federal de Medicina - Art. 22 da Resolução CFM n. 2.217/2018. Disponível em: https://portal.cfm.org.br/images/PDF/ cem2019.pdf, acessado dia 20 de Março de 2020.

23. Brasil. Conselho Federal de Medicina - Art. 24 da Resolução CFM n. 2.217/2018. Disponível em: https://portal.cfm.org.br/images/PDF/ cem2019.pdf, acessado dia 20 de Março de 2020.

24. Brasil. Conselho Federal de Medicina - Art. 31 da Resolução CFM n. 2.217/2018. Disponível em: https://portal.cfm.org.br/images/PDF/ cem2019.pdf, acessado dia 20 de Março de 2020. 

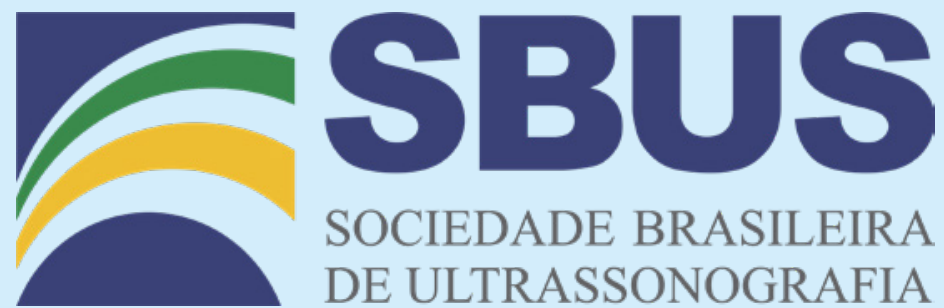

SOCIEDADE BRASILEIRA DE ULTRASSONOGRAFIA 

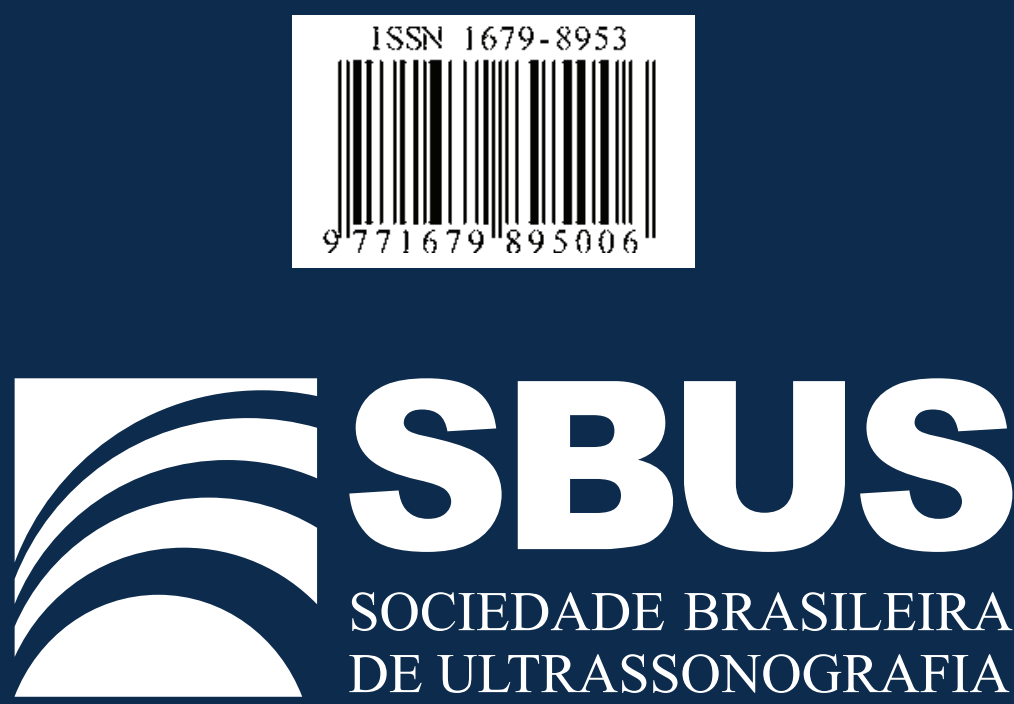